\title{
CARACTERIZAÇÃo ELETROSTÁTICA DE TAPETES E CARPETES
}

Annete S. Faesarella

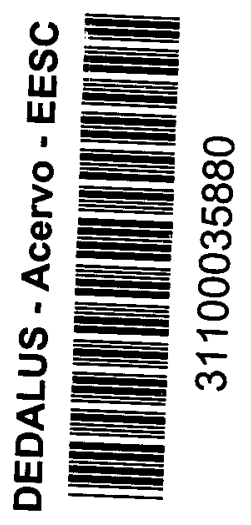

Tese apresentada à Área Interunidades da Universidade de São Paulo, para obtenção do título de Doutor em Ciência e Engenharia de Materiais.

Orientador: Prof. Dr. Ruy Alberto C. Altafim

São Carlos

2000

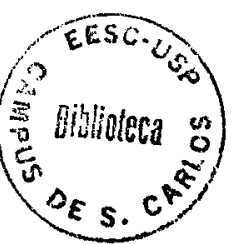




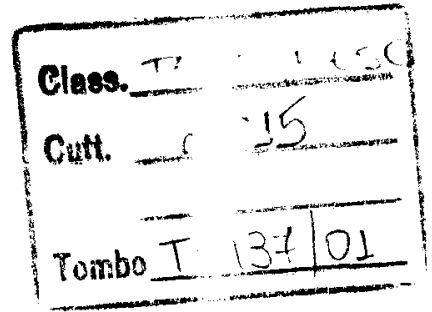

Ficha catalográfica preparada pela Seção de Tratamento dá informaçāo do Serviço de Biblioteca - cEscCusp

Faesarella, Annete S.

F149c Caracterização eletrostática de tapetes e carpetes /

Annete S. Faesarella. - - São Cartos, 2000.

Tese (Doutorado) - - Escola de Engenharia de São Carlos / Instituto de Física de São Carlos / Instituto de

Química de São Carlos - Universidade de São Paulo, 2000.

Área Interunidades: Ciência e Engenharia de Materiais.

Orientador: Prof. Dr. Ruy Alberto C. Altafim.

1. Caracterização eletrostática de revestimentos

Têxteis. 2. Eletrostática em revestimentos têxteis. I. Título. 


\section{Ciência e Engenharia de Materiais}

E-mail: erica@if.sc.us

MEMBROS DA COMISSÃO JULGADORA DA TESE DE DOUTORADO DE ANNETE SILVA FAESARELLA, APRESENTADA AO PROGRAMA DE PÓS-GRADUAÇÃO INTERUNIDADES EM CIÊNCIA E ENGENHARIA DE MATERIAIS, DA UNIVERSIDADE DE SÃO PAULO, EM 29/03/2001.

\section{COMISSÃO JULGADORA:}

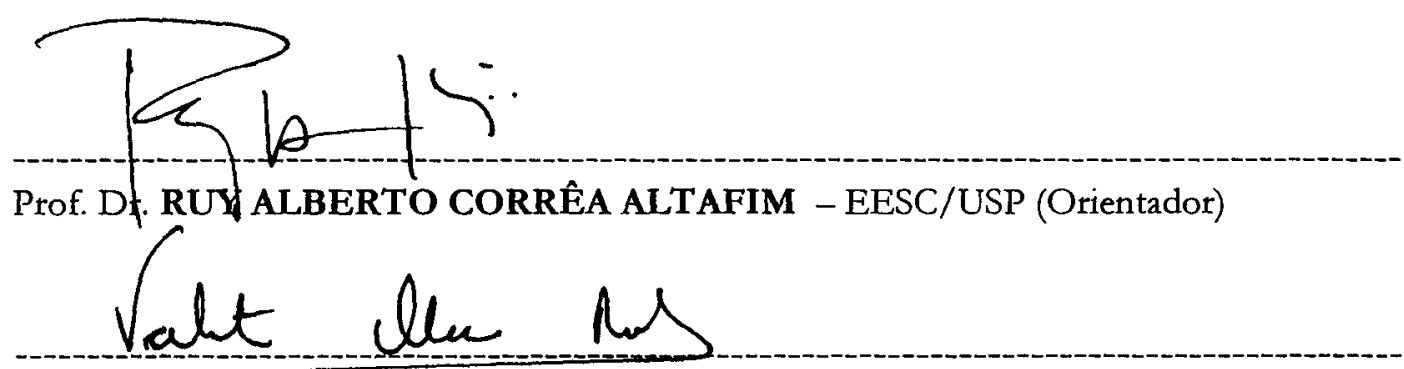

Prof. Or. VALENTIN OBAC RODA - EESC/USP

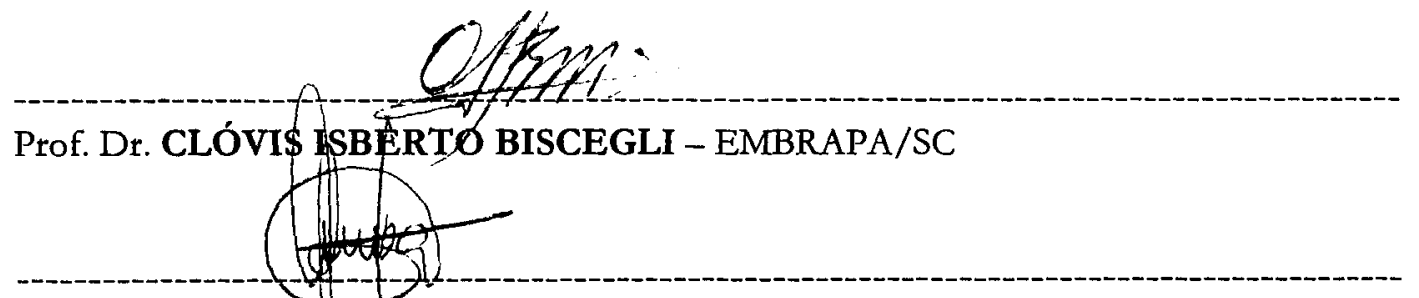

Prof. Dr. JOÃO SI ÉTIO DE CARVALHO CAMPOS - UNICAMP 12M 2

Prof. Dr. NERI ALVES - UNESP/Pres.Prudente 
Esta tese é carinhosamente dedicada ao meu pai José Luiz, cuja vida de coragem e força foi uma inspiração para mim. 


\section{AGRADECIMENTOS}

- À FAPESP - Fundação de Amparo à Pesquisa do Estado de São Paulo, pelo apoio financeiro.

- À Fábrica de Tapetes São Carlos, pelo apoio técnico.

- Ao Prof. Dr. Ruy Alberto C. Altafim, pela orientação e confiança depositadas em mim, sem as quais esse trabalho não teria sido realizado.

- Aos técnicos e amigos Rui Berto, César Domingues, Alessandro R. Locatti e Odair da Silva pelo inestimável apoio técnico.

- À Secretária Rosane Aranda pela sua ajuda e amizade.

- Aos amigos dos laboratório de Padrões (LAP), de Aquisição e Desenvolvimento Computacional (LADESC) e Alta Tensão (LAT), Marcos, Jorge e Cacilda.

- A minha mãe, Maria Lélia, meus irmãos Paulo, Ivy, e Má, e ao meu namorado Antonio, pelo apoio. 


\section{SUMÁRIO}

LISTA DE FIGURAS

LISTA DE TABELAS

RESUMO

ABSTRACT iv

1. INTRODUÇÃO 1

2.PESQUISA BIBLIOGRÁFICA 4

2.1. Medição de dissipação estática em materiais 4

2.2. Cargas eletrostáticas em revestimentos têxteis 23

2.3. Quadro comparativo dos métodos de medição do potencial de $\begin{array}{ll}\text { superficie e carga superficial } & 28\end{array}$

3. ELETROSTÁTICA 30

4. NOVA METODOLOGIA 36

1. Considerações Gerais 36

2. Descrição do Método 37

2.1. Câmara de ionização 39

2.2. Oscilador 44

2.3. Amplificador do sinal do oscilador 44

2.4. Fonte de alimentação para o oscilador e amplificador 44

2.5. Fonte de alta tensão $\quad 45$

2.6. Fonte regulada de tensão e regulador de tensão 47

2.7. Amplificador de sinal 48

2.8. Módulo de controle $\quad 49$

2.9. Interface entre o equipamento e a Placa LAB PC ${ }^{+}$ 
2.10. Amplificador de potência

2.11. Computador 53

2.12. Programa AD 32

3. Preparação das amostras $\quad 55$

4. Metodologia desenvolvida para o ensaio $\quad 57$

5. Equacionamento da câmara 64

$\begin{array}{ll}\text { 5.1. Configuração eletrodo-amostra } & 67\end{array}$

5. COMPORTAMENTO DO PROTÓTIPO PARA

CARACTERIZAÇÃO DE REVESTIMENTOS TÊXTEIS - PCRT 72

5.1. Considerações gerais $\quad 72$

5.2. Influência da umidade $\quad 73$

5.3. Estudos para a determinação da geometria dos eletrodos 74

5.3.1. Resultados dos testes com amostras de filme de Teflon FEP 75

5.4. Influência da resistência parasita da câmara de ionização 77

5.5. Testes utilizando amostras de tapetes e carpetes $\quad 81$

6. PROPOSTA DE MODELAGEM DE REVESTIMENTOS TÊXTEIS 83

6.1. Considerações gerais $\quad 83$

6.2. Modelagem de um revestimento têxtil $\quad 84$

7. CONCLUSÃO 92

8. ANEXO I-Manual do usuário do programa computacional AD32 94

I. Introdução $\quad 94$

I.1. Programa AD32 94

I.2. Placa LAB PC ${ }^{+} \quad 95$

I.3. Objetivos 95

I.4. Configuração mínima 95

I.5. Especificação do programa AD32 96

I.6. Recursos utilizados $\quad 99$

I.7. Instalação 99

II. Conteúdo 99

II.1. Entrada do programa $\quad 99$

$\begin{array}{ll}\text { II.2. Arquivo } & 100\end{array}$ 
$\begin{array}{ll}\text { II.3. Cliente } & 101\end{array}$

II.4. Amostra 105

II.5. Caracterização da amostra 106

$\begin{array}{ll}\text { II.6. Configuração do sistema } & 111\end{array}$

$\begin{array}{ll}\text { II.7. Ajuda } & 112\end{array}$

9. ANEXO II-Circuitos contidos no equipamento para medição de decaimento do potencial eletrostático de amostra têxteis $\quad 114$

$\begin{array}{ll}\text { II.1. Oscilador } & 114\end{array}$

II.2. Amplificador do sinal do oscilador 115

II.3. Fonte de alimentação para o oscilador e o amplificador 116

II.4. Fonte regulada de tensão e regulador de tensão 117

$\begin{array}{ll}\text { II.5. Amplificador de sinal } & 119\end{array}$

$\begin{array}{ll}\text { II.6. Amplificador de potência } & 120\end{array}$

10. ANEXO III-Páginas da "Internet" utilizadas no trabalho 123

III.1. Primeiros passos da Eletrostática 124

III.2. JCI 155 Charge Decay Test Unit 125

$\begin{array}{ll}\text { III.3. Zeolite Molecular Sieves } & 130\end{array}$

$\begin{array}{ll}\text { III.4. Humans and sparks } & 131\end{array}$

III.5. ESD Systems.com Introdution to ESD 137

11. REFERÊNCIAS BIBLIOGRÁFICAS 144 


\section{LISTA DE FIGURAS}

Figura 2.1 - Diagrama mostrando os principais elementos do medidor de decaimento de carga.

Figura 2.2 - Diagrama esquemático do equipamento para medição do decaimento de cargas elétricas de um fio de náilon.

Figura 2.3 - Diagrama esquemático do equipamento para carregamento corona.

Figura 2.4 - Configuração básica para o medidor de carga induzida.

Figura 2.5 - Medidor por sonda corona.

Figura 2.6 - Arranjo típico para o "field mill", tipo de medidor de campo elétrico.

Figura 2.7 - Sonda balística para medição de campo elétrico na presença de cargas livres.

Figura 2.8 - Sistema do cilindro de Faraday para medição de carga eletrostática.

Figura 2.9 - Diagrama esquemático do Eletroscan-analisador eletrostático de alta resolução. 
Figura 2.10 - Esquema de montagem para medição da densidade superficial de cargas.

Figura 2.11 - Diagrama esquemático para medição de corrente.

Figura 2.12 - Princípio básico de operação do método de comparação.

Figura 2.13 - Medidor de carga superficial em forma de moinho: "field mill".

Figura 2.14 - Método do eletrodo vibrante para medição de carga superficial de um eletreto.

Figura 2.15 - Aparelho experimental para carregamento corona e medição do decaimento de carga superficial.

Figura 2.16 - Resistividade superficial ou resistividade volumétrica Relacionada com características eletrostáticas dos materiais, segundo A Norma EIA 541 [22]

Figura 2.17 - Foto do JCI 155 charge "decay test unit".

Figura 3.1 - a. Átomo equilibrado, carga zero; b. Átomo com deficiência de elétrons, carga positiva; c. Átomo com excesso de elétrons, carga negativa.

Figura 3.2 - Cargas eletrostáticas sendo adquiridas por um indivíduo ao caminhar e ocorrência de faísca elétrica quando este toca um trinco metálico de porta. 
Figura 4.1 - Diagrama esquemático do equipamento para medição do tempo de decaimento eletrostático de amostras de tapetes e carpetes.

Figura 4.2 - Esquema de montagem da câmara de ionização.

Figura 4.3 - Detalhe da ponta corona Isolada por Teflon.

Figura 4.4 - Câmara de ionização.

Figura 4.5 - Aparelho responsável pela vibração do alto-falante.

Figura 4.6 - Circuito para descobrir a tensão de saída da fonte SPELLMAN.

Figura 4.7 - Circuito para determinação da tensão de alimentação

da fonte chaveada.

Figura 4.8 - Fonte de baixa tensão e regulador de tensão, conectados à fonte chaveada de alta tensão DC.

Figura 4.9 - Sistema de temporização.

Figura 4.10 - Circuito de interface entre a placa $\mathrm{LAB} \mathrm{PC}^{+}$

e a o equipamento para medição do potencial eletrostático de tapetes e carpetes.

Figura 4.11 - Detalhes do circuito de interface entre a placa $\mathrm{LAB} \mathrm{PC}^{+}$e a câmara de ionização.

Figura 4.12 - Diagrama esquemático do programa computacional AD32. 
Figura 4.14 - Dissecador utilizado para retirar a umidade das amostras de tapete ou carpete.

Figura 4.15 - Peneira molecular.

Figura 4.16 - Exemplo de aquisição de dados pelo computador, gerenciado pelo programa AD32.

Figura 4.17 - Resistividade volumétrica, relacionada com as características eletrostáticas dos materiais,segundo Norma EIA - 541 [22].

Figura 4.18 - Circuito elétrico representando a câmara de ionização.

Figura 4.19 - Circuito da figura 4.18 - modificado.

Figura 4.20 - Diagrama esquemático da disposição dos eletrodos/amostra, no interior da câmara de ionização.

Figura 4.21 - Circuito equivalente da Câmara contendo uma amostra carregada, onde o $\mathrm{C}_{\mathrm{E}}$ é o capacitor vibrante.

Figura 5.1 - Gráfico mostrando a influência da umidade no carregamento de amostras de tapetes e carpetes.

Figura 5.2 - Escoamento das cargas elétricas pela distância entre a ponta corona e o eletrodo superior.

Figura 5.3 - Carregamento da amostra por descarga elétrica. 
Figura 5.4 - Descarregamento da amostra por descarga de retorno e descarga lateral.

Figura 5.5 - Eletrodo superior para filmes finos e tapetes com espessuras menores do que $1 \mathrm{~mm}$.

Figura 5.6 - Descarregamento do sistema pelo eletrodo terra.

Figura 5.7 - Potencial de carregamento, sem amostra em função do tempo

$\begin{array}{ll}\text { Figura 5.8 - Tempo de decaimento do sistema. } & 79\end{array}$

$\begin{array}{ll}\text { Figura } 5.9 \text { - Tempo de decaimento do sistema. } & 79\end{array}$

Figura 6.1 - a) Revestimento têxtil; b) Circuito elétrico equivalente de uma fibra.

Figura 6.2 - Fibra de tapete ou de carpete.

Figura 6.3 - Gráfico do comportamento da resistividade

superficial na presença de umidade, de uma amostra de vidro [41].

88

Figura 6.4 - Análise exponencial de primeira ordem do

Gráfico da figura 6.3 .

89

Figura 6.5 - Resistividade superficial ou resistividade volumétrica,

Relacionada com as características eletrostáticas dos

Materiais, segundo a Norma EIA - 541 [22].

91

Figura I.1- Ícone do programa computacional AD32.

Figura I.2 - Entrada do programa AD 32. 
Figura I.3 - Opção arquivo.

Figura I.4 - Opção cliente.

Figura I.5 - Opção amostra.

Figura I.6 - Opção ajuda.

Figura I.7 - Tela de entrada do programa AD32.

Figura I.8 - Opção para sair do programa AD32.

100

Figura I.9 - Tela para finalizar o uso do programa AD32.

100

Figura I.10 - Tela da opção cliente.

Figura I.11 - Tela de busca do cliente.

102

Figura I.12 - Cadastro do cliente.

103

Figura I.13 - Alteração dos dados de um cliente.

104

Figura I.14 - Botões para procura de um cliente-procura lenta e rápida.

Figura I.15 - Excluir os dados de um cliente.

Figura I.16 - Amostra.

Figura I.17 - Tela para caracterização das amostras. 
Figura I. 18 - Busca de uma amostra cadastrada.

Figura I.19 - Cadastro de uma nova amostra.

109

Figura I.20 -Tela para alteração dos dados de uma amostra previamente cadastrada.

Figura I.21-Tela para excluir uma amostra do banco de dados.

Figura I.22 -Tela do configuração do sistema.

Figura I.23 - Tela da opção ajuda.

Figura II. 1 - Oscilador.

Figura II.2 - Amplificador do sinal do oscilador.

116

Figura II.3 - Fonte DC para alimentação do oscilador e do amplificador.

Figura II.4 - Fonte regulada de baixa tensão.

Figura II.5 - Regulador de tensão.

118

Figura II.6 - Circuito completo: fonte de baixa tensão DC e regulador de tensão.

Figura II.7 - Amplificador para o sinal do potencial eletrostático. 


\section{LISTA DE TABELAS}

Tabela 1- Série triboelétrica.

Tabela 2 - Tempo de decaimento " $\tau$ ". 


\section{RESUMO}

Quando uma pessoa fricciona os sapatos num tapete, seu corpo pode carregar-se com um potencial de alguns milhares de volts em relação ao referencial de terra. Se esta pessoa tocar um objeto aterrado, uma faísca pode saltar entre o objeto e a ponta do seu dedo. O corpo desta pessoa age como um capacitor, e um fluxo rápido de eletricidade estática armazenada, resultado das cargas estáticas armazenadas no corpo, flui deste para um objeto de potencial menor. Essas descargas podem provocar desde pequenos danos, como desconforto fisico, até incêndios em grandes construções. Na tentativa de minimizar ou eliminar esses problemas, tapetes e carpetes antiestáticos são utilizados. Muitos métodos têm sido propostos para caracterizar esses produtos de acordo com suas características eletrostáticas. Dentre eles, o recomendado pela norma francesa NF G35-025 /Essais des Revêtements de Sol Textiles-Propension à l'accumulation de Charges Életrostatiques, Méthode d'essai et spécification, Décembre 1983], prescreve que alguém usando sapatos especiais deve caminhar em uma amostra de tapete por longo período e, então, o potencial eletrostático adquirido por ele é medido através de um eletrômetro. Por este método são reproduzidas as condições reais, mas, ele é muito caro e trabalhoso, pois requer uma sala climatizada. Na tentativa de descobrir métodos alternativos, encontram-se na literatura vários estudos $e$ métodos. Taylor [An Instrument for Measuring Static Dissipation from Materials, Journal of Electrostatics, (1987) 53-64, Elsevier Science Publishers B.V., Amsterdam-Printed in the Netherlands] desenvolveu um medidor de decaimento de carga para medir tempo de decaimento em polímeros antiestáticos. Nesse método, ele determinou uma boa correlação entre a resistência superficial e o tempo de meia-vida do material. Usando a mesma idéia, foi possivel desenvolver o método apresentado nesta tese, aplicado a amostras de tapetes e carpetes. Neste método, a caracterização eletrostática de tapetes ou carpetes é realizada também através da medida do tempo de decaimento do potencial eletrostático. Porém, sua idéia principal é que todas as medidas são realizadas dentro de uma câmara especial isenta de umidade, pois esta pode influenciar o carregamento das amostras. Dentro desta câmara, as amostras de tapete ou carpete são inicialmente carregadas através de descarga corona, após cessar o carregamento, é medido o seu tempo de decaimento. Um programa computacional especialmente desenvolvido para este fim permite o controle da medição e do processo de carregamento. 


\section{ABSTRACT}

When a person rubs his shoes in a rug, his body may be charged with a potential of some thousands of volts in relation to the earth reference. If this person touches a grounded object, a spark can travel between the object and the tip of his finger. The person's body acts like a capacitor, and a fast flow of stored static electricity, which is a result of the static loads stored in the body, flows from the body to an object in a smaller potential. Those discharges can cause from small damages, as physical discomfort, to fires in big constructions. In the attempt to minimize or to eliminate these problems, antiestatic rugs and carpets are used. Many methods have been proposed to characterize those products in agreement with the electrostatic characteristics. Among them the recommended methods by the French standard NF G35-025 [Essais des Revêtements de Sol Textiles-Propension à l'accumulation de Charges Életrostatiques, Méthode d'essai et spécification, Décembre 1983], prescribe that somebody using special shoes should walk in a rug sample for a long period, and then the electrostatic potential acquired by him is measured using na electrometer. In this method the real conditions are reproduced, but, it is very expensive and difficult, because it requires an aclimatized room. There are in the literature several studies attempting to devise alternative methods. Taylor [An Instrument goes Measuring Static Dissipation from Materials, Journal of Electrostatics, (1987) 53-64, Elsevier Science Publishers B. V, Amsterdam-Printed in the Netherlands] developed a meter of charge decline to measure time of decline in antistatic polymers. In his method, Taylor determined a good correlation between the superficial resistance and the time of stocking-life of the material. Using the same idea, it was possible to develop the method that is presented in this thesis, applied to samples of rugs and carpets. In this method the electrostatic characterization of rugs or carpets is also accomplished through the measurement of the time of decline of the electrostatic potential. However its main idea is that all the measures are accomplished inside a special camera without humidity, since it can influence the charging of the samples. Inside this camera, the rugs or carpet samples are initially charged using corona discharge, after interrupting the charging, time of decline is measured. A computer program was especially developed for this reason, it allows the control of the measurement and of the charging process. 


\title{
CAPITULO I
}

\section{INTRODUÇÃo}

\author{
Neste capitulo, serão apresentados os \\ principais objetivos dessa pesquisa \\ e os elementos que a justificam.
}

\begin{abstract}
É muito conhecido o fato de que cargas eletrostáticas são geradas por meio da friç̧ão entre dois materiais diferentes, como o vidro e a lã. Quando ocorre friç̧ão e separação entre dois materiais, acontece uma transferência de elétrons entre os átomos da superfície dos materiais que se carregam eletrostaticamente; este fenômeno chama-se triboeletricidade. Estas cargas eletrostáticas podem ser positivas ou negativas, dependendo da abundância ou defíciência de elétrons livres. Quando uma pessoa fricciona os sapatos num tapete, o seu corpo pode se carregar com um potencial de alguns milhares de volts em relação ao referencial de terra. Se esta pessoa tocar um objeto aterrado, uma faísca pode saltar entre o objeto e a ponta do seu dedo. $O$ corpo desta pessoa age como um capacitor ${ }^{1}$ [1], e um fluxo rápido da eletricidade estática armazenada, resultado das cargas estáticas armazenadas no corpo, flui deste para um objeto de potencial menor. Estas descargas podem provocar desde pequenos danos, como desconforto físico, até graves incêndios[2,3].
\end{abstract}

1. Assunto melhor detalhado no Anexo III, página 123. 
$\mathrm{Na}$ tentativa de minimizar ou eliminar esses problemas, tapetes e carpetes antiestáticos são utilizados. Muitos métodos têm sido propostos para caracterizar esses produtos de acordo com suas características eletrostáticas.

Dentre eles, o recomendado pela norma francesa NF G35-025 [4], em que um técnico, usando sapatos especiais, deve caminhar sobre uma amostra de tapete por um longo período e, então, seu potencial eletrostático pode ser medido por um eletrômetro

Por este método, são reproduzidas as condições reais, mas ele é muito caro e trabalhoso, pois requer uma sala climatizada. $\mathrm{Na}$ tentativa de descobrir métodos alternativos, foram desenvolvidos vários estudos, como o método do Triodo Corona [5], o qual é utilizado para caracterização de materiais isolantes e fracamente condutivos [6]. Taylor [7] desenvolveu um medidor de decaimento de carga, para medir o tempo de decaimento em polímeros antiestáticos [8]. Nesse método, ele determinou uma boa correlação entre a resistência superficial e o tempo de meia-vida das amostras de polímero. Usando a mesma idéia, foi possível desenvolver o presente método aplicado a amostras de tapetes e carpetes. Neste método, a caracterização eletrostática de tapetes ou carpetes é realizada também por meio da medida do tempo de decaimento do potencial eletrostático, porém, de maneira totalmente automatizada, tendo como cerne uma câmara de ionização especial com controle de umidade. Dentro dessa câmara, as amostras de tapete ou carpete são inicialmente carregadas por descarga corona através de uma nova configuração eletrodo/amostra. Nesta nova configuração, problemas como o espaçamento do eletrodo para as diversas espessuras de amostras existentes, sujeira da câmara provocada pelo carregamento de tapetes felpudos, causando erro de medida, e o sério problema relacionado ao carregamento das amostras, causado pela presença de umidade, foram totalmente solucionados. Todo o conceito da nova metodologia desenvolvida será melhor detalhado no capítulo IV deste trabalho.

Após cessar o carregamento, o seu tempo de decaimento é determinado por um mecanismo que utiliza a técnica do capacitor vibrante [9] e uma placa de aquisição de dados A/D, controlada por um programa computacional, AD32, especialmente desenvolvido para o projeto. $\mathrm{O}$ novo método apresentado neste trabalho traz também a 
descrição de todos os padrões definidos para medição do decaimento do potencial eletrostático de revestimentos têxteis.

O programa $\mathrm{AD} 32$, permite o total controle da temporização, tanto da medição quanto do processo de carregamento.

O capítulo II desta tese consiste em uma revisão dos principais métodos e técnicas de medição de potencial eletrostático em materiais de uma forma geral, e, em especial, nos revestimentos têxteis.

No capítulo III, é apresentado um resumo explicativo a respeito da eletrostática; já o capítulo IV descreve toda a parte experimental do trabalho, e todo o equacionamento dos fenômenos que ocorrem durante o processo do carregamento das amostras de revestimentos têxteis e da câmara de ionização e de toda a metodologia desenvolvida.

No capítulo $\mathrm{V}$, encontram-se os resultados conseguidos com o equipamento para medição do decaimento do potencial eletrostático de tapetes e carpetes.

O capítulo VI apresenta uma proposta de modelagem das fibras do revestimento têxtil, analisando-o como um circuito elétrico, e também uma análise do comportamento dele na presença ou não de umidade.

No capítulo VII, é apresentada a conclusão do trabalho, juntamente com algumas propostas para futuros projetos.

No Anexo L, é apresentado um manual do usuário do programa computacional AD32, sendo todos os seus recursos muito bem detalhados.

No Anexo II, são detalhados todos os circuitos construídos para a montagem do equipamento para medição do decaimento do potencial eletrostático de revestimentos têxteis.

Cabe ressaltar que mesmo os circuitos mais simples construídos para o projeto estão aqui minuciosamente descritos com o intuito de auxiliar futuros trabalhos que venham a necessitar deles. 


\section{CAPÍTULO II}

\section{PESQUISA BIBLIOGRÁFICA}

Neste capítulo, são revistos os principais

métodos e técnicas de medição de cargas

eletrostáticas em materiais, de um modo

geral, e em revestimentos têxteis.

\subsection{MEDIÇÃO DE DISSIPAÇÃo ESTÁTICA EM MATERIAIS}

Taylor e Elias [7] descrevem um equipamento capaz de medir a dissipação de cargas estáticas, em amostras, na forma de folhas, de vários produtos antiestáticos, incluindo papéis e plásticos obtidos de diferentes fornecedores.

Segundo Taylor e Elias, nas áreas onde há riscos de prejuízos causados por descargas eletrostáticas, como, por exemplo, na indústria eletrônica, há também exigências de produtos antiestáticos e estático-dissipativos. Usualmente esses materiais são classificados de acordo com sua resistência superficial. Esse parâmetro não é suficiente para a classificação do material quanto à habilidade de dissipar cargas eletrostáticas, sendo necessário o conhecimento do tempo que as cargas eletrostáticas permanecem na superficie do material.

O equipamento desenvolvido é mostrado na figura 2.1 . 


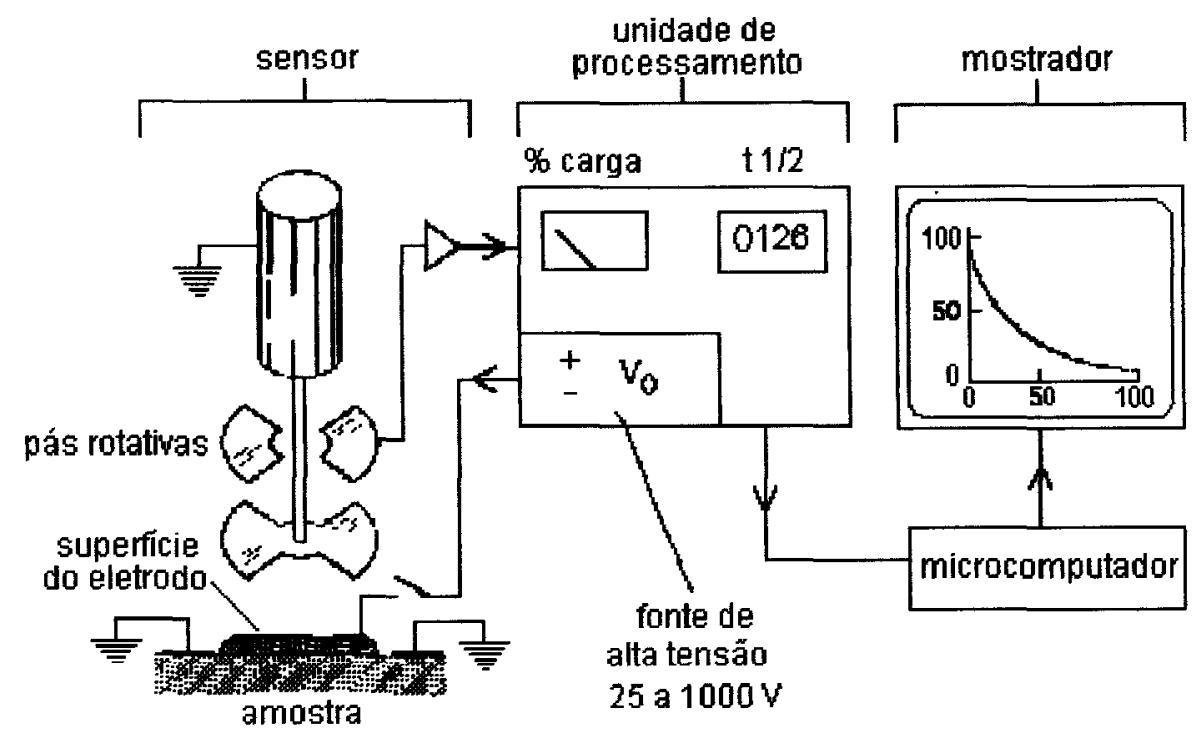

Figura 2.1: Diagrama mostrando os principais elementos do Medidor de Decaimento de Carga

O equipamento carrega uma amostra de $15 \mathrm{~cm}^{2}$ com uma tensão de 25 a $1.000 \mathrm{~V}$ através de um eletrodo de superficie, e o decaimento eletrostático é medido por pás rotativas, as quais formam o sensor do equipamento. Obtém-se o tempo de decaimento de meia-vida da carga contida na amostra, ou seja, o tempo necessário para o sensor detectar a metade do seu valor inicial.

Taylor mediu a resistência superficial das amostras (com um medidor de resistência superficial IBD modelo 482) e chegou à conclusão de que quanto maior é a resistência superficial do material maior é o tempo de decaimento de meia carga da amostra. Observou também que os materiais têm um decaimento eletrostático inicial rápido, mas permanecem com $20 \%$ da carga inicial, mesmo após $100 \mathrm{~s}$. Isso pode ser atribuído ao fato de o material resistir somente a uma polarização, cuja resposta ao potencial aplicado na superficie do material é limitada, ou ao fato de, em materiais compostos e isolantes, ser exigido um valor mínimo de campo para romper o "gap" entre as partículas condutoras, a fim de que aconteça o transporte de cargas. 
Seja qual for o processo envolvido, o fato de um material antiestático conservar, por longo tempo, um certo nível de potencial eletrostático, representa um perigo, por exemplo, aos componentes eletrônicos, os quais se danificam com descargas eletrostáticas.

Arridge [10] estudou o decaimento de cargas elétricas em um fio de náilon, na presença de diferentes valores de umidade do ar, e descobriu que sendo o valor desta aproximadamente $35 \%$, as cargas ficam localizadas no material, estando seu decaimento muito próximo de uma curva exponencial. Já para valores acima de $35 \%$, as cargas espalham-se ao longo do fio.

Arridge utilizou um equipamento no qual o fio de náilon permanecia preso, pelas extremidades, por grampos isolantes, tendo os eletrodos móveis circundando o fio; esses eletrodos deslocavam-se através do fio com um carrinho sobre minitrilhos. Outro carrinho deslocava o fio, já carregado, através de um cilindro de Faraday, ou anel coletor, o qual fornecia os registros da distribuição de carga ao longo do fio. Um esquema do equipamento desenvolvido é mostrado na figura 2.2 .

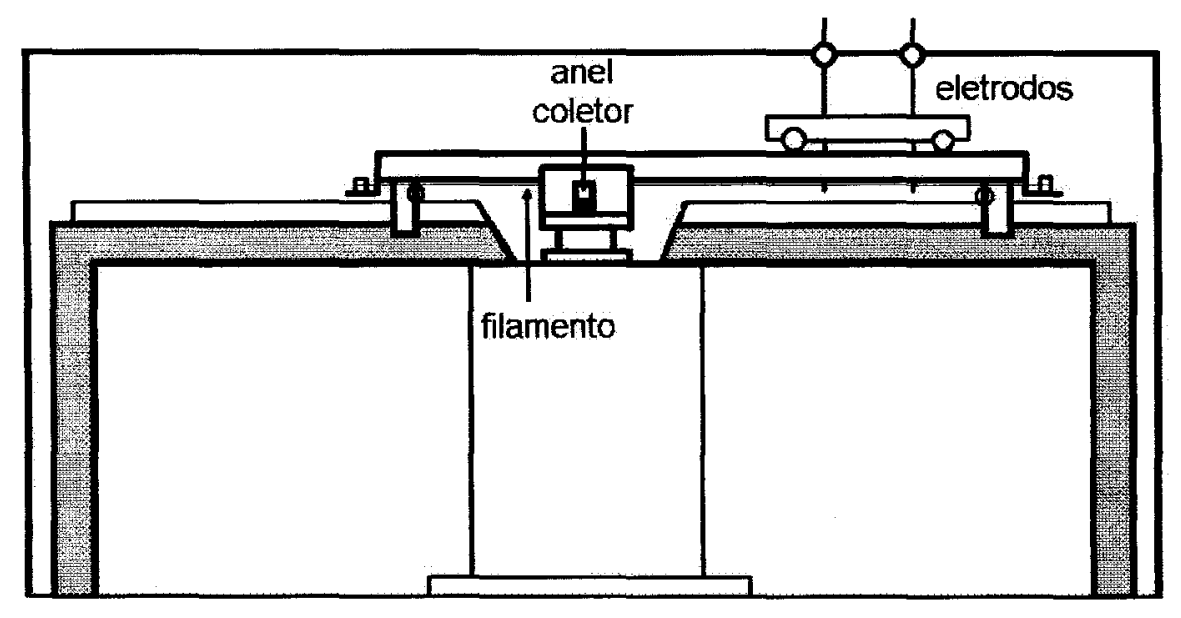

Figura 2.2: Diagrama esquemático do equipamento para medição do decaimento de cargas elétricas de um fio de náilon

O equipamento ficava encapsulado numa cabine feita de folha de alumínio, o que proporcionava, além da blindagem eletrostática, o seu uso em qualquer ambiente. 
Existem, no entanto, alguns fatores que limitam a precisão dos resultados, como, por exemplo, o fato de a concentração das cargas não acontecer estritamente num ponto, e a medição da carga pelo anel coletor também não ser precisa, porque seu potencial é proporcional à carga e à posição do fio; assim, um fio carregado exige uma posição centrada no anel coletor e uma abertura limitada deste. Há também o fato de o tempo gasto pelo fio para atravessar o anel coletor, com altos valores da umidade do ar, ser uma fração do tempo de difusão das cargas, havendo necessidade de uma correção para este efeito.

Alfaro [11] projetou um equipamento para estudar o transporte de cargas em filmes isolantes, com o objetivo de medir simultaneamente as correntes totais e as diferenças de potencial numa amostra, durante o período de carga, no estacionário e no decaimento, isto é, todas as fases de uma descarga corona, uma vez que o carregamento das amostras é feito por esta descarga. $O$ aparelho é constituído de um capacitor vibrante, no qual uma das placas é feita de uma malha metálica fina e fixa, que divide o aparelho em duas partes: uma é a região onde são gerados os íons, e a outra é a região do capacitor vibrante, ou região de medida onde se localiza a amostra em estudo. Todo este conjunto fica dentro de uma câmara cilíndrica, também metálica para que se tenha a blindagem eletrostática do equipamento. A oscilação do capacitor é proporcionada por um alto-falante, cuja membrana é ligada diretamente no conjunto de eletrodos, ou seja, no inferior e no eletrodo guarda. A corrente que atravessa a amostra é medida por meio de um eletrômetro e, depois, com o auxílio de um transdutor eletroóptico, estes dados vão para um registrador. O potencial de superficie é medido por um voltímetro eletrostático, fornecendo uma curva da distribuição de potencial da superfície da amostra.

Baum, Lewis e Toomer [12], ao estudarem o carregamento de filmes de polietileno, não tratados com a descarga corona, perceberam algumas diferenças no decaimento eletrostático quando o carregamento era realizado com corona positiva e negativa.

No carregamento com descarga corona de polaridade negativa, tem-se um tempo de decaimento mais rápido da área central da amostra do que das áreas periféricas; essa diferença não é notada quando se tem o carregamento com corona positiva. 
Perceberam, também, que a densidade superficial de cargas numa amostra influencia, e muito, o tempo de decaimento quando o carregamento é realizado com corona negativa. No carregamento por corona, de polaridade positiva, notou-se que a razão de decaimento diminui com a diminuição da umidade do ar. A figura 2.3 mostra o diagrama esquemático da montagem do carregamento corona.

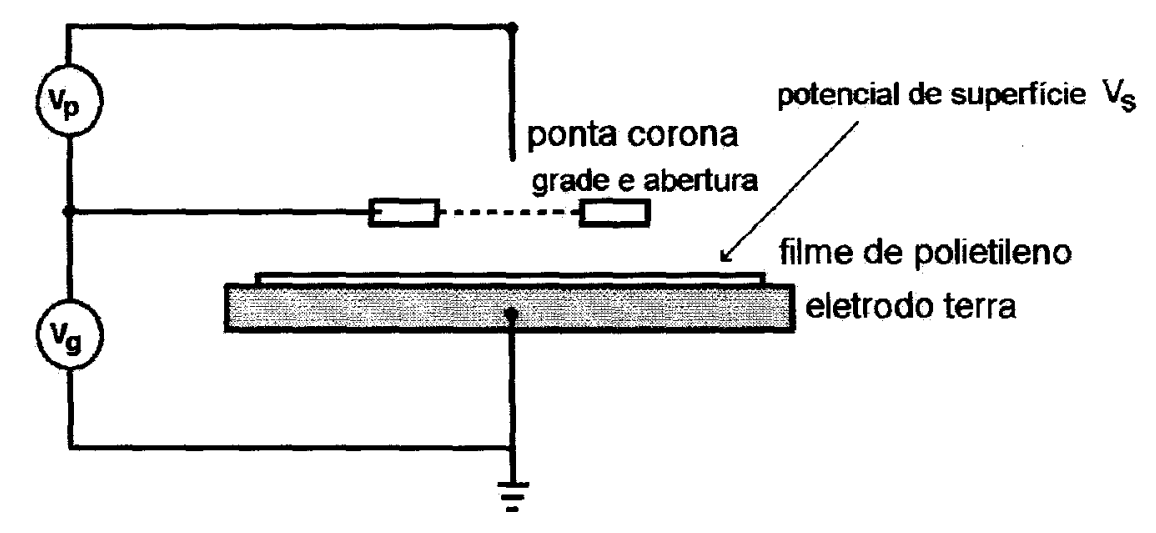

Figura 2.3: Diagrama esquemático do equipamento para carregamento corona

Esses pesquisadores [12] também procuraram uma explicação para a presença do fenômeno "cross-over" nas curvas de decaimento do potencial eletrostático e chegaram à conclusão de que, provavelmente, o fenômeno era causado pelo efeito da fotoinjeção de elétrons, mais na superficie que no volume do polímero, o que induz um decaimento mais rápido. Viram também que o processo de carregamento do polímero só acontecia no seu volume se houvesse a presença de uma energia de ativação, a qual poderia ser proporcionada pelas próprias cargas superficiais, que gerariam um campo, fazendo com que elétrons fossem injetados no volume do material.

Secker e Chubb [13] chegaram à conclusão, por meio de uma revisão dos métodos, de que, enquanto as cargas eletrostáticas são um parâmetro chave para medições, não é muito conveniente medi-las diretamente, sendo mais fácil a medição de 
um parâmetro a elas associado, como é o caso do campo elétrico gerado por estas cargas.

Dentro da revisão feita por Secker e Chubb, a respeito dos métodos de medição, encontra-se um medidor de campo, bem simples, contendo um capacitor, um amplificador, um disco sensor e um eletrômetro, representado na figura 2.4 .

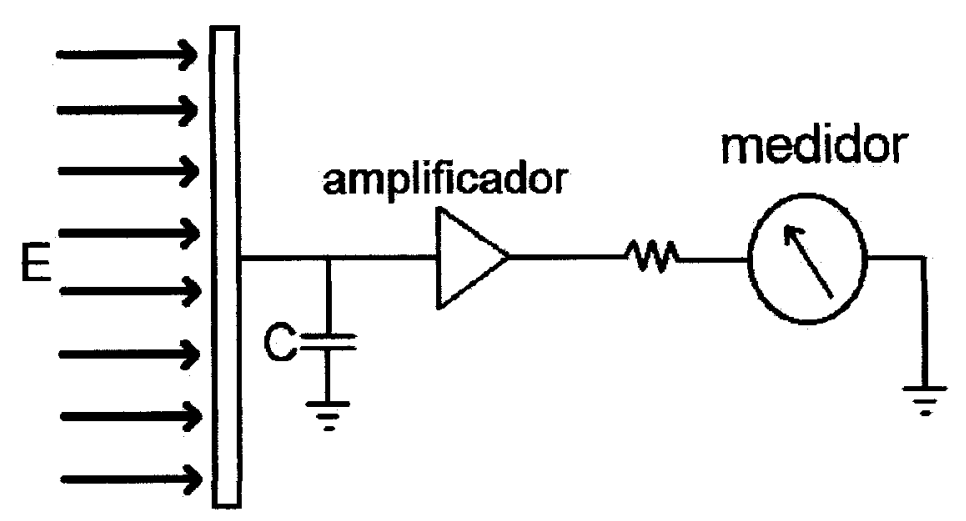

Figura 2.4: Configuração básica para o medidor de carga induzida

Apesar da simplicidade e do baixo custo, características que incentivam sua utilização, este equipamento apresentou problemas como, por exemplo, a incapacidade de distinguir um campo elétrico dos elétrons livres presentes na atmosfera.

Existe um outro medidor de campo, também de construção simples, que consiste em uma sonda (ou ponta corona). Quando a sonda é exposta a um campo elétrico que excede o valor limite da tensão entre ela e o espaço ao seu redor, ocorre uma descarga corona. Acontece, então, um fluxo de corrente, acendendo-se um tubo de neon, e a razão com que este emite luz é proporcional ao campo elétrico medido pela sonda. Esse equipamento é mostrado na figura 2.5 . 


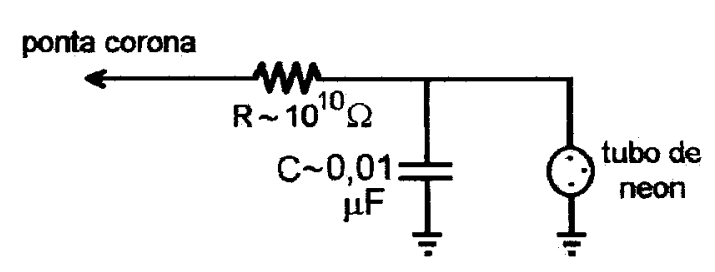

Figura 2.5: Medidor por sonda de corona

$\mathrm{Na}$ prática, o medidor corona serve como um guia para indicar superfícies altamente carregadas de materiais isolantes. Existe um medidor de campo elétrico que anula o efeito da presença de íons no ar, mostrado na figura 2.6.

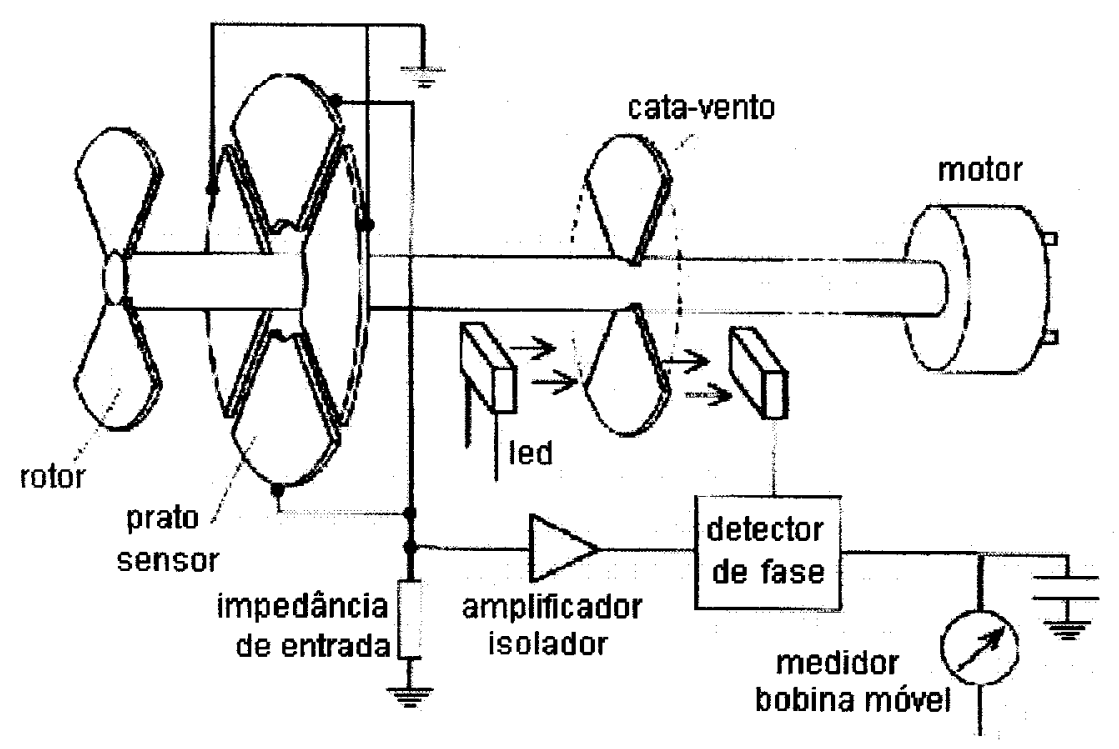

Figura 2.6: Arranjo tipico para o "field mill", tipo de medidor de campo elétrico 
Esse medidor é construído a partir de peças, do tipo cata-vento, com movimentos cíclicos, fazendo com que o efeito acima citado seja anulado. A presença de campo eletrostático é indicada por um instrumento de bobina móvel, acoplado ao conjunto. Um problema relacionado a este equipamento é o fato de a medição do campo depender do tamanho da abertura dentro da qual se encontra o elemento sensor.

Esse tipo de medidor é utilizado em locais onde há necessidade de medição por longo período de tempo, em ambientes carregados de energia, com a presença de partículas úmidas no ar, e para medição de campos flutuantes.

Há um instrumento baseado no efeito provocado por alguns materiais quando ativados opticamente na presença de um campo elétrico; esse efeito permite a realização de medições remotas, sem necessitar de conexões por meio de fios. Porém, na presença de qualquer fluxo de partículas de carga, ocorrerão erros nas medições.

Existe a sonda balística, que explora a propriedade do campo local, adquirida por uma bolinha, condutora e isolada, colocada em local ionizado. Esse sistema tem considerável valor na caracterização do comportamento de precipitadores eletrostáticos e no desempenho de pistolas para pintura eletrostática. Um diagrama esquemático desse equipamento é mostrado na figura 2.7 .

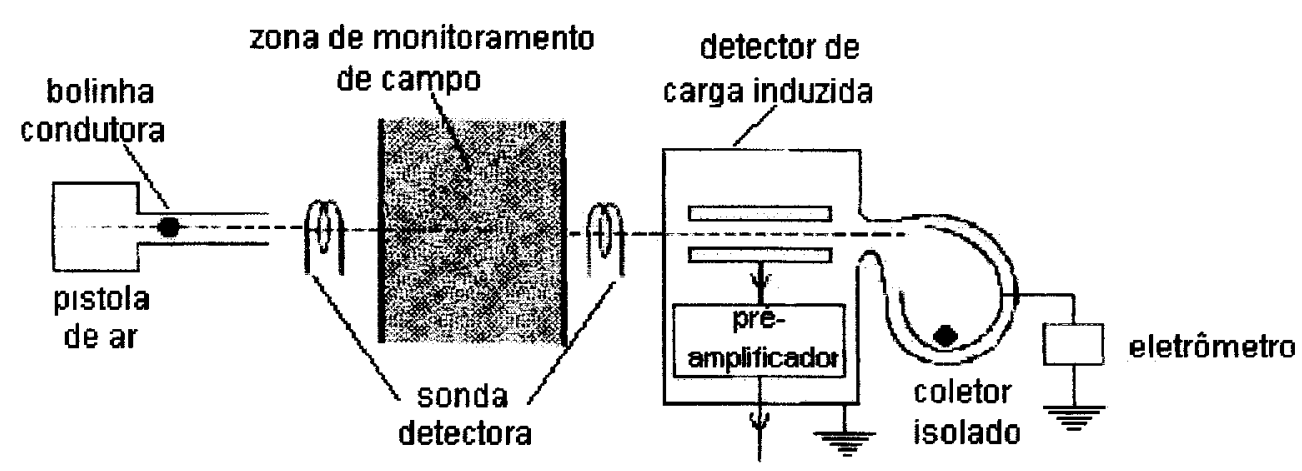

Figura 2.7: Sonda balística para medição de campo elétrico na presença de cargas livres 
Secker e Chubb [13] estabelecem regras úteis para a medição de campo eletrostático, como, por exemplo, o fato de a proximidade do medidor de campo não dever aumentar a capacitância do corpo, pois, se isto ocorrer, o potencial medido sofrerá uma mudança de valor (sendo menor que o valor real). Uma outra regra é a de a configuração do campo elétrico entre o corpo e o medidor precisar ser conhecida; assim, o valor do campo medido pode ser relacionado ao potencial do corpo.

Para a medição de cargas eletrostáticas, o método-padrão é o cilindro de Faraday, acoplado a um circuito medidor de cargas induzidas. $\mathrm{O}$ cilindro de Faraday consiste em um copo de material condutor, cercado por uma tela metálica aterrada (para evitar a interferência de ruídos), dentro do qual é colocado o objeto carregado, de modo que todas as linhas de campo do material carregado fiquem envolvidas pelo cilindro. Esse equipamento é mostrado na figura 2.8 .

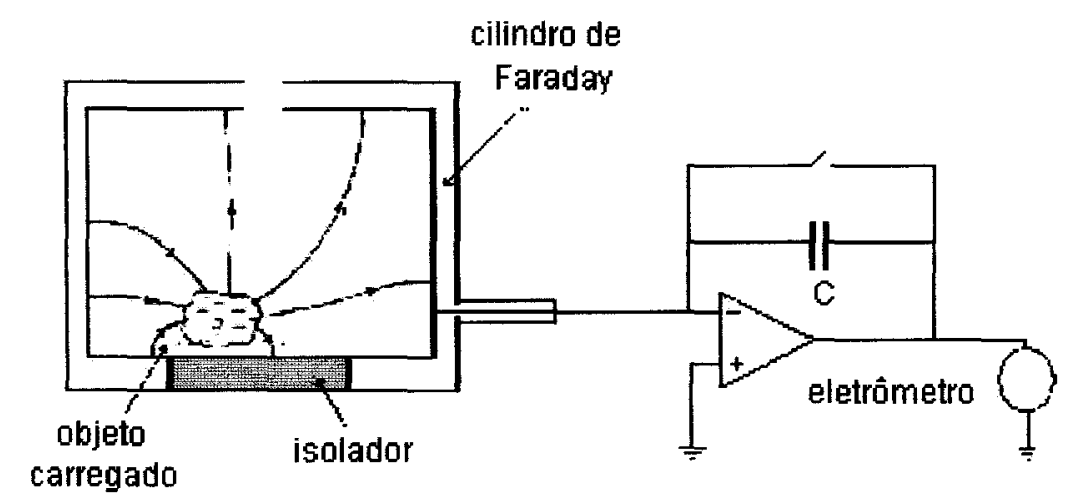

Figura 2.8: Sistema do cilindro de Faraday para medição de carga eletrostática

O circuito acoplado ao cilindro de Faraday consiste em um amplificador, um capacitor e um eletrômetro.

A medição de densidade de cargas superficiais, as quais podem prejudicar muito os processos industriais, pode ser realizada pela medição do campo elétrico por elas criado; quanto à medição da densidade volumétrica de cargas, é usualmente realizada pela medição do campo elétrico envolvido ou pela medição do valor máximo do potencial espacial, criado pela distribuição de cargas. 
A resistividade do material não está relacionada com sua capacidade de geração de cargas eletrostáticas, mas determina a rapidez com que estes materiais irão dissipar a carga adquirida.

Assim, é muito importante garantir o aterramento de todas as partes do sistema em processos de fabricação, quando há possibilidade de as descargas eletrostáticas provocarem grandes prejuizos. A resistividade $(\rho)$ e a constante de tempo $t$ (s), incorporadas na relaxação de cargas, são expressas pela relação:

$$
t=\varepsilon_{0} \cdot \varepsilon_{r} . \rho
$$

sendo: $\varepsilon_{0}$ a permissividade do vácuo $\left(8,85 \times 10^{-12} \mathrm{~F} \cdot \mathrm{m}^{-1}\right) \mathrm{e}$

$\varepsilon_{\mathrm{r}}$ a permissividade relativa do material.

Para medição de corrente, utiliza-se um eletrômetro, necessitando, porém, de proteção contra correntes associadas a transientes, que danificariam o equipamento de medição. Utilizam-se também, quando a corrente a ser medida é de valor baixo, fontes emissoras de luz, sendo a luz emitida proporcional à corrente no material.

Para a medição de descargas eletrostáticas, existem pequenas sondas sensoras, as quais ficam localizadas num dos eletrodos de descarga. Se a sonda estiver bem posicionada, será induzida na sua superfície uma pequena fração do total da corrente de descarga que vai para o eletrodo de descarga.

Coelho, Levy, Sarrail e Marque [14], trabalhando em conjunto com os laboratórios de pesquisa públicos Office National d'Etudes et Recherchs Aerospatiales (Onera), CNRS e a indústria Ecopol, descreveram laboratórios compactos como a Bancada de Ensaio e Medidas Eletrostáticas (Beme) e o Analisador eletrostático de Alta Resolução (Eletroscan). O primeiro deles permite o estudo da propensão de um material isolante carregar-se através de jato de ar e de descarregar-se espontaneamente ou por contato com objetos metálicos. 
Com o Beme, pode-se obter o valor do campo elétrico irradiado pela amostra, bem como o valor da energia de uma faísca ocorrida durante o descarregamento da amostra em contato com metal. $O$ descarregamento da amostra também é realizado por um neutralizador através de um jato de ar apropriado.

É possível caracterizar materiais partindo-se do decréscimo do campo elétrico emitido por uma amostra carregada e pressupondo-se que essa amostra não se carrega no volume, sendo associada a um circuito RC. Assim, o tempo de relaxação do material é:

$$
\tau=R \cdot C
$$

sendo: $\tau$, o tempo de relaxação do material (s),

$\mathrm{R}$, a resistividade $\left(\Omega \mathrm{cm}^{2}\right.$ ou $\left.\Omega \mathrm{cm}\right)$ e

C, a capacitânia (F).

O Eletroscan é um equipamento que contém uma sonda capacitiva de alta resolução; nele, a amostra é fixada num sistema pneumático, carregada por descarga corona através de uma ponta metálica e, depois, deslocada para uma outra posição, onde é feita a leitura do potencial por meio da sonda, a qual transmite estes dados para um osciloscópio.

O Eletroscan é muito sensível e confiável quando utilizado para testes com filmes isolantes finos (resultados precisos com filmes de $25 \mu \mathrm{m}$ ), além de proporcionar o cálculo da resistividade e da permissividade do material. $O$ diagrama esquemático do Eletroscan é mostrado na figura 2.9. 


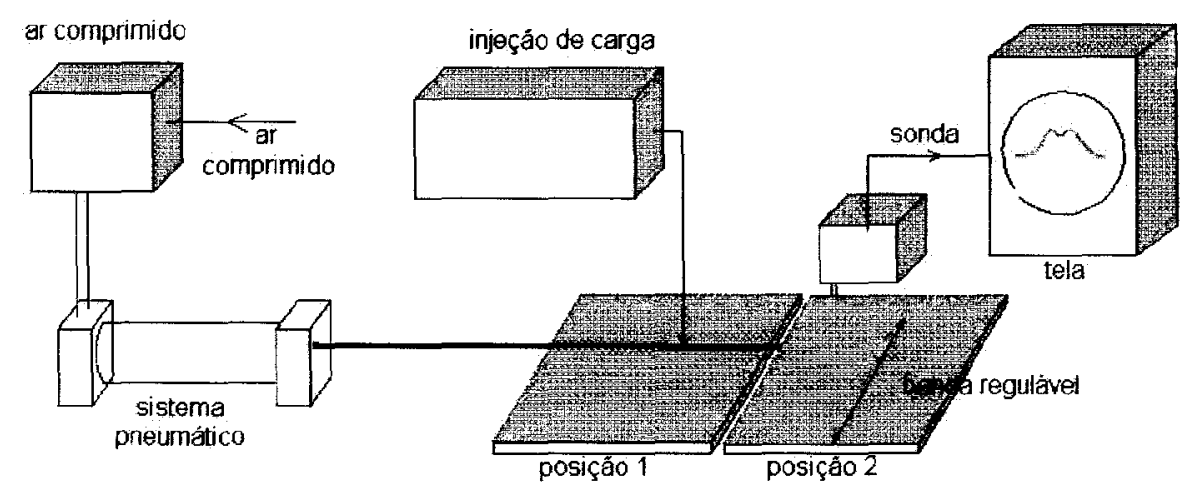

Figura 2.9: Diagrama esquemático do Eletroscan - Analisador Eletrostático de Alta Resolução

Sessler [15] desenvolveu um método para determinar a densidade de cargas retidas em um dielétrico carregado. $O$ equipamento contém um eletrodo planar, no qual a amostra é fixada, uma sonda, também de forma planar, e um eletrômetro. Quando é mantida uma certa distância entre a sonda e o dielétrico carregado (eletreto), pode-se medir a densidade de cargas presas na superficie deste, por meio do eletrômetro. $\mathrm{O}$ diagrama esquemático dessa situação encontra-se na figura 2.10 .

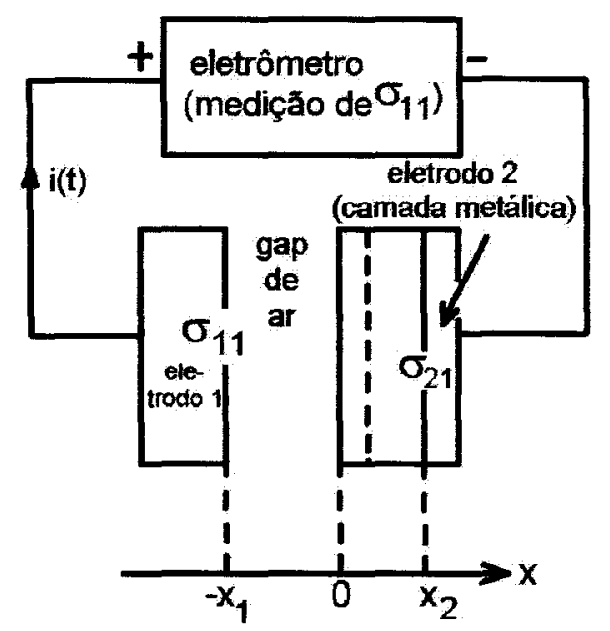

Figura 2.10: Esquema de montagem para medição de densidade superficial de carga 
Da mesma maneira, apenas aproximando a sonda da amostra, mede-se a corrente de deslocamento de cargas em função do tempo. $O$ diagrama esquemático dessa situação encontra-se na figura 2.11 .

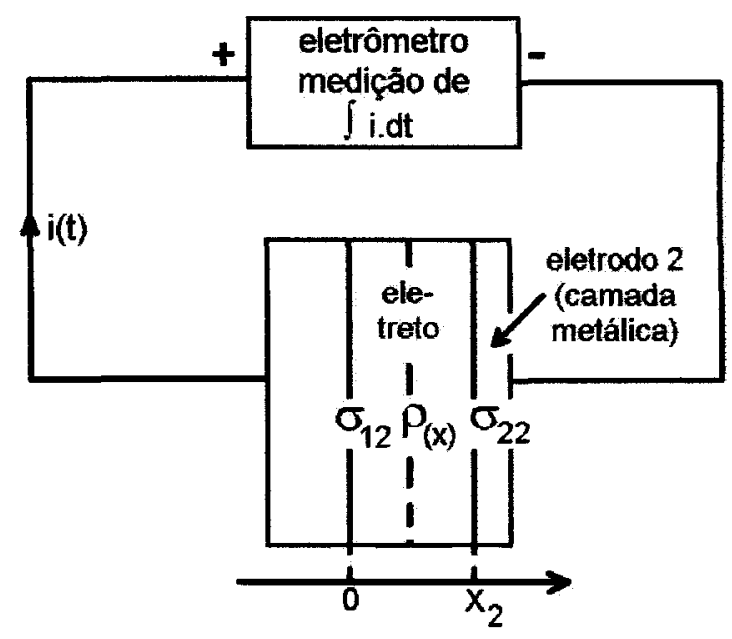

Figura 2.11: Diagrama esquemático para medição de corrente

Weimberg, Matthies, Johnson e Lampert [16] criaram um método de medição de potencial de superficie em filmes isolantes muito útil nos casos em que, logo após o desligamento da carga, o decaimento do potencial superficial é muito rápido (portanto, difícil de ser medido).

Neste método, é utilizada uma placa metálica de referência, com geometria superficial idêntica à da amostra e colocada à mesma distância que a da amostra à ponta corona. $\mathbf{O}$ carregamento é feito por descarga corona, por meio de uma ponta metálica, na presença de gás (aproximadamente à pressão atmosférica) e, por comparação, conseguese $o$ valor do potencial de superficie do filme isolante. $O$ diagrama esquemático desse método encontra-se na figura 2.12 .

Secker [17] projetou um medidor de tensão - um medidor de potencial de carga superficial em forma de "moinho", contendo um rotor ligado a pás rotativas que são colocadas na presença do campo elétrico a ser medido. 


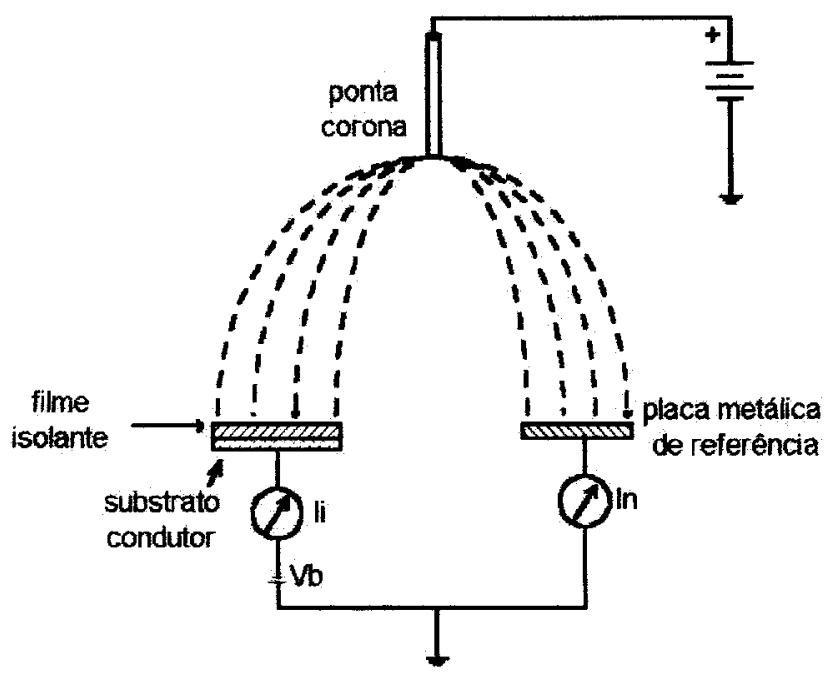

Figura 2.12: Princípio básico de operação do método de comparação. A tensão aplicada $V_{b}$ é ajustada até que $I_{i}=I_{n}$, ponto no qual a tensão através do isolador $V_{i}$ deve ser $V_{i}-V_{b}$

O rotor gira em frente a um sensor, conectado ao terra através de uma impedância $Z$. A tensão alternada gerada em $Z$ é amplificada e medida. A polaridade do campo elétrico não é mostrada nesse equipamento.

O "field mill" acima citado é muito versátil na indicação de cargas estáticas em uma amostra de filme isolante. $O$ diagrama esquemático desse equipamento é mostrado na figura 2.13 . 


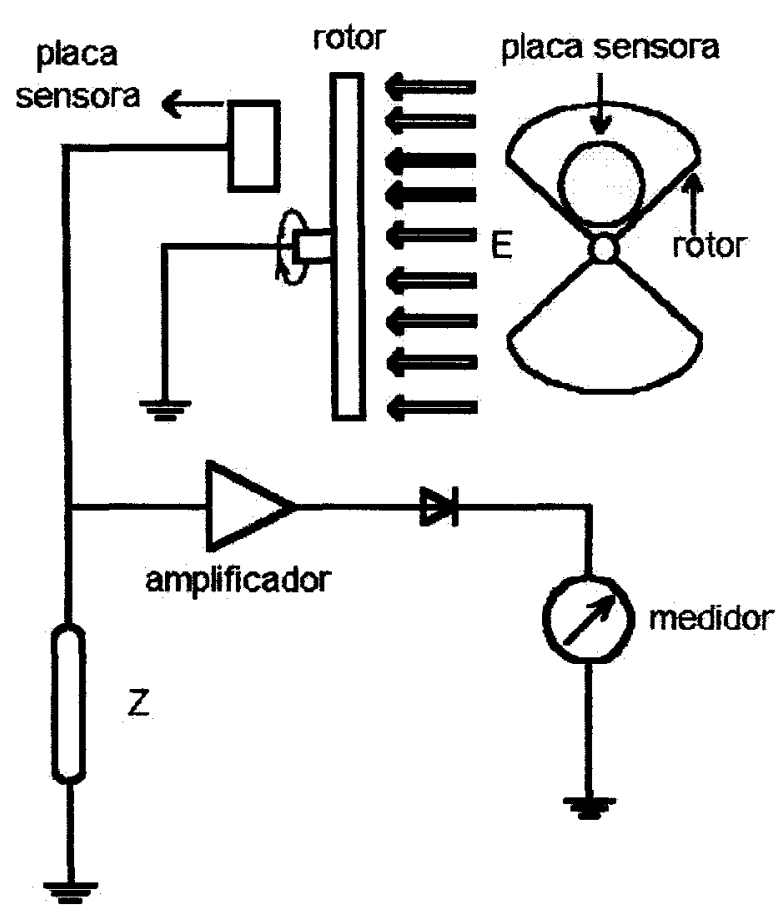

Figura 2.13: Medidor de carga superficial em forma de moinho: "field mill"

Já a sonda de potencial, também desenvolvida por Secker, fornece-nos informações detalhadas da distribuição de cargas estáticas e é colocada bem próxima ao filme isolante que se quer medir, tendo um pré-amplificador a ela conectado. $O$ sinal que sai do pré-amplificador é mostrado por um registrador. Existem, porém, alguns problemas quanto à utilização deste equipamento, como, por exemplo, a presença de ruídos, ou microfonia, no sinal do potencial, as variações na espessura da amostra e a distância sonda/amostra podem provocar erros na saída do sinal do potencial.

Taylor e Williams [18] observaram em muitos experimentos que o decaimento de carga de uma amostra de material isolante tem um decaimento inicial rápido, seguido de um nível quase estacionário; e estudaram, ainda, a possibilidade de o processo de decaimento envolver injeção de cargas superficiais no volume do isolante. 
Chegou-se à conclusão de que a dependência da injeção de cargas superficiais com o campo depende do desarmadilhamento superficial e da mobilidade de campo e de que a carga superficial de um isolante decai exponencialmente.

Haenen [19] estudou as características de decaimento de cargas superficiais em alguns dielétricos como vidro-Pyrex, Perspex e Teflon, por meio de um equipamento contendo uma sonda eletrostática, um eletrômetro, uma fonte de alta tensão para o carregamento por corona e um registrador de potencial eletrostático.

Todo este conjunto é móvel nas direções x e y. Assim, o potencial do dielétrico é dado como uma função da coordenada $x$ com o tempo $t$, e a tensão medida pelo eletrômetro corresponde ao potencial de cargas superficiais. $O$ tempo de meia-vida do decaimento de cargas nos dielétricos considerados por Haenen é muito longo, levando, aproximadamente, 20 horas para perder $1 / 3$ da carga inicial, sendo o tempo de relaxação do material muito menor do que o tempo de meia-vida.

Notou-se que a distância entre a sonda e o dielétrico, a umidade relativa do ar, o modo de armazenamento, bem como a contaminação do material influenciam na medição do potencial de cargas superficiais da amostra.

Ballik [20] reporta uma nova técnica para medição de cargas superficiais em eletretos, a qual é baseada em medições ópticas do deslocamento de um dielétrico em forma de membrana. Nesse método, que é não destrutivo, é utilizado um sistema de eletrodos, sendo a amostra (Mylar - filme de poliéster tendo um dos lados metalizado com alumínio) fixada no meio deles. Com a aplicação de uma diferença de potencial entre os eletrodos, aparece um deslocamento no eletreto, resultado da força eletrostática gerada. $O$ deslocamento, proporcional ao potencial eletrostático da amostra, é medido por um equipamento óptico. Na figura 2.14 pode-se observar um esquema do equipamento criado por Ballik. 


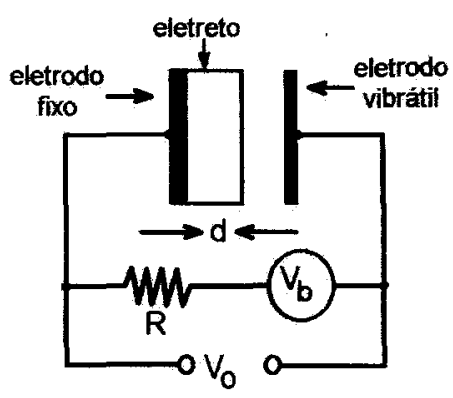

Figura 2.14: Método do eletrodo vibrante para medição de carga superficial de um eletreto

Das-Gupta [21] estudou o comportamento do decaimento de cargas superficiais do polietileno de baixa densidade (LDPE). Para isso, utilizou um filme do material, com um dos lados metalizado e descarregado com banho de álcool isopropílico, com secagem posterior. No equipamento construído por Das-Gupta, a amostra é colocada sobre um disco de metal (eletrodo terra), que, numa certa posição, a deixa sob a agulha, através da qual acontece o carregamento por descarga corona. Quando essa fase é finalizada, o disco é girado, e a amostra fica sob a sonda eletrostática, a qual está conectada a um registrador do potencial eletrostático da amostra. Tanto o processo de carregamento como a sonda ficam no interior de uma campânula com vácuo, preenchida com gás nitrogênio. Um esquema do equipamento é mostrado na figura 2.15 .

Foi notado que na região central da amostra, localizada bem abaixo da ponta corona, quando acontece o processo de carregamento, tem-se um decaimento mais rápido de cargas.

Como explicação para o acontecimento citado, tem-se que a taxa de decaimento da região central da amostra será alta se existir injeção considerável de cargas no volume do material. Estas cargas vêm da superficie do material, assim haverá uma redução nas cargas superficiais, permitindo a chegada de mais íons na superficie, sendo este processo mantido durante o carregamento. 


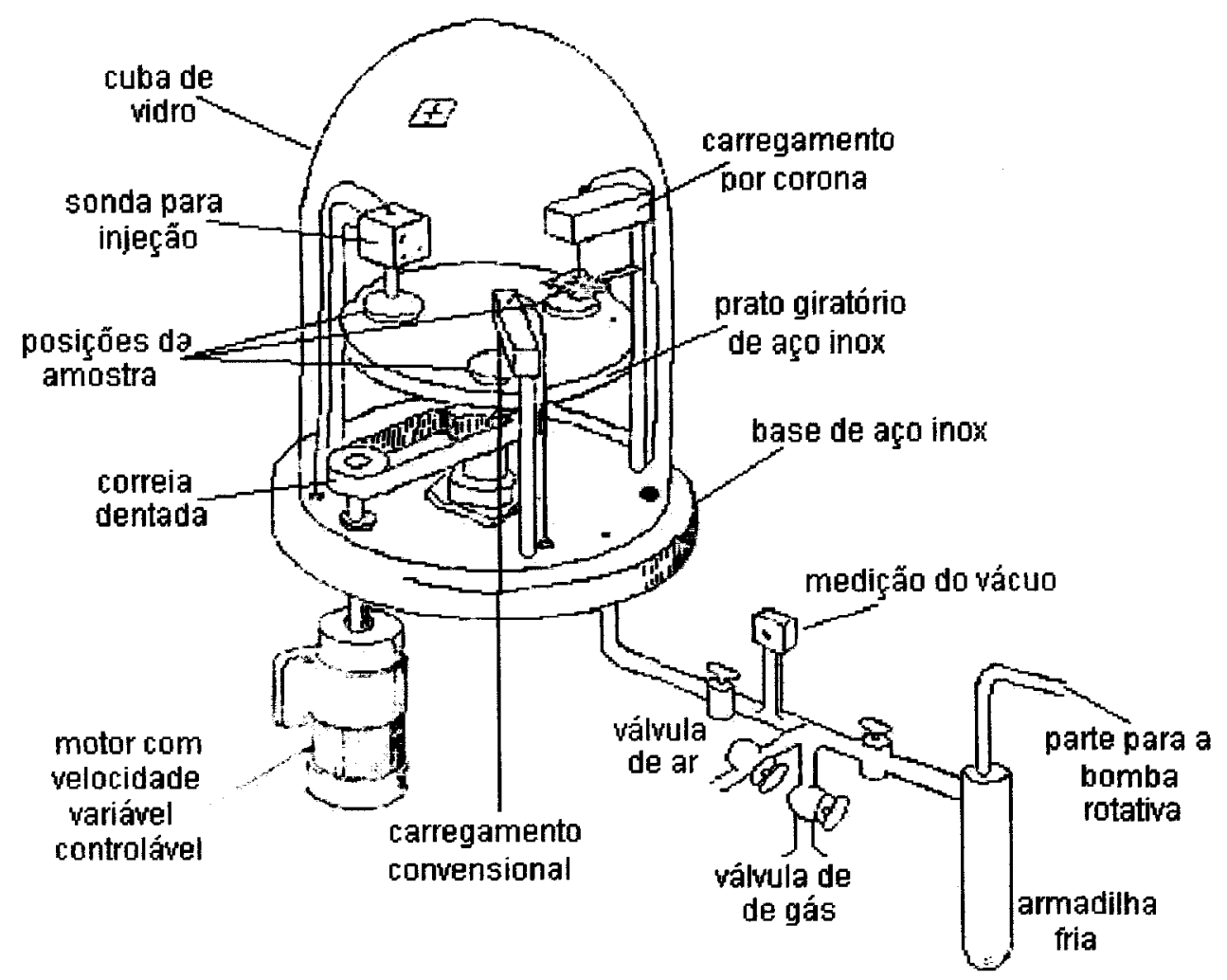

Figura 2.15: Aparelho experimental para carregamento corona e medição do decaimento de carga superficial

A Norma EIA - 541 [22] estabelece que um material com característica antiestática refere-se à habilidade de ele resistir à geração de carga triboelétrica. A propensão do material depende da natureza do próprio material e do material com o qual entra em contato.

A norma também estabelece as características dos materiais com relação à sua resistividade superficial, que é uma propriedade intrínseca usada para definir o seu grau de condutividade.

Para que um material tenha blindagem eletrostática ele deve ter resistência superficial menor que $1 \times 10^{4} \Omega \mathrm{cm}^{2}$, ou resistividade volumétrica menor que $1 \times 10^{3} \Omega \mathrm{cm}$ por milímetro de espessura. Já, para que o material seja condutivo, a resistividade 
superficial deve ser menor que $1 \times 10^{5} \Omega \mathrm{cm}^{2}$, e a resistividade volumétrica menor que $1 \times 10^{4} \Omega \mathrm{cm}$ por milímetro de espessura.

Um material é dissipativo se a resistividade superficial for igual ou maior que $1 \times 10^{5} \Omega \mathrm{cm}^{2}$, porém menor que $1 \times 10^{12} \Omega \mathrm{cm}^{2}$, e a resistividade volumétrica for igual ou maior que $1 \times 10^{4}$, mas menor que $1 \times 10^{11} \Omega \mathrm{cm}$ por milímetro de espessura. Um material é considerado isolante se sua resistividade superficial for maior que $1 \times 10^{12} \Omega \mathrm{cm}^{2}$, sendo a resistividade volumétrica igual ou maior que $1 \times 10^{11} \Omega \mathrm{cm}$ por milímetro de espessura.

Os valores citados anteriormente podem ser melhor visualizados com o auxílio da fogura 2.16 .

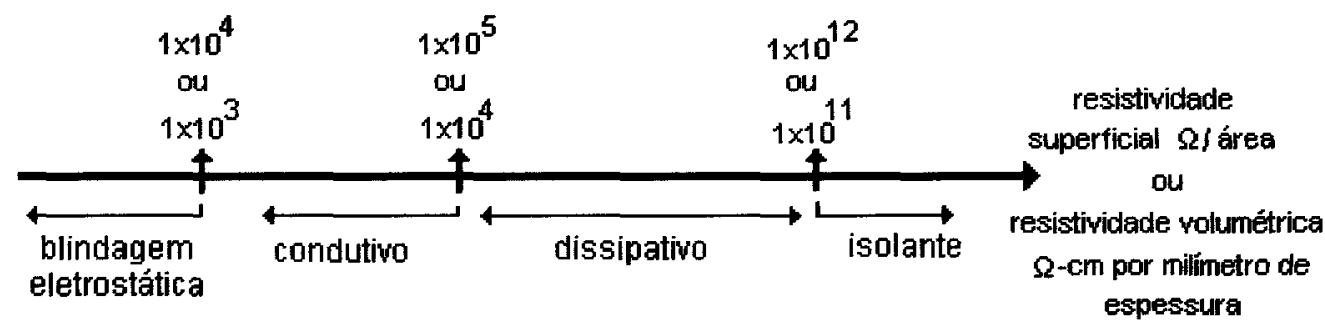

Figura 2.16: Resistividade superficial ou resistividade volumétrica,relacionada com as caracteristicas eletrostáticas dos materiais,segundo a Norma EIA - 541 [22]

A Norma ASTM D. 4470-91 [23] descreve um método de medição de cargas eletrostáticas e o campo gerado por elas, tanto em sólidos como em líquidos. $O$ equipamento para execução desse método consiste em um mecanismo de carregamento, o qual se estabelece pelo contato entre a amostra e as paredes de um tubo. 
Depois do carregamento, a amostra é colocada numa Gaiola de Faraday ${ }^{2}$ conectada a capacitores shunt, pois pode ser necessária a diminuição da tensão da amostra antes de ser lida pelo eletrômetro; existe ainda um visor conectado ao eletrômetro para que seja mostrada a tensão medida por ele.

Quanto à amostra, ela necessita de preparação especial antes do teste. No que diz respeito à limpeza e à retirada de umidade, a preparação da amostra depende do seu tamanho e do material de que é feita, sendo recomendados tempos que vão de $24 \mathrm{~h}$ a $72 \mathrm{~h}$ de acondicionamento num dissecador.

A respeito das condições de ensaio, a norma estipula que a temperatura da sala deve estar entre $23{ }^{\circ} \mathrm{C} \pm 2{ }^{\circ} \mathrm{C}$, e a umidade relativa do ar, entre $20 \% \pm 2 \%$.

Giacometti [24] descreve a construção de um triodo corona com uma grade de malha uniforme e com uma ponta corona, montados no interior de um tubo isolante (PVC) e blindado. O triodo corona, neste caso, funciona com corrente de carregamento mantida constante por meio do controle da tensão da grade e promove a medição da distribuição da densidade de corrente e da distribuição superficial de cargas, em testes com amostras de polímero (PET). A pesquisa realizada por Giacometti foi de grande valia para o estudo da dinâmica do processo de carregamento uniforme de dielétricos.

\subsection{CARGAS ELETROSTÁTICAS EM REVESTIMENTOS TÊXTEIS}

Segundo Wilson [25], as cargas estáticas são produzidas durante o contato e separação de duas superficies sólidas quaisquer, sendo esse efeito mais observado quando os materiais são altamente isolantes e, dessa forma, não sendo capazes de dissipar rapidamente a carga adquirida.

2. Gaiola de Faraday são dois recipientes condutores, isolados um do outro. A parte externa é conectada ao terra para evitar que as medições sejam afetadas por campos eletromagnéticos externos, e a parte interna deve envolver totalmente a amostra, sendo esta conectada a um instrumento medidor de potencial elétrico, por exemplo, um eletrômetro [22]. 
Durante o contato acontece transferência de cargas, através da interface, até que seja estabelecido um equilíbrio. Na separação, algumas cargas permanecem em uma ou outra superfície. São exatamente estas cargas livres as causadoras dos principais problemas estáticos.

Alguns fatores, como a afinidade relativa entre os materiais, a resistência elétrica deles, a área de contato e pressão entre os materiais e a umidade relativa do ar, definem a magnitude das cargas geradas.

Wilson sugere que a maioria dos portadores de cargas são provavelmente íons, isto porque as fibras têxteis contêm muitas impurezas. Só nas últimas décadas é que se relacionou eletricidade estática com danos e prejuízos, como os observados, por exemplo, nas indústrias têxteis e de papel, onde tecido ou fitas de papel aderem às máquinas e quando faíscas resultantes de descargas eletrostáticas causam incêndios em ambientes onde se encontram vapores inflamáveis.

Wilson citou que, para solucionar esses tipos de problemas, o fabricante precisa apenas tomar algumas medidas temporárias, como o aumento da umidade do ar ou a aplicação de agentes antiestáticos nos produtos manufaturados.

A norma ISO/TR 6356-1982 (E) [26] estabelece um método de análise da propensão ao acúmulo de eletricidade estática em revestimentos têxteis. Por esse método é medida a tensão gerada no corpo de uma pessoa que caminha sobre um revestimento têxtil, usando um calçado especial e estando num ambiente controlado. Alguns cuidados são necessários para esta metodologia de ensaio, como, por exemplo, a eliminação das cargas residuais nos materiais de teste antes de procedê-lo, a manutenção de uma umidade relativa do ar bem baixa no ambiente de ensaio e a limpeza muito bem feita do calçado a ser utilizado no teste. $O$ calçado consiste em uma sandália aberta nos dedos do pé, com salto ajustável, contendo na sola cravos de alumínio, além de uma peça de aço inox, isso tudo para que se estabeleça um contato entre a sola e o indivíduo. $O$ indivíduo deve caminhar a dois passos por segundo por um determinado tempo e, depois, segurar um eletrodo manual, conectado a um voltímetro e a um registrador de potencial; assim, o potencial adquirido pelo indivíduo pode ser medido. $\mathrm{O}$ mesmo método é descrito pela Norma Francesa NF G35-025 [27]. 
Fujiwara [28] propõe dois métodos de caracterização eletrostática de materiais têxteis: a adaptação do triodo corona [24] com a medição do tempo de decaimento eletrostático, e a obtenção da resistividade elétrica do material. $\mathrm{O}$ autor implementou o método descrito na Norma EIA-541 [22], ou seja, a medição da resistividade elétrica. Por esse método, é aplicada uma tensão DC na amostra e, posteriormente, medida a corrente que a atravessa. Assim sendo, e conhecendo-se as dimensões da amostra, obtém-se a resistividade volumétrica pela expressão:

$$
\rho=\frac{V \cdot A}{I \cdot L}
$$

sendo: $\rho=$ resistividade volumétrica da amostra $(\Omega \mathrm{cm})$

$\mathrm{V}=$ tensão aplicada $(\mathrm{V})$

$\mathrm{A}=$ área da amostra $\left(\mathrm{cm}^{2}\right)$

$\mathrm{I}=$ corrente que atravessa a amostra (A) e

$\mathrm{L}=$ espessura da amostra $(\mathrm{cm})$

Com o valor da resistividade volumétrica, classifica-se o material quanto à sua característica condutiva, dissipativa ou isolante. Foram encontrados, porém, alguns problemas com relação à temperatura, à umidade e à pressão de contato entre o eletrodo e a amostra. Assim, foi necessária uma modificação na montagem do experimento, bem como o controle térmico do local de sua realização.

Os testes foram realizados com 15 minutos de carregamento, sendo as amostras preparadas (desumidificadas e descarregadas) previamente. $\mathbf{O}$ autor chegou à conclusão de que o método é inadequado para a caracterização de materiais têxteis do ponto de vista eletrostático, pois, além de demorado, o método não se adapta a todos os tipos de amostras.

Já o método de medição do tempo de decaimento eletrostático foi realizado com o triodo corona com grade vibrátil [24] e a medição do potencial de superficie, realizada por meio de um capacitor vibrante, conectado a um circuito eletrônico.

Fujiwara mostra que a densidade de cargas superficiais nas amostras carregadas produz o mesmo campo elétrico e potencial externo que a distribuição real de cargas na amostra. 
$\mathrm{O}$ autor também encontrou alguns problemas com essa metodologia de ensaio: a necessidade por parte do sistema de eletrodos de uma nova calibração a cada teste a ser realizado; o carregamento da grade vibrátil durante o carregamento das amostras; a permanência de cargas residuais na amostra (provocando erros na leitura do potencial); a dificuldade de ter um bom contato elétrico com as amostras de tapete e a presença de ruídos, introduzindo erros nas medidas.

Chubb, J.N $\mathrm{N}^{3}$. [29] afirma que os riscos e problemas devidos à eletricidade estática serão melhor evitados se pudermos assegurar que as cargas estáticas dissipam-se por completo através das superficies dos materiais e vão para a terra mais rapidamente do que elas são geradas. Falando-se em manuseio e ação nos corpos humanos, isto significa que o tempo de decaimento de carga precisa estar abaixo de $1 / 2$ segundo.

Preocupado com essas características necessárias aos materiais, Chubb construiu o JCI 155 "Charge Decay Test Unit", ou seja, um instrumento compacto para medição fácil e direta da habilidade dos materiais de dissipar eletricidade estática.

A figura 2.16 mostra uma foto do JCI 155 conectado a um microcomputador para coleta automática, análise e armazenagem dos dados do decaimento de carga. 


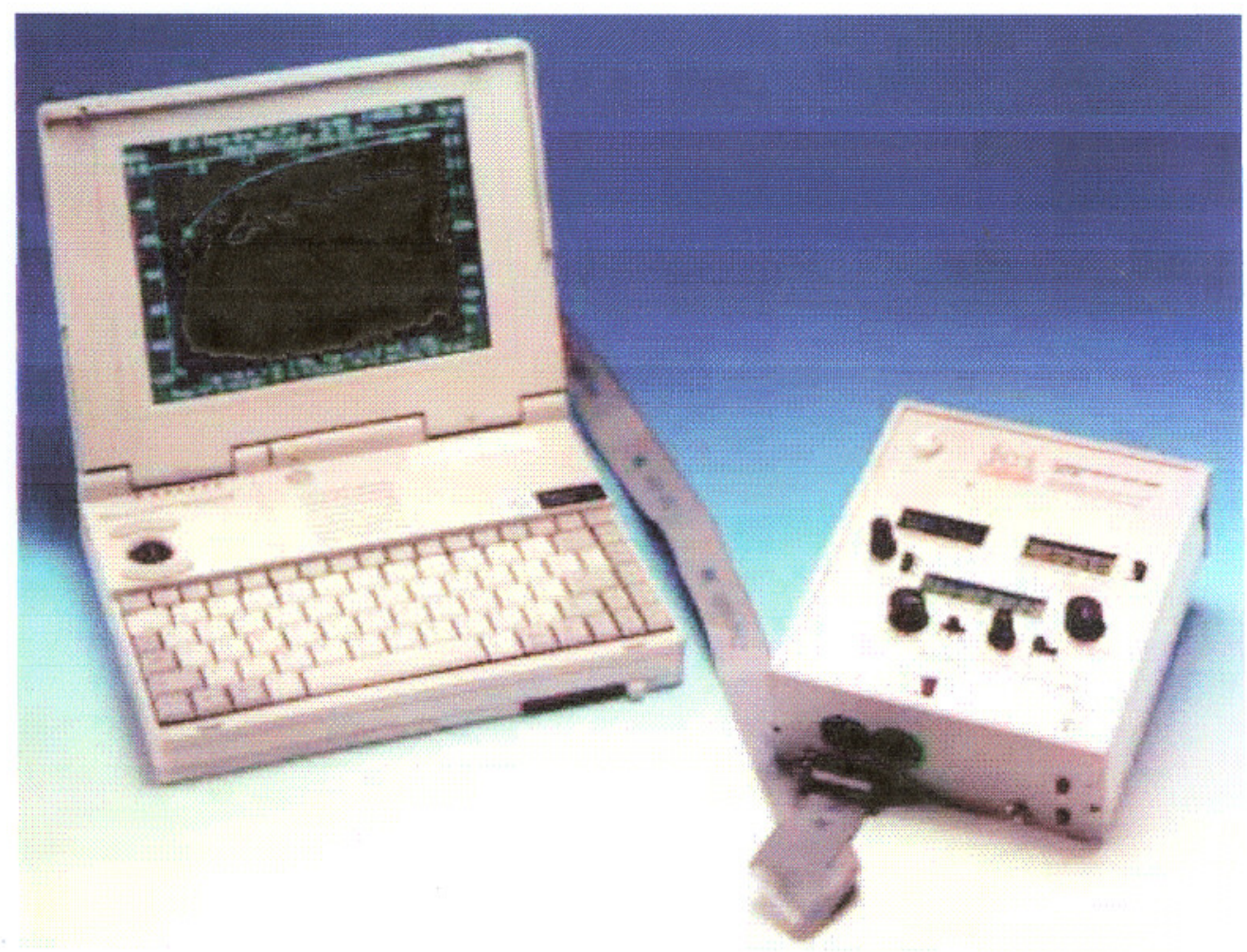

Figura 2.17: Foto do JCI 155 Charge Decay Test Unit

O aparelho é colocado diretamente sobre o material a ser testado, e, com um pulso de descarga corona $(5-10 \mathrm{kV})$, o material é carregado; depois, um medidor de campo do tipo "field mill" mede o potencial de superfície. 


\subsection{QUADRO COMPARATIVO DOS MÉTODOS DE MEDIÇÃo DE POTENCIAL DE SUPERFÍCIE E CARGA SUPERFICIAL}

\begin{tabular}{|c|c|c|c|c|}
\hline AUTOR & TÉCNICA & FACILIDADES & AMOSTRA & PROBLEMAS \\
\hline $\begin{array}{c}\text { Taylor, Elias, } \\
\text { Williams, Arridge, } \\
\text { Baum, Lewis e } \\
\text { Toomer }\end{array}$ & $\begin{array}{c}\text { Medição de } \\
\text { dissipação de } \\
\text { cargas elétricas }\end{array}$ & $\begin{array}{l}\text { Fornece o tempo de } \\
\text { decaimento e a } \\
\text { distribuição de cargas } \\
\text { superficiais. }\end{array}$ & $\begin{array}{l}\text { Amostras de } \\
\text { material } \\
\text { isolante na } \\
\text { forma de } \\
\text { filmes }\end{array}$ & $\begin{array}{l}\text { Presença de carga } \\
\text { residual nas amostras } \\
\text { já testadas } \\
\text { prejudicando os } \\
\text { resultados do } \\
\text { decaimento de } \\
\text { potencial, limite na } \\
\text { precisão dos } \\
\text { resultados }\end{array}$ \\
\hline Alfaro & $\begin{array}{c}\text { Estudo do } \\
\text { transporte de } \\
\text { cargas elétricas }\end{array}$ & $\begin{array}{l}\text { Fornece a distribuição } \\
\text { de cargas superficiais } \\
\text { e do potencial de } \\
\text { superficie. }\end{array}$ & Fio de Nylon & \\
\hline Secker e Chubb & $\begin{array}{c}\text { Revisão da } \\
\text { metodologia de } \\
\text { medição de } \\
\text { cargas elétricas }\end{array}$ & $\begin{array}{c}\text { Estabelece o método } \\
\text { mais adequado para } \\
\text { cada tipo de medição e } \\
\text { dá o tempo de } \\
\text { decaimento } \\
\text { eletrostático. }\end{array}$ & $\begin{array}{c}\text { Filmes e } \\
\text { material têxtil }\end{array}$ & $\begin{array}{l}\text { Detectaram problemas } \\
\text { quanto à medição de } \\
\text { campo elétrico } \\
\text { realizada por vários } \\
\text { equipamentos. }\end{array}$ \\
\hline $\begin{array}{l}\text { Coelho, Levy, } \\
\text { Sarrail, Marque, } \\
\text { Weimberg, } \\
\text { Matthies, Johnson, } \\
\text { Lampert e Secker }\end{array}$ & $\begin{array}{l}\text { Medição de } \\
\text { campo elétrico e } \\
\text { potencial de } \\
\text { superficie }\end{array}$ & $\begin{array}{l}\text { Fornece o cálculo da } \\
\text { resistividade e } \\
\text { permissividade e } \\
\text { medição de tempo de } \\
\text { decaimento } \\
\text { eletrostático que } \\
\text { ocorre de maneira } \\
\text { muito rápida }\end{array}$ & $\begin{array}{l}\text { Amostras de } \\
\text { material } \\
\text { isolante na } \\
\text { forma de } \\
\text { filmes }\end{array}$ & $\begin{array}{c}\text { Técnicas e } \\
\text { equipamentos } \\
\text { aplicados apenas nas } \\
\text { amostras em forma de } \\
\text { filmes }\end{array}$ \\
\hline $\begin{array}{l}\text { Sessler, Haenen, } \\
\text { Ballik e Das-Gupta }\end{array}$ & $\begin{array}{l}\text { Medição da } \\
\text { densidade } \\
\text { superficial de } \\
\text { cargas }\end{array}$ & $\begin{array}{c}\text { Estabelece as técnicas } \\
\text { para descarregamento } \\
\text { de filmes. }\end{array}$ & $\begin{array}{l}\text { Amostras de } \\
\text { material } \\
\text { isolante - } \\
\text { filmes }\end{array}$ & $\begin{array}{c}\text { Técnicas e } \\
\text { equipamentos } \\
\text { aplicados apenas nas } \\
\text { amostras - filmea }\end{array}$ \\
\hline
\end{tabular}




\begin{tabular}{|c|c|c|c|c|}
\hline Norma EIA-541 & $\begin{array}{c}\text { Medição da } \\
\text { resistividade do } \\
\text { material. }\end{array}$ & $\begin{array}{c}\text { Estabelece relação } \\
\text { entre resistividade } \\
\text { superficial ou } \\
\text { volumétrica e } \\
\text { características } \\
\text { eletrostáticas. }\end{array}$ & $\begin{array}{l}\text { Amostras de } \\
\text { material } \\
\text { isolante na } \\
\text { forma de } \\
\text { filmes }\end{array}$ & $\begin{array}{c}\text { Aplicado somente para } \\
\text { alguns tipos de } \\
\text { material isolante }\end{array}$ \\
\hline Norma ASTM 4470 & $\begin{array}{l}\text { Medição de } \\
\text { cargas } \\
\text { superficiais }\end{array}$ & $\begin{array}{l}\text { Estabelece técnicas } \\
\text { para evitar ação da } \\
\text { umidade nos ensaios. }\end{array}$ & $\begin{array}{l}\text { Amostras } \\
\text { liquidas ou } \\
\text { sólidas }\end{array}$ & $\begin{array}{c}\text { Resultados com limite } \\
\text { de precisão }\end{array}$ \\
\hline Wilson & $\begin{array}{c}\text { Estudo do } \\
\text { preocesso de } \\
\text { geração de } \\
\text { cargas }\end{array}$ & $\begin{array}{l}\text { Esclarecimento de } \\
\text { todos os problemas } \\
\text { relacionados com } \\
\text { eletricidade estática }\end{array}$ & $\begin{array}{l}\text { Amostras de } \\
\text { material têxtil }\end{array}$ & \\
\hline Fujiwara & $\begin{array}{l}\text { Medição do } \\
\text { tempo de } \\
\text { decaimento } \\
\text { eletrostático e } \\
\text { resistividade }\end{array}$ & $\begin{array}{c}\text { Dá o tempo de } \\
\text { decaimento do } \\
\text { potencial eletrostático } \\
\text { diretamente num } \\
\text { visor. }\end{array}$ & $\begin{array}{l}\text { Amostras de } \\
\text { material têxtil }\end{array}$ & $\begin{array}{c}\text { Eletrodos não se } \\
\text { adaptam a todos os } \\
\text { tipos de amostra, pêlos } \\
\text { (sujeira) grudados na } \\
\text { câmara de ionização } \\
\text { após o carregamento } \\
\text { das amostras, os quais } \\
\text { provocam imprecisão } \\
\text { nos resultados. }\end{array}$ \\
\hline $\begin{array}{l}\text { Giacometti } \\
\text { e Sinézio }\end{array}$ & $\begin{array}{c}\text { Medição de } \\
\text { densidade de } \\
\text { corrente e } \\
\text { distribuição } \\
\text { superficial de } \\
\text { cargas }\end{array}$ & $\begin{array}{l}\text { Esclarece a dinâmica } \\
\text { do processo de } \\
\text { carregamento } \\
\text { uniforme. }\end{array}$ & $\begin{array}{l}\text { Amostras de } \\
\text { material } \\
\text { isolante na } \\
\text { forma de } \\
\text { filmes }\end{array}$ & \\
\hline
\end{tabular}




\title{
CAPÍTULO III
}

\section{ELETROSTÁTICA}

\author{
Neste capítulo, encontra-se a definição do \\ fenômeno eletrostático, bem como a \\ explicação da maneira como ocorre, \\ citando-se alguns exemplos.
}

\begin{abstract}
Quando se fala da Eletrostática, referindo-se aos primeiros passos dessa Área do Conhecimento, deve-se lembrar de que a primeira teoria a esse respeito foi formulada por Benjamin Franklin ${ }^{4}$ [30] e é conhecida como teoria do fluido único. De acordo com essa teoria, todo corpo possui certa quantidade de um fluido indestrutível associado à matéria em maior ou menor quantidade. Um corpo em estado neutro tem uma quantidade desse fluido elétrico que é a chamada quantidade normal de fluido para este corpo. Se o corpo tiver excesso deste fluido, estará eletrizado positivamente. Se o corpo tiver falta, estará eletrizado negativamente. Para explicar as atrações e repulsões entre os corpos eletrizados, Franklin admitia que as partículas que constituem a matéria se repeliam e atraíam o fluido elétrico. A eletrização por atrito entre dois corpos era explicada pela passagem de fluido de um corpo a outro.
\end{abstract}

4. Assunto melhor detalhado no Anexo III, página 123. 
Posteriormente, criou-se a teoria dos dois fluidos, que admitia existir, nos corpos, em quantidades praticamente ilimitadas, dois fluidos elétricos: um positivo, outro negativo. Os fluidos de mesma espécie repelir-se-iam, e os de espécies diferentes atrairse-iam. Um corpo estaria eletrizado positivamente ou negativamente de acordo com o excesso de um fluido sobre o outro. As idéias atuais a respeito da eletricidade só puderam surgir depois que os pesquisadores começaram a desconfiar da existência do elétron, em fins do século passado, e pouco tempo depois vieram a confirmá-la.

Hoje em dia, porém, tomando como ponto de partida que os elétrons e os prótons são partículas dotadas de carga elétrica, consegue-se explicar quase a totalidade dos fenômenos elétricos conhecidos. A explicação para o fenômeno da eletrostática está no fato de toda matéria ser composta de átomos, e de todos os átomos serem compostos de partículas subatômicas carregadas, ou seja, de prótons, que têm carga positiva, e de elétrons, com carga negativa. Normalmente os átomos têm o mesmo número de prótons e elétrons, sendo, neste caso, "neutros". Mas, se dois materiais diferentes são esfregados um contra o outro, por exemplo, vidro e lã, elétrons podem ser transferidos de um material para o outro, sendo que um deles ficará com excesso de elétrons (no caso, a lã), e o outro, com escassez destes (no caso, o vidro). Este acúmulo de cargas nos materiais resulta no fenômeno comumente chamado de eletricidade estática ou triboeletrificação, que explica o fato de materiais com cargas opostas atraírem-se, e até ficarem aderidos um ao outro, e materiais com a mesma carga repelirem-se.

Esta situação pode ser visualizada na figura 3.1.

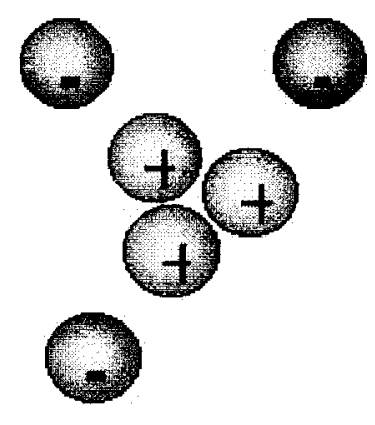

$\mathbf{a}$

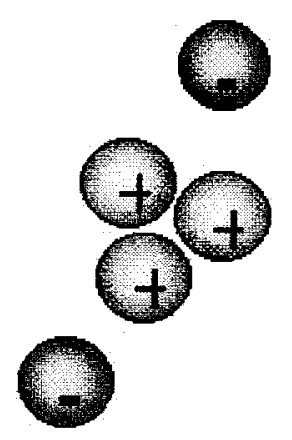

b

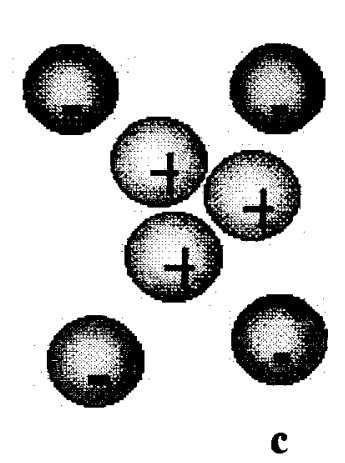

c

Figura 3.1: a. Átomo equilibrado, carga zero; b. Átomo com deficiência de elétrons, carga positiva; c. Átomo com excesso de elétrons, carga negativa 
Chama-se o fenômeno de eletricidade estática porque as cargas tendem a permanecer no material, a menos que uma força externa venha a interagir, ou seja, a carga triboelétrica acumula-se nos dois materiais e, quando eles tocam superfícies de menor potencial elétrico, surge uma faísca, e as cargas eletrostáticas são transferidas para as superficies. Portanto, este fluxo de eletricidade é resultado do acúmulo de cargas estáticas, que são rapidamente descarregadas num objeto de menor potencial elétrico.

Existem eventos relacionados à eletricidade estática que ocorrem no dia-a-dia, como, por exemplo, roupas que se agarram ao corpo, pó que se acumula nos monitores de TV ou de computadores. O simples fato de uma pessoa caminhar sobre um tapete ou mesmo sobre um piso de ladrilho faz com que cargas eletrostáticas se acumulem no seu corpo, devido à fricção entre seus sapatos e o piso, o que proporciona a transferência de elétrons entre a sola do sapato, que geralmente é feita de material isolante, e o piso. Esse efeito ocorre com maior freqüência em tapetes e carpetes. Quanto mais esta pessoa caminha, maior é o potencial desenvolvido no seu corpo; portanto, ela age como se fosse um capacitor. Os choques ocorrem quando esta pessoa toca em objetos metálicos, como, por exemplo, trincos de portas. Este fenômeno pode ser visualizado na figura 3.2.
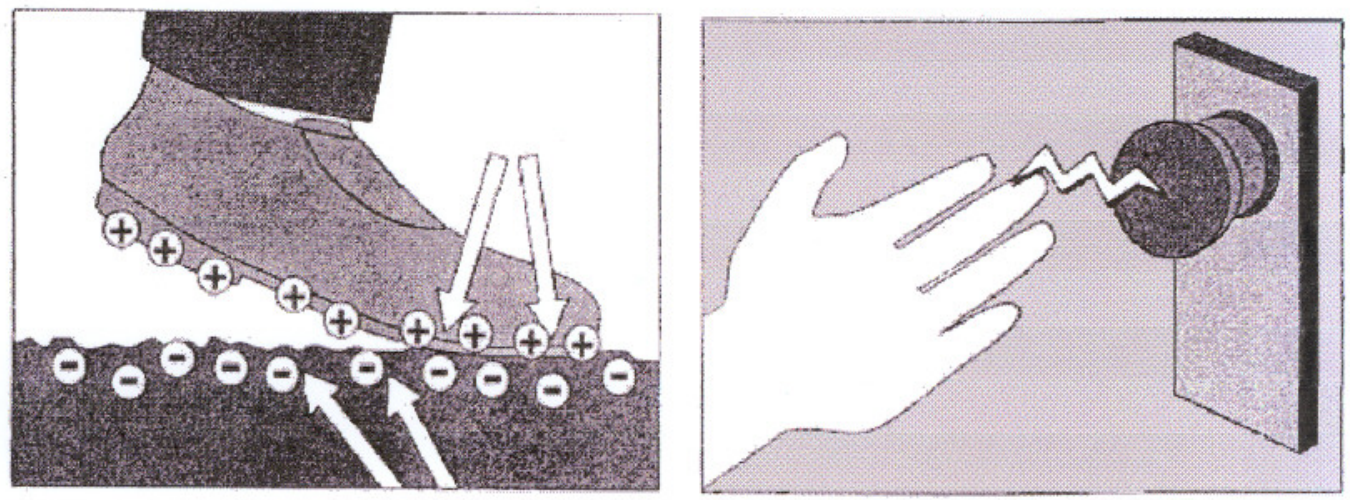

Figura 3.2: Cargas eletrostáticas sendo adquiridas por um indivíduo ao caminhar, e ocorrência de faísca elétrica quando ele toca um trinco metálico de porta 
O carregamento do indivíduo também ocorre pelo esfregamento das suas roupas com os estofados dos móveis, ou mesmo com o banco do carro, pois, quando isso acontece na presença de baixa umidade do ar, as roupas agem como uma superficie isolante, e o assento, como outra. Acontece, então, a transferência de cargas entre as superficies, ficando uma delas com um desequilíbrio negativo, e a outra, positivo. Quando o indivíduo sai do carro ou levanta-se da cadeira, ele apresenta uma polaridade de carga ao longo do corpo, e o banco do carro e o assento da cadeira apresentam polaridade oposta. A tensão entre o corpo do indivíduo e o carro é enorme, entre 10.000 e 20.000 volts $^{5}$ [31]; juntando-se o fato de as solas dos sapatos serem, na maioria, isolantes, não permitindo o escoamento das cargas armazenadas pelo indivíduo ao fechar o carro ou tocar num trinco, acontece uma descarga eletrostática, como resultado da tentativa de equilibrio de cargas pelos corpos em questão.

A quantidade de carga gerada pelo processo de fricção e separação pode ser influenciada por diversos fatores, como: materiais envolvidos, extensão do contato, umidade relativa do ar e textura do material.

Cargas estáticas acima de $30.000 \mathrm{~V}$ não são incomuns e podem ser geradas pelo simples ato de caminhar sobre um determinado tipo de piso; já descargas de apenas $10 \mathrm{~V}$ podem destruir componentes eletrônicos da Classe de sensibilidade-1, para ESD $^{6}[32]^{7}$.

A eletricidade estática é em essência invisível, embora freqüentemente possamos vê-la, senti-la e medir o campo eletrostático envolvido. Quando é criado um desequilíbrio de elétrons num determinado material, este não se encontra no seu estado natural ou estável. No momento em que é possível o retorno do material para o estado estável, acontece, rapidamente, uma faísca, que está associada à ocorrência da descarga eletrostática.

5. Assunto melhor abordado no Anexo III, página 130.

6. ESD - Eletrostatic discharge - descarga eletrostática.

7. Assunto melhor detalhado no Anexo III, página 136. 
Pode-se sentir esta faísca se o potencial for maior que $3.000 \mathrm{~V}$. As descargas eletrostáticas abaixo deste valor estão no limite da sensibilidade humana, mas podem ser letais para componentes eletrônicos associados a semicondutores; já os potenciais eletrostáticos acima de $6.000 \mathrm{~V}$ podem ser visualizados [1].

Os problemas relacionados à eletricidade estática ocorrem, normalmente, no inverno, porque nesta época do ano a umidade relativa do ar é baixa (20\% a 30\%) [25].

A presença de água auxilia os elétrons a movimentarem-se mais rapidamente, não havendo acúmulo de cargas. Assim sendo, com a umidade relativa do ar entre $50 \%$ e $60 \%$, é muito dificil ocorrer os efeitos indesejáveis da eletricidade estática [25].

Existe uma relação de materiais colocados numa série denominada Série Triboelétrica [20], na qual uma lista de substâncias é organizada de maneira que ela começa com substâncias positivamente carregadas quando atritadas com uma outra mais abaixo da lista. A principal utilidade da lista é indicar a provável polaridade resultante das cargas, depois da geração triboelétrica.

A Série Triboelétrica é mostrada na tabela I.

Os efeitos provocados pelas descargas eletrostáticas nas indústrias podem levar a grandes prejuizos, como, por exemplo, incêndios em indústrias têxteis ou de papel e danos em indústrias de componentes eletrônicos.

Muitas técnicas são utilizadas no intuito de reduzir esses problemas, entre elas, o aterramento das estruturas das máquinas, a ionização do ar (com partículas positivas e negativas, induzindo a neutralização e causando o decaimento do potencial eletrostático), sapatos com sola condutora, tapete dissipativo, pulseira de aterramento, luvas ou dedeiras (antiestáticas ou dissipativas), umidificação do ambiente e, para revestimentos têxteis, técnicas permanentes e temporárias.

As técnicas temporárias consistem na pulverização do revestimento têxtil com produtos químicos (porém, o efeito antiestático desses produtos desaparece após o uso de xampus e abrasão) e no tratamento do seu avesso, também com produtos químicos (resiste a 6 ou 7 xampus). 
Já as técnicas com eficiência permanente consistem em introduzir no revestimento têxtil fibras condutoras (fibras de aço ou fibras poliméricas modificadas), introduzir fibras têxteis recobertas com material condutor (carbono) ou, ainda, tratar a base do revestimento com material condutor (carvão ativo).

Tabela 1: Série Triboelétrica

\begin{tabular}{|l|}
\hline \multicolumn{1}{|c|}{ MATERIAIS } \\
\hline Quartzo \\
Vidro \\
Mica \\
Cabelo humano \\
Náilon \\
Lã \\
Pele animal \\
Chumbo \\
Seda \\
Alumínio \\
Papel \\
Algodão \\
Aço \\
Madeira \\
Âmbar \\
Graxa selante \\
Borracha rígida \\
Níquel, cobre \\
Latão, prata \\
Ouro, platina \\
Enxofre \\
Acetato de raiom \\
Poliéster \\
Celulóide \\
Orlon®, Saran® \\
Poliuretano \\
Polietileno \\
Polipropileno \\
PVC (Vinil) \\
Silicone \\
Teflon®
\end{tabular}




\section{CAPÍTULO IV}

\section{NOVA METODOLOGIA}

Neste capitulo, estão descritas todas

as partes de que se compõe o equipamento

para medição de tempo de decaimento

eletrostático em tapetes e carpetes e também

o equacionamento de toda a câmara de

ionização e do processo de carregamento

das amostras de revestimento têxtil.

\subsection{CONSIDERAÇÕES GERAIS}

Esta nova metodologia para caracterização de revestimentos têxteis foi resultado de extenuantes pesquisas para eliminar os problemas originados pelo tipo de material ensaiado. Os revestimentos têxteis diferentes dos filmes finos ou dos materiais sólidos apresentam características sui generis; são felpudos, não mantêm sua espessura durante os testes, são aglomerados de fibras finas que normalmente desprendem-se ao serem carregadas eletricamente e podem reter facilmente umidade em seu volume. Isso os torna elementos inviáveis para serem ensaiados nos muitos métodos anteriores desenvolvidos.

Fujiwara [28], desenvolvendo seu método, levantou inúmeros problemas que ocorrem com este tipo de medição. Agora, nesta pesquisa, com o desenvolvimento de um novo tipo de câmara de ionização, onde o processo de carregamento e o de medição podem ser realizados seqüencialmente, os problemas de espaçamento, ruídos, umidade e 
sujeira durante o carregamento de tapetes felpudos foram praticamente solucionados e encontram-se melhor descritos nos tópicos subseqüentes

\subsection{DESCRIÇÃO DO MÉTODO}

O novo método de caracterização eletrostática de revestimentos têxteis consiste basicamente em carregar amostras de pequenas dimensões $\left(20 \times 10^{-4} \mathrm{~m}^{2}\right)$ por descarga corona e, logo em seguida, medir o tempo de decaimento das cargas armazenadas no volume das amostras pelo método do capacitor vibrante [9]. Sua originalidade, contudo, consiste: no desenvolvimento da nova câmara de ionização, que possibilita carregar as amostras de revestimento têxtil por descarga corona, simulando o carregamento da amostra por fricção de uma sola de sapato quando uma pessoa caminha sobre ela; na medição de revestimentos com diferentes espessuras, mantendo-se a calibração do equipamento; na minimização da influência da umidade e no controle computacional de todo o processo de medição.

Um diagrama esquemático de todo o equipamento desenvolvido encontra-se na figura 4.1

Como pode-se observar, o equipamento compõe-se de diversos blocos que realizam funções específicas; dentre eles encontram-se: a câmara de ionização e medição, a fonte de alta tensão, o conjunto amplificador/oscilador, o conjunto de controle de medição, a interface sistema/microcomputador e o microcomputador. Cada um desses blocos também será melhor descrito nos itens subseqüentes. 


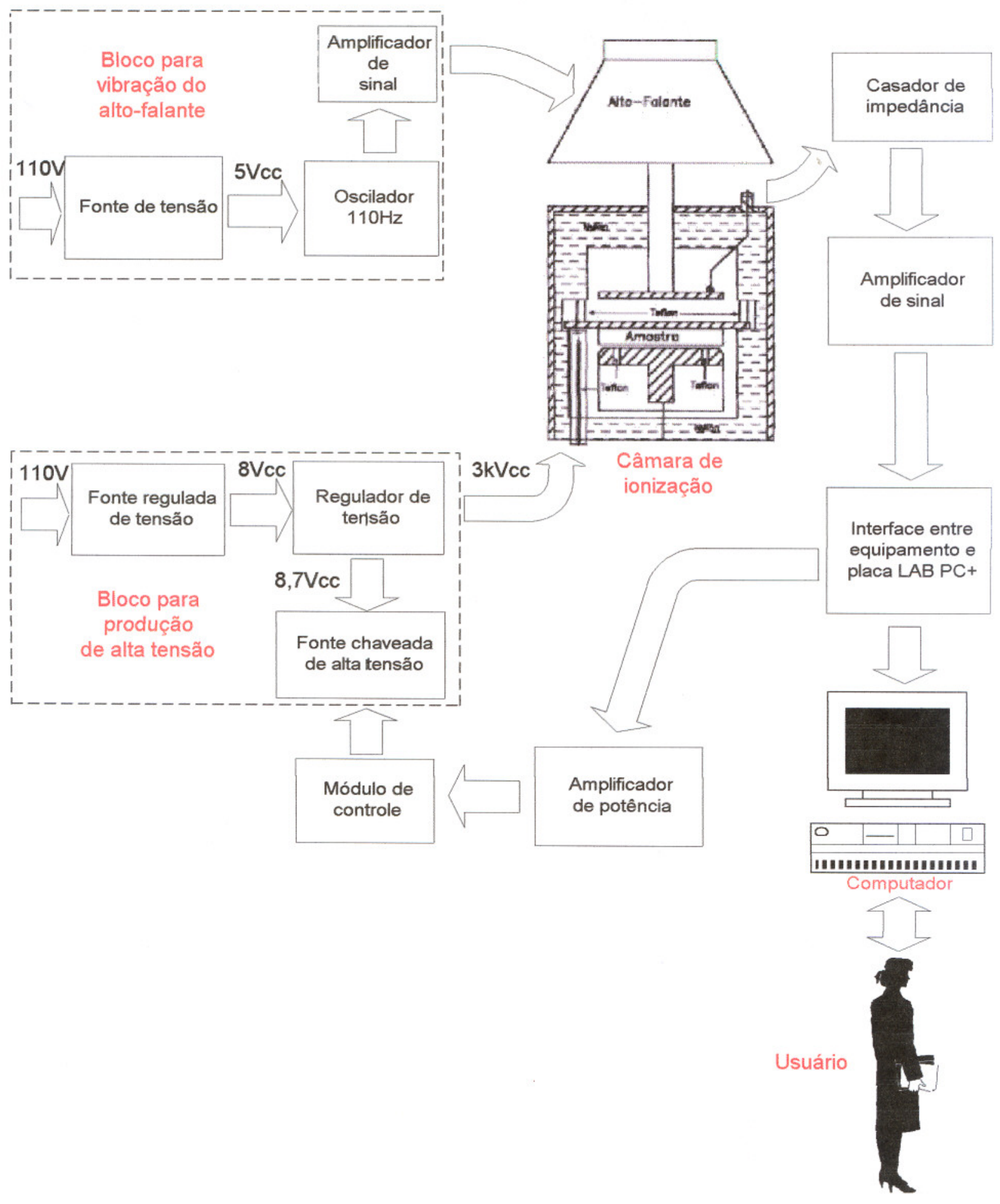

Figura 4.1: Diagrama esquemático do equipamento para medição do tempo de decaimento eletrostático de amostras de tapetes e carpetes 


\subsubsection{CÂMARA DE IONIZAÇÃO}

A câmara de ionização consiste no principal elemento deste equipamento de caracterização eletrostática que pode ser vista em detalhes na figura 4.2.

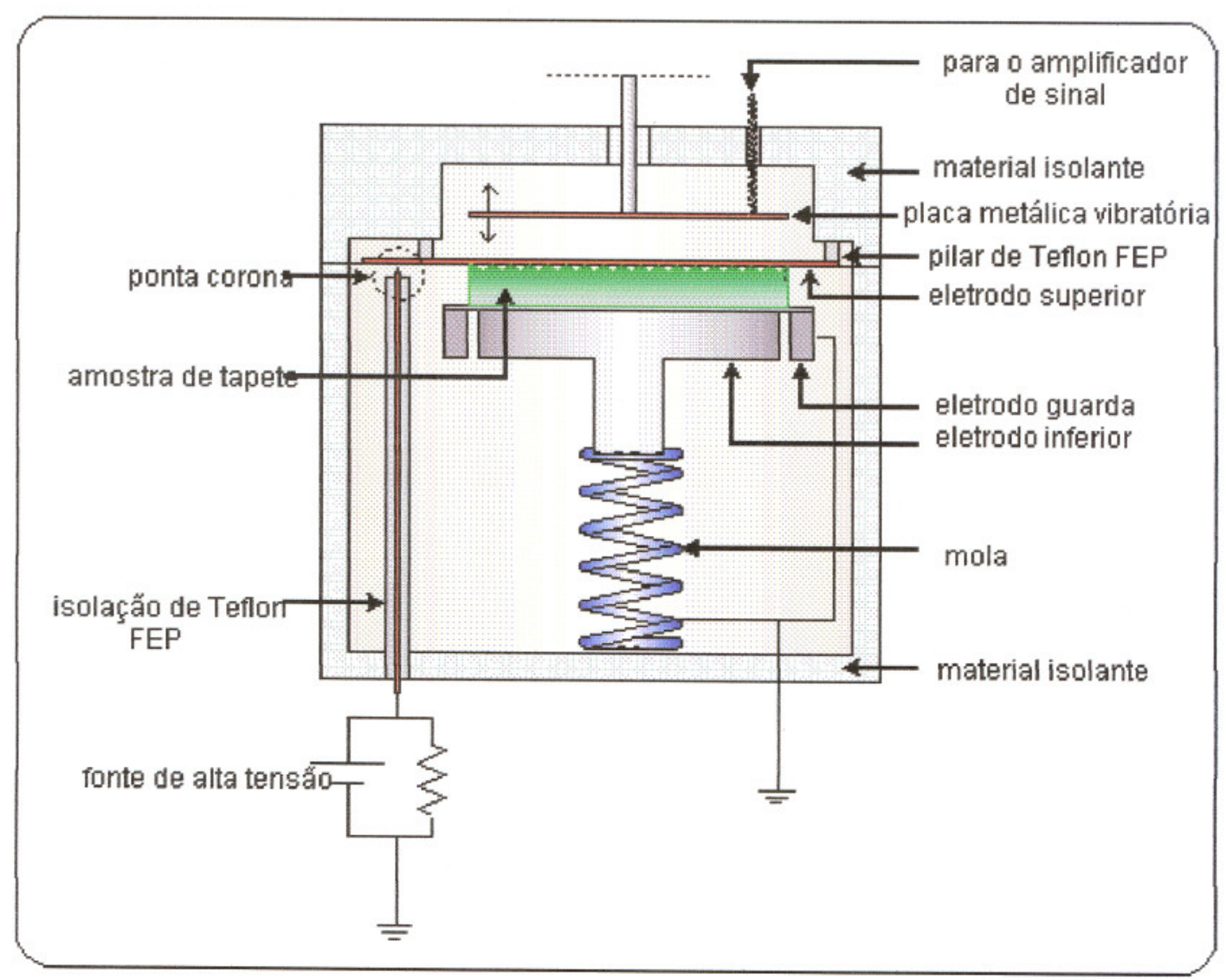

Figura 4.2: Esquema de montagem da câmara de ionização

É nessa câmara que acontece o carregamento da amostra de material têxtil por descarga corona, ou seja, por deposição de íons gerados pela ionização do ar quando uma alta tensão é aplicada em uma ponta metálica, localizada a uma certa distância da amostra. 
No interior da câmara de ionização, existe um conjunto de eletrodos composto por um eletrodo terra, sobre o qual se coloca a amostra a ser testada, e por um eletrodo guarda, responsável pelo escoamento das correntes parasitas indesejáveis nas medições, pelo fato de ficarem em paralelo com um elemento de resistência bem mais baixa, tornando a resistência da amostra o único caminho direto entre os terminais de medição e também eliminando o efeito de capacitância de borda pelo eletrodo superior. Este consiste em uma placa de cobre, presa no interior da câmara de ionização por meio de pilares de material isolante (Teflon FEP) para que não se tenha um descarregamento da amostra pelas paredes da câmara, ficando em contato com a amostra, sendo um importante fator responsável pelo carregamento uniforme dela.

O carregamento da amostra de tapete ou carpete é realizado por descarga corona no eletrodo superior, que, por sua vez, está em contato com a amostra. A ponta corona fica totalmente envolvida por um tubo de Teflon FEP, para que se tenha uma boa isolação entre a alta tensão e o interior da câmara. Pode-se observar a disposição da ponta corona no tubo de Teflon, através da figura 4.3.

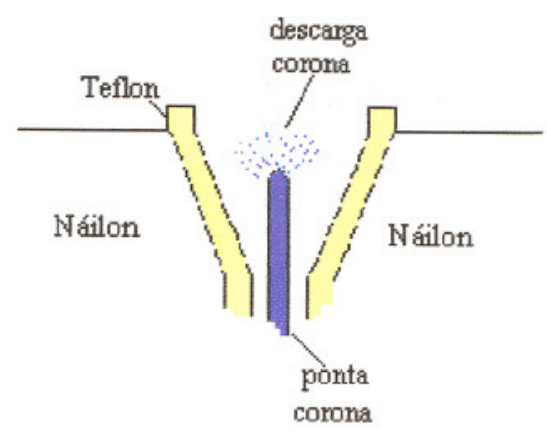

Figura 4.3: Detalhe da ponta corona isolada por Teflon

Logo abaixo do eletrodo terra, existe uma mola de fraca compressão com a finalidade de manter a amostra sempre em contato com o eletrodo superior, seja qual for a espessua da amostra. 
Toda a câmara foi construída com material isolante (PVC) de grande espessura, evitando-se assim que o descarregamento da amostra se dê pelas paredes da câmara de ionização.

Logo acima do eletrodo superior $(2,5 \mathrm{~cm})$, ou seja, da placa metálica na qual fica encostada a amostra, existe uma placa também metálica, mas vibrante, o que constitui o método do capacitor vibrante, que, segundo Reedyk e Perlman [9] é um método vantajoso pois as medições, como no caso do decaimento do potencial eletrostático, podem ser realizadas à pressão atmosférica, além de ser um método não destrutivo.

A vibração da placa metálica é conseguida por meio de um alto-falante, com a suspensão colada à placa através de um tubo de fenolite. Conectado com esta placa vibrante, há um fio metálico, ligado a um terminal do tipo $\mathrm{BNC}$, o qual leva o sinal do potencial eletrostático da amostra para um amplificador de sinal.

A câmara de ionização foi revestida externamente de um material metálico para que se tenha uma blindagem capaz de eliminar os ruídos nas medições do potencial eletrostático, pois, segundo Gerhard Sengberg [33], a blindagem metálica tem a função de eliminar o campo elétrico, numa certa região, causado por cargas elétricas existentes nas proximidades. Na prática, uma simples tela metálica envolvendo certa região no espaço já produz uma blindagem eletrostática satisfatória.

A blindagem externa é conseguida quando, havendo ou não cargas elétricas na câmara de ionização ou nas proximidades desta, o vetor campo elétrico é nulo.

Ligando-se a blindagem à terra, como foi feito com a câmara de ionização, impõe-se que seu potencial se anule.

Na figura 4.4, pode-se ter uma visão geral da câmara de ionização construída.

Com este tipo de câmara, pôde-se solucionar inúmeros problemas existentes nos métodos anteriores. 


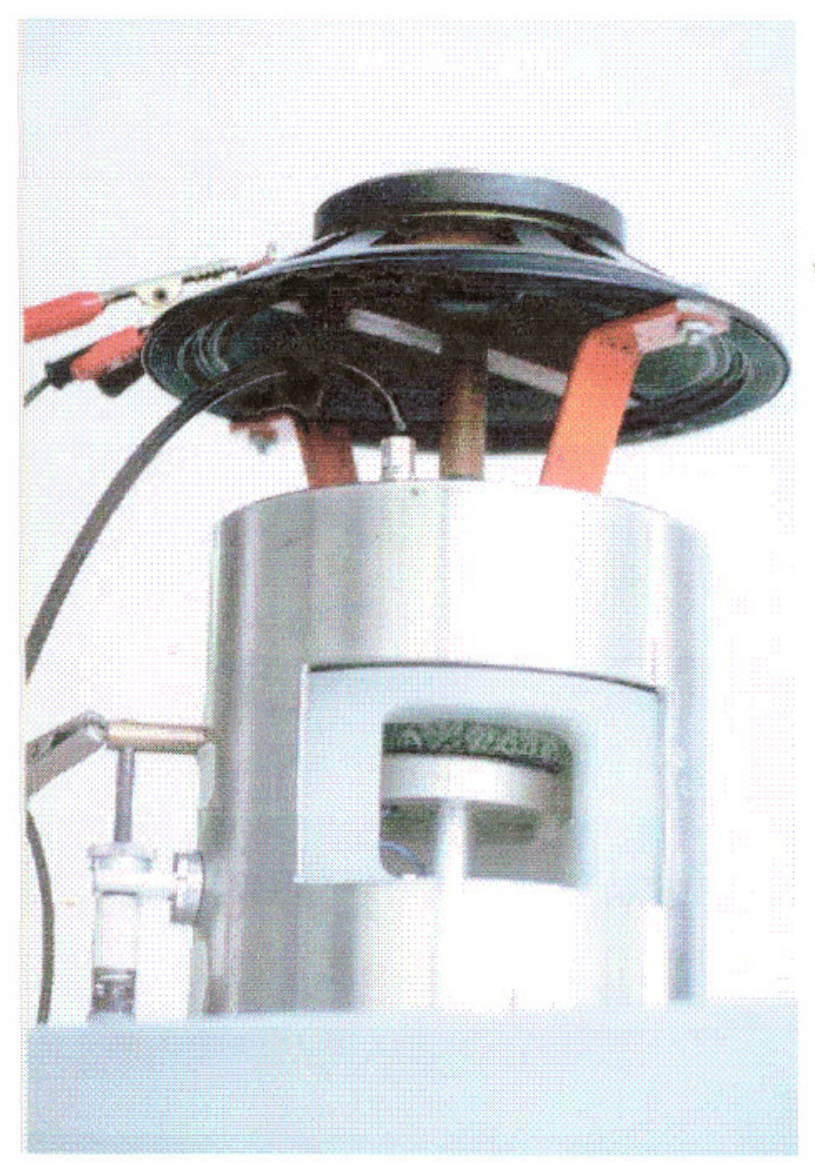

Figura 4.4: Câmara de ionização

A calibração das medições em amostras com diferentes espessuras e texturas foi solucionada ao colocar-se o eletrodo de carregamento diretamente em contato com a amostra a ser testada, através de uma mola que oferece uma fraca compressão, localizada no eletrodo terra, que proporcionou o carregamento de diversos tipos de amostras; a nova configuração mostrou um perfeito funcionamento para todos os tipos de amostras carregadas.

A idéia proposta neste projeto, para as diversas espessuras das amostras de revestimentos têxteis, ou seja, a nova configuração eletrodos/amostra, acabou por solucionar o problema da sujeira na câmara de ionização no carregamento de tapetes felpudos, o qual não havia sido solucionado pelos métodos anteriores. 
Colocando-se o eletrodo de carregamento em contato com a amostra e fazendo com que a ponta corona fique posicionada ao lado e logo abaixo do eletrodo de carregamento, diferentemente dos métodos anteriores, que tinham um posicionamento acima da amostra para a ponta corona e ainda necessitavam de uma grade entre o eletrodo e a amostra, obteve-se um carregamento uniforme. A configuração dos métodos anteriores que foram citados neste trabalho causava uma ionização do espaço entre a ponta corona e o tapete, fazendo com que os pêlos fossem atraídos pelas paredes e pela própria grade existente no interior da câmara, sujando a câmara e provocando erros de medição.

Pela nova metodologia de medição apresentada aqui, não existe o problema de sujeira na câmara, pois não há espaço entre a amostra e o eletrodo de carregamento e, portanto, não existe erros na medição causados pela presença dos pêlos dos tapetes felpudos.

Um outro problema que dificultava muito a realização de medição de tempo de decaimento eletrostático pelos métodos anteriores ao apresentado neste trabalho era a presença de umidade dentro da câmara de ionização, o que faz com que não aconteça um carregamento suficientemente alto a ponto de ser medido. Solucionou-se este problema, colocando-se uma pequena porção de peneira molecular, juntamente com sílica-gel, no interior da câmara e esperando-se 30 minutos, com a amostra no interior da câmara, antes de realizar um teste de carregamento e medição do tempo de decaimento eletrostático.

Todo o processo de carregamento, medição e temporização foi desenvolvido para funcionar de maneira automatizada, por meio de um programa computacional e de módulos de controle e tendo como parte importante uma placa de aquisição de dados.

$\mathrm{O}$ equipamento para caracterização de revestimentos têxteis foi desenvolvido de maneira que o usuário tenha total segurança no manuseio, uma vez que a alta tensão responsável pelo carregamento das amostras testadas fica isolada do microcomputador, instrumento através do qual se tem total acesso aos resultados dos testes bem como ao controle de todo o processo. 


\subsubsection{OSCILADOR}

A vibração do alto-falante é promovida por um oscilador, pois foi a maneira mais prática de se vibrar $o$ alto-falante, tendo o controle da frequência da vibração. $O$ Oscilador está mais detalhado no Anexo II.

O oscilador foi construído tendo na sua saída uma forma de onda quadrada, a qual proporciona melhor vibração do alto-falante, melhor sinal do potencial eletrostático e uma freqüência de $110 \mathrm{~Hz}$. A freqüência anteriormente citada foi escolhida por apresentar maior uniformidade e melhor visualização da forma de onda do potencial eletrostático do que as outras freqüências testadas, como $120 \mathrm{~Hz}, 100 \mathrm{~Hz}, 90 \mathrm{~Hz}$, etc.

\subsubsection{AMPLIFICADOR DO SINAL DO OSCILADOR}

Para que se tenha a potência desejável na saída do oscilador, isto é, para que se consiga uma boa vibração da suspensão do alto-falante, é necessário que exista um amplificador para o sinal do oscilador.

O amplificador utilizado encontra-se detalhado no Anexo II.

\subsubsection{FONTE DE ALIMENTAÇÃO PARA OSCILADOR E AMPLIFICADOR}

A fonte de alimentação para o oscilador e para o amplificador também encontrase detalhada no Anexo II. Ela é composta de três partes: o retificador, o estabilizador e o regulador da tensão de saída da fonte DC.

Pode-se ver o oscilador construído, na figura 4.5. 


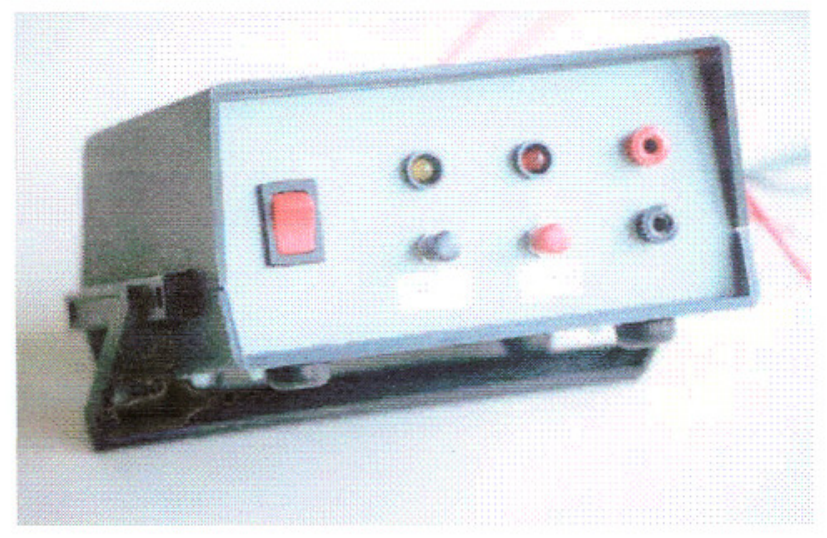

Figura 4.5: Aparelho responsável pela vibração do alto-falante

\subsubsection{FONTE DE ALTA TENSÃO}

O carregamento da amostra de tapete ou de carpete era realizado por descarga corona, gerada por uma fonte de alta tensão DC da marca "SPELLMAN". Com o intuito de tornar o protótipo para medição do tempo de decaimento eletrostático mais portátil, faz-se necessária a substituição desta fonte de alta tensão por uma de menor tamanho.

Para proceder-se essa substituição, foi necessário saber exatamente qual a tensão de saída da fonte SPELMANN, a qual faz o carregamento das amostras de tapete ou carpete. Assim sendo, fez-se um teste para descobrir qual era essa tensão, com o auxílio de uma ponta redutora de tensão (TEKTRONIX) conectada à saída da fonte de alta tensão SPELLMAN. A ponta redutora de tensão é interligada a um osciloscópio no qual se pode observar o nível de tensão desejado, ou seja, o valor da alta tensão DC de saída, suficiente para o carregamento da amostra testada.

O circuito montado para esse procedimento está representado na figura 4.6. 


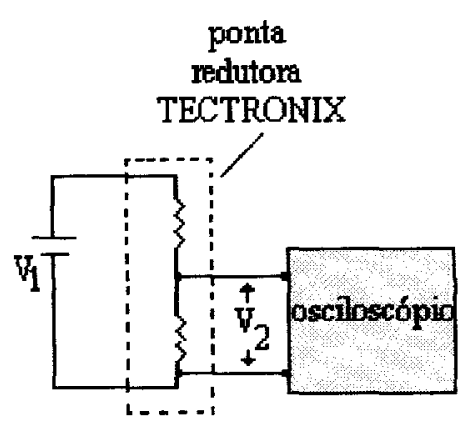

Figura 4.6: Circuito para descobrir a tensão de saida da fonte SPELLMAN

Sendo: $\begin{aligned} V_{1} & =\text { Fonte de alta tensão DC SPELLMAN } \\ V_{2} & =\text { Tensão de saída da fonte, visualizada no osciloscópio }\end{aligned}$

$O$ resultado obtido neste ensaio foi que a tensão suficiente para o carregamento de amostras de tapetes e carpetes pode estar entre 2.800 e $3.000 \mathrm{~V}$.

Assim sendo, a fonte de alta tensão DC SPELLMAN foi substituída por uma portátil. A fonte escolhida, com o intuito de ser portátil, foi uma do tipo chaveada, que, segundo Mello [34], tem a vantagem de não gerar calor no elemento série (transistor), porque este elemento é utilizado com pulsos que o colocam na saturação. Assim, o transistor funciona como uma chave e, devido a sua baixa tensão de saturação, o calor gerado nele é muito baixo, aumentando a eficiência da fonte.

Também cita-se como uma grande vantagem em se utilizar a fonte chaveada o fato de poder usar um capacitor cerâmico, de baixo valor, para filtrar o "ripple" da fonte, uma vez que a mesma trabalha com freqüências altas. 


\subsubsection{FONTE REGULADA DE TENSÃO E REGULADOR DE TENSÃO}

Para que a fonte chaveada de alta tensão forneça 3.000 volts na sua saída, é necessário que na sua entrada haja um certo nivel de baixa tensão.

Afim de descobrir qual o valor desta tensão de alimentação da fonte chaveada, monta-se o circuito da figura 4.7.

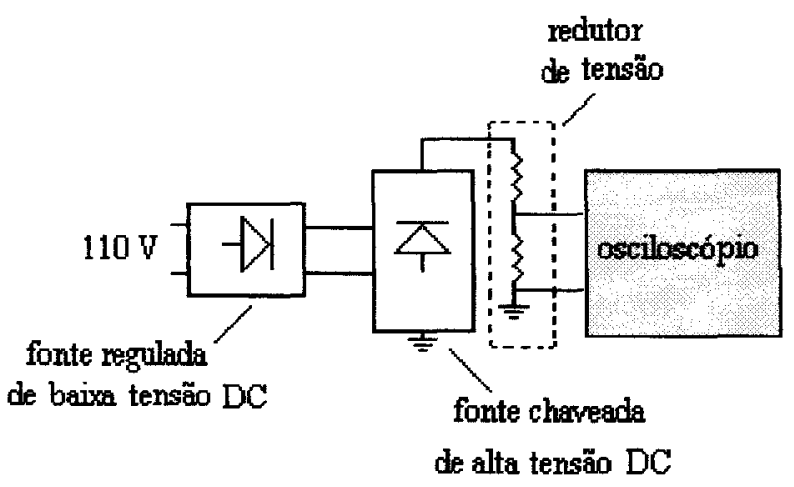

Figura 4.7: Circuito para determinação da tensão de alimentação da fonte chaveada

Com o auxílio da ponta redutora de tensão - Tektronix - e do osciloscópio, pode-se determinar a tensão de entrada da fonte de alta tensão DC, chaveada, para que esta tenha $3 \mathrm{kV}$ na sua saída. Esta tensão foi encontrada como sendo exatamente 8,7 volts.

Assim sendo, para o funcionamento da fonte chaveada, foi necessária a construção de uma fonte de baixa tensão DC que forneça $8,7 \mathrm{~V}$ na saída.

Para se construir uma fonte DC com este valor de tensão de saída, é muito apropriada a ligação de um regulador de tensão em sua saída.

Esse regulador, como o próprio nome diz, irá regular a tensão de saída da fonte de baixa tensão DC para $8,7 \mathrm{~V}$.

$\mathrm{O}$ circuito construído para a fonte regulada de baixa tensão e para o regulador de tensão é mostrado no Anexo II. 
$\mathrm{Na}$ figura 4.8, têm-se detalhes da fonte regulada de baixa tensão conectada ao regulador de tensão, alimentando a fonte chaveada de alta tensão DC.

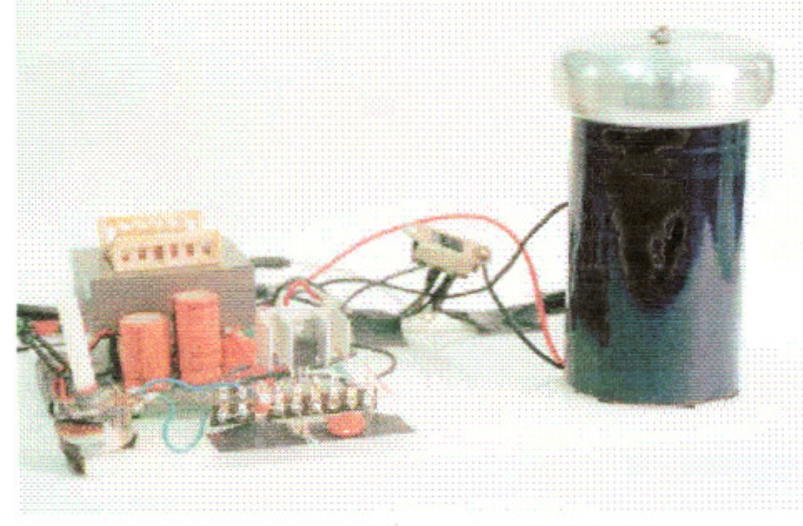

Figura 4.8: Fonte regulada de baixa tensão e regulador de tensão, conectados à fonte chaveada de alta tensão DC.

Para a fonte de alta tensão chaveada DC, utiliza-se como invólucro isolante um tubo de fenolite não polar, conforme pode ser visto na figura 4.8.

Acima do tubo de fenolite, encontra-se uma peça de alumínio com as bordas arredondadas. Esse formato torna-se necessário pelo fato de que em qualquer ponta existente num circuito no qual se trabalha com alta tensão pode acontecer uma descarga corona, o que não é, em nosso caso, desejado.

\subsubsection{AMPLIFICADOR DE SINAL}

Para a interligação da câmara de ionização com o computador, isto é, com a placa de aquisição de dados $\mathrm{A} / \mathrm{D}$ (LAB - PC+), a qual irá processar os dados do potencial eletrostático da amostra, foi necessário um amplificador de ganho 67 para o sinal do potencial eletrostático. Esse amplificador foi construído conforme o esquema mostrado no Anexo II. 
Este amplificador foi escolhido pela simplicidade da montagem e por solucionar o problema do baixo sinal do potencial eletrostático vindo da câmara de ionização, o que faz a aquisição dos dados pela Placa $\mathrm{A} / \mathrm{D}(\mathrm{LAB}-\mathrm{PC}+)$ ser totalmente imprecisa.

O limite mínimo de valor do sinal que a Placa $\mathrm{A} / \mathrm{D}(\mathrm{LAB}-\mathrm{PC}+)$ consegue ler é de alguns milivolts, mas o máximo é de $\pm 5 \mathrm{~V}$. Assim, o amplificador de sinal construído foi de ganho 67, o qual satisfaz as nossas necessidades para aquisição do sinal do potencial eletrostático, sem saturar a leitura.

A conexão do amplificador com a Placa A/D (LAB-PC+) é feita através de um cabo "flat" de 50 vias (PC 50) e da interface que será apresentada nos próximos itens.

\subsubsection{MÓdULO DE CONTROLE}

O módulo de controle faz o controle e a temporização de todas as etapas dos testes realizados com o equipamento para medição do potencial eletrostático de tapetes e carpetes.

Esse controle foi realizado através de dois outros componentes do protótipo: a interface entre o equipamento e a Placa LAB-PC+ e o amplificador de potência, sendo estes equipamentos controlados por um "software" (AD 32), especialmente desenvolvido para este projeto de pesquisa e que será descrito mais adiante.

A temporização do sistema, realizada pelo computador, está representada na figura 4.9 . 


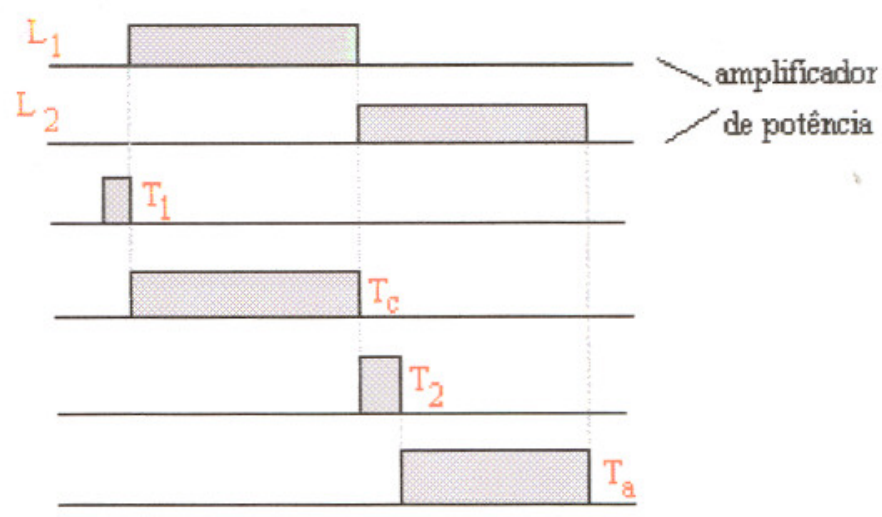

Figura 4.9: Sistema de temporização

Em que: $\quad \mathbf{L}_{\mathbf{1}}=$ pulso vindo da Placa de Aquisição de Dados $\mathrm{LAB} \mathrm{PC}^{+}$para temporizar o carregamento

$\mathbf{L}_{2}=$ pulso vindo da Placa $\mathrm{LAB} \mathrm{PC}^{+}$para temporizar a aquisição de dados

$\mathbf{T}_{\mathbf{c}}=$ tempo de carga

$\mathbf{T}_{\mathbf{a}}=$ tempo de aquisição

$\mathbf{T}_{\mathbf{1}}=$ pulso que, na descida, aciona o $\mathbf{T}_{\mathbf{c}}$

$\mathbf{T}_{2}=$ pulso que, na descida, aciona o $\mathbf{T}_{\mathbf{a}}$

$\mathbf{L}_{\mathbf{1}}$ e $\mathbf{L}_{\mathbf{2}}$ correspondem a dois sinais contendo pulsos, vindos da interface, os quais irão temporizar o carregamento das amostras e o tempo de aquisição dos dados do carregamento. Esses dois pulsos estão sincronizados com $\mathbf{T}_{\mathbf{1}} \mathbf{e} \mathbf{T}_{\mathbf{2}}$, que estão presentes no sistema para que se tenha segurança na ligação da fonte de alta tensão para o carregamento da amostra e a fim de que sejam eliminados ruídos na aquisição dos dados, expressando uma maior estabilidade no sinal do potencial eletrostático vindo da placa vibratória. 


\subsubsection{INTERFACE ENTRE O EQUIPAMENTO E A PLACA LAB PC ${ }^{+}$}

A figura 4.10 mostra um "layout"

A figura 4.11 mostra detalhes da conexão da placa.

Os pinos numerados de $\mathbf{1}$ a $\mathbf{5 0}$ correspondem aos pinos de entrada da Placa LAB PC+. As conexões que vão de ACH0in até ACH7in são entradas analógicas. Já as conexões DAC0out e DAC1out são saídas analógicas.

Os pinos MM1, MM2, MM3 e MM4 são pinos de saída de configuração, ou seja, pinos de controle digital.

Os pinos MM6, 7, 8 e MM9, 10 são "jumpers" de conexão.

Na figura 4.10 tem-se uma visão geral da interface.

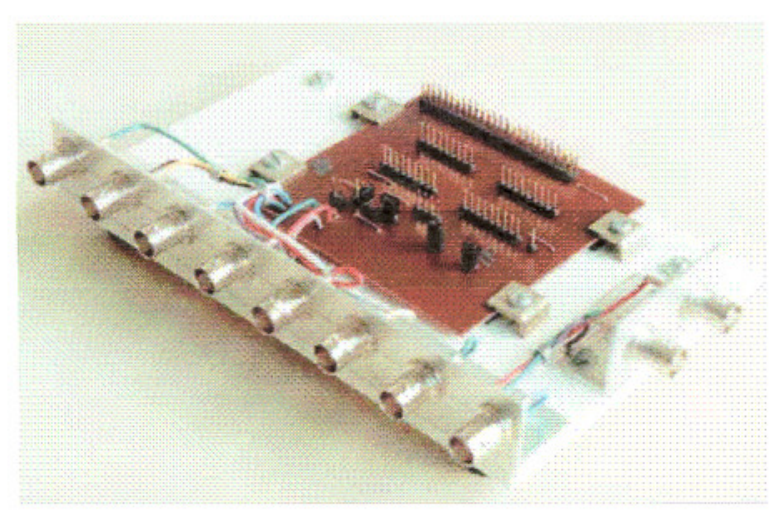

Figura 4.10: Circuito de interface entre a placa $L A B P C^{+}$e o equipamento para medição do potencial eletrostático de tapetes e carpetes 

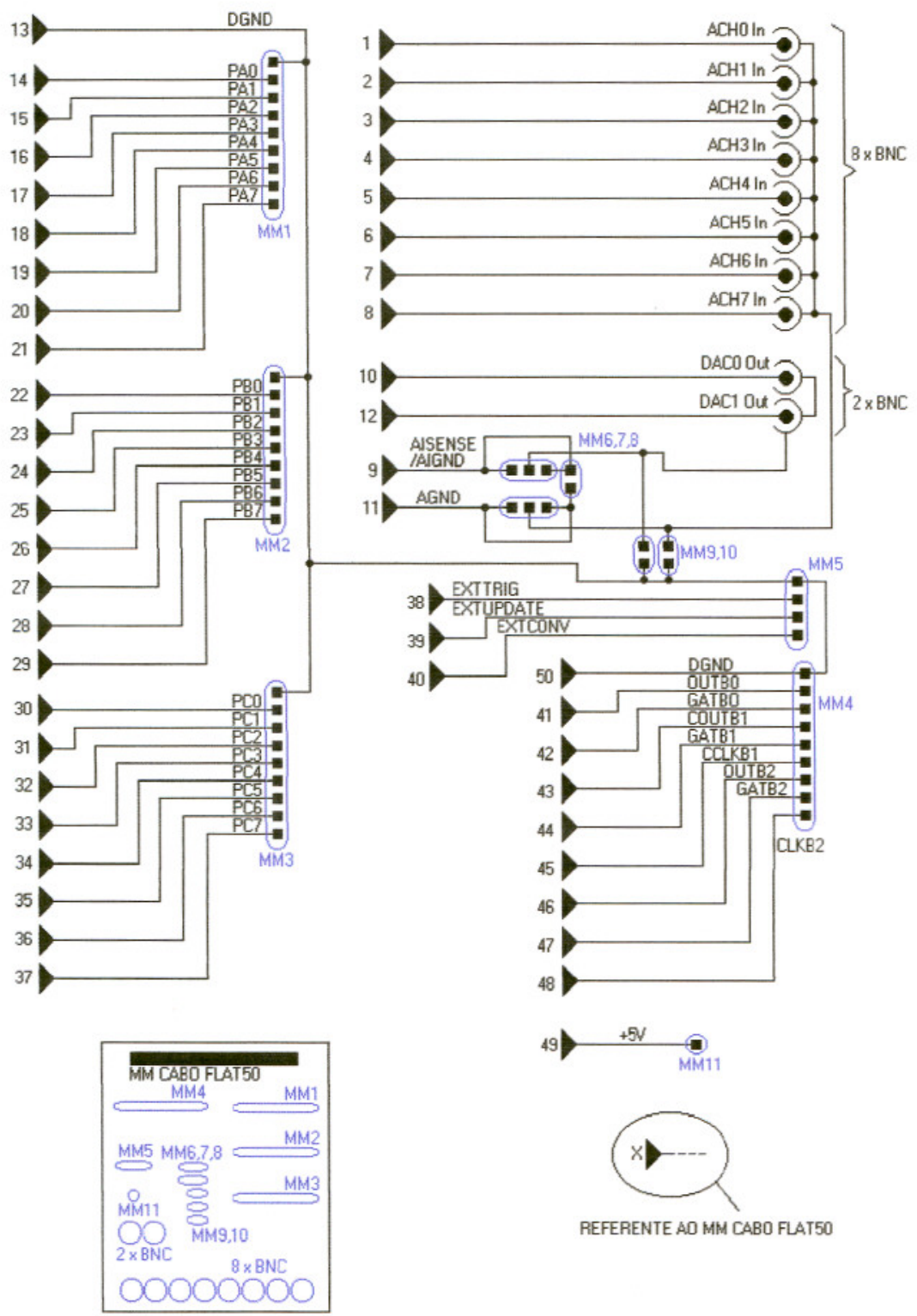

40

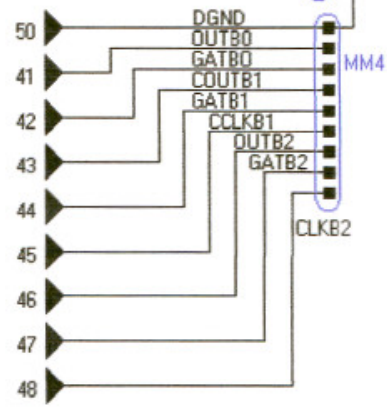

49) $+5 \mathrm{~V}$

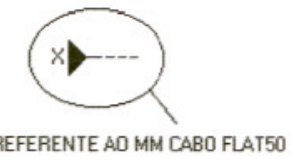

Figura 4.11: Detalhes do circuito de interface entre a placa $L A B P C^{+}$e a câmara de ionização 


\subsubsection{AMPLIFICADOR DE POTÊNCIA}

O segundo equipamento que faz parte do módulo de controle é o amplificador de potência, que é inserido no sistema com a função de excitar os relés de controle do tempo de carregamento da amostra testada e os da aquisição dos dados do decaimento eletrostático, porém sem drenar corrente da interface.

O circuito do amplificador de potência está representado no Anexo II.

\subsubsection{COMPUTADOR}

O computador faz o papel da interface usuário/equipamento, pois é por meio dele que acessamos os controles de todas as partes do equipamento para medição do potencial eletrostático de tapetes e carpetes.

O computador está conectado ao equipamento por meio da interface: Placa LAB $\mathrm{PC}^{+}$-protótipo.

Os comandos acessíveis ao usuário pelo computador serão descritos no Anexo I, no qual estaremos descrevendo o Programa AD32, desenvolvido por Canova [35] especialmente para esta pesquisa.

\subsubsection{PROGRAMA AD32}

O programa $\mathrm{AD} 32$ permite, além de caracterizar as amostras de tapetes e carpetes, armazenando os dados do decaimento eletrostático, cadastrar o cliente e o tipo de amostra, descrevendo suas características. Um diagrama esquemático deste programa é apresentado na figura 4.12 e um pequeno tutorial encontra-se descrito no Anexo I. 


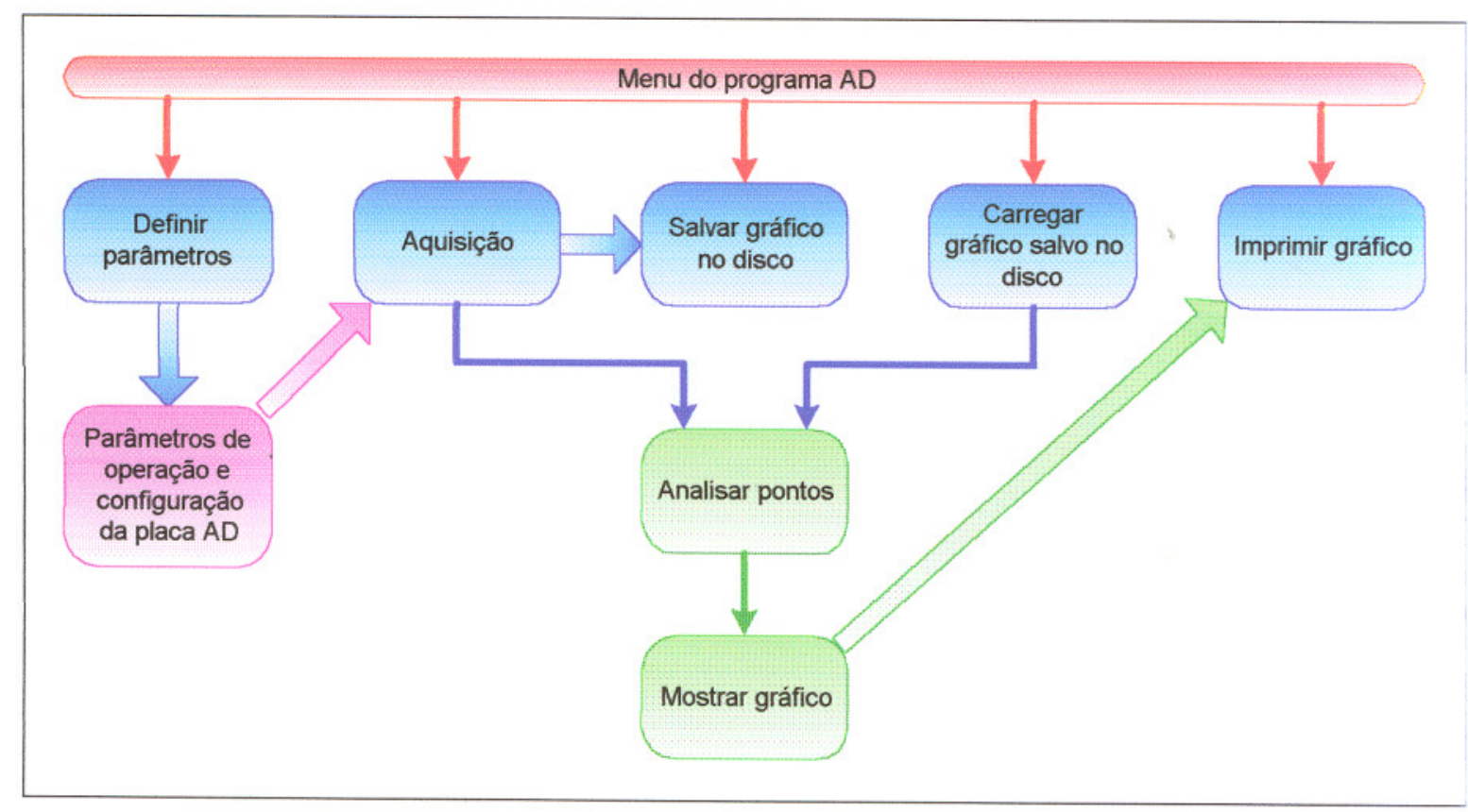

Figura 4.12: Diagrama esquemático do programa computacional AD32

O Programa computacional AD32 primeiramente define alguns parâmetros como canal analógico de aquisição, portas e canais digitais para controle de temporização, dos relés, tempo de aquisição, "delays", etc., no bloco "Definir parâmetros".

Após serem definidos estes parâmetros, inicia-se a fase chamada de Aquisição de dados, já no bloco chamado de "Aquisição", onde é efetuada a coleta dos dados a serem analisados e visualizados. O bloco "Aquisição" é controlado a partir do bloco "Parâmetros de operação e configuração da placa AD", o qual é definido pelo bloco "Definir parâmetros".

No bloco "Definir parâmetros" também se faz a temporização de todo o sistema, permitindo, assim, que a placa de aquisição de dados envie para o equipamento de medição do tempo de decaimento eletrostático os pulsos de temporização para todas as fases do processo.

A primeira temporização corresponde ao tempo necessário para o carregamento da amostra, e a segunda temporização corresponde ao tempo necessário para a aquisição de dados propriamente dita. 
É importante salientar que a aquisição de dados do carregamento e do descarregamento das amostras testadas só pode ser efetuada se os parâmetros estiverem definidos corretamente.

Os dados adquiridos ficam na memória do programa, através dos blocos "Salvar gráfico no disco", "Analisar pontos" e "Carregar gráfico salvo no disco", podendo ser vistos em gráfico ou salvos no disco para futuras visualizações. Os dados são gravados em arquivos individuais, um para cada aquisição.

Todos os dados do carregamento e descarregamento da amostra são gravados num banco de dados do próprio programa, através do bloco "Salvar gráfico no disco". Depois dessa fase, os dados são analisados, e posteriormente mostrados em forma de gráfico, na tela do microcomputador, através do bloco "Mostrar gráfico".

É importante esclarecer que um gráfico só pode ser visualizado ou impresso se ele já foi adquirido pelo bloco "Aquisição" ou carregado pelo bloco "Carregar gráfico salvo no disco" e, ainda, após a aquisição ou o carregamento de um arquivo, sempre ocorre a análise dos dados e depois a visualização no gráfico.

Do bloco chamado "Analisar pontos" resulta o cálculo do tempo de decaimento eletrostático $(\tau)$, o qual é apresentado na tela do microcomputador, e que é um dos objetivos desse projeto, para que se possa caracterizar os revestimentos têxteis de acordo com suas características eletrostáticas.

Com o bloco "Mostrar gráfico" pode-se ter, na tela do microcomputador, a imagem do gráfico com os dados do decaimento eletrostático da amostra em teste e, através do bloco "Imprimir gráfico", pode-se ter esse gráfico impresso, por meio de qualquer impressora conectada ao microcomputador.

\subsection{PREPARAÇÃo dAS AMOSTRAS}

Antes de submeter uma amostra de revestimento têxtil à medição do seu decaimento eletrostático, é necessária a preparação prévia dela. Essa preparação consiste no total descarregamento da amostra, para que não se tenha a presença de cargas 
remanescentes, as quais provocam erros nas medições, inclui ainda, a completa desumidificação da amostra, para que o carregamento eletrostático aconteça.

Para a preparação das amostras de revestimento têxtil a serem ensaiadas, primeiramente deve-se cortar, com uma ferramenta especial, a amostra do material. Essa ferramenta é constituída por um tubo de metal, com uma das extremidades cortante e a outra própria para encaixar em furadeiras de bancada. $\mathrm{O}$ diâmetro da ferramenta de corte é de 4,0 cm, o que garante a preparação de amostras sempre com o mesmo tamanho. Pode-se observar uma amostra de tapete da forma como é utilizada nos testes, na figura 4.13.

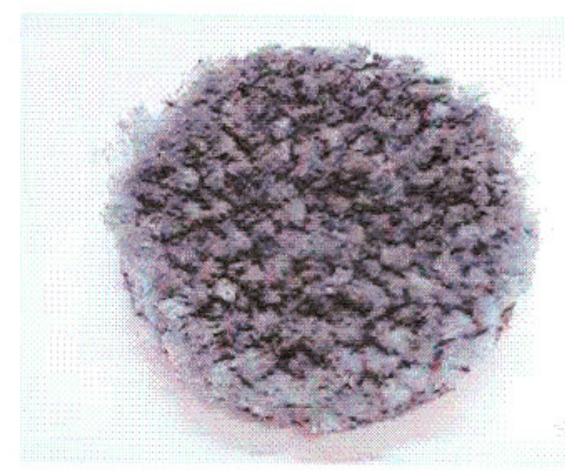

Figura 4.13: Amostra de tapete

O segundo passo para a preparação da amostra é deixá-la por 24 horas envolta em papel alumínio (que é um material bom condutor elétrico) para garantir o completo descarregamento das cargas elétricas superficiais da amostra.

Depois desses dois passos, coloca-se a amostra dentro de um dissecador contendo sílica-gel no seu interior, para a desumidificação dela. Essa fase deve também durar 24 horas. 
Pode-se observar o dissecador utilizado, na figura 4.14.

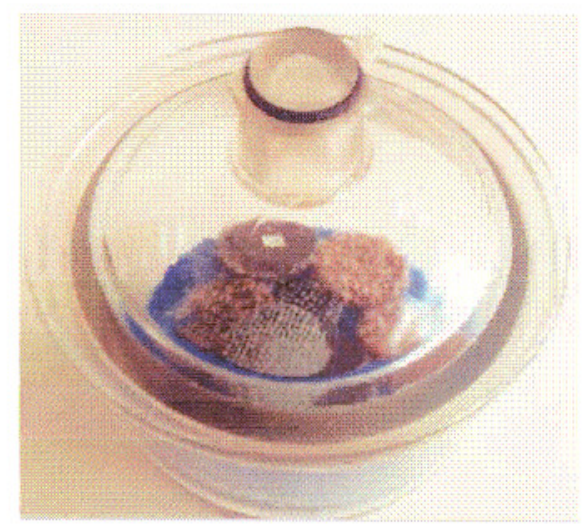

Figura 4.14: Dissecador utilizado para retirar a umidade das amostras de tapete ou carpete

Após esse processo, ou seja, o corte, o descarregamento elétrico e a desumidificação da amostra, ela já está pronta para ser ensaiada, procedimento que será detalhado no próximo item (4. METODOLOGIA DESENVOLVIDA PARA O ENSAIO).

Gostaríamos de salientar que todas as amostras utilizadas neste projeto foram fornecidas pela empresa Tapetes São Carlos.

\subsection{METODOLOGIA DESENVOLVIDA PARA O ENSAIO}

Para iniciar-se a nova metodologia de ensaio desenvolvida nesse projeto ou, mais precisamente, para iniciar um teste de medição do tempo de decaimento do potencial eletrostático de uma amostra de revestimento têxtil, é necessário, antes de tudo, que se limpe o interior da câmara de ionização para evitar interferências, causadas por poeira, na medição. 
A limpeza da câmara foi feita com álcool isopropílico (material apolar) que foi passado no seu interior com o auxílio de uma haste com algodão na ponta. Depois secou-se a câmara com a utilização de um secador portátil (tipo secador de cabelos), para que o álcool restante nas paredes, evaporasse. Esse procedimento foi realizado a cada três ensaios, uma vez que se notou acúmulo de sujeira no interior da câmara, a medida que os ensaios eram realizados.

Dessa forma a câmara estava pronta para receber a amostra a ser testada, depois dela ter sido preparada para o ensaio, como relatado no item 3 deste capítulo.

A amostra foi então retirada do dissecador, onde permaneceu por 24 horas, e colocada diretamente no interior da câmara, mais precisamente sobre o eletrodo terra.

Nesse momento foi também colocada no interior da câmara uma porção de peneira molecular, com o intuito de adsorver a umidade presente no interior dela, pois, como Yashima e Kawamoto [36] escreveram, os materiais isolantes, sólidos, com pequena capacitância, facilmente se descarregam, devido a vazamentos de carga em sua superfície, causados pela umidade do ar. Utilizou-se também uma pequena quantidade de sílica-gel para que se pudesse visualizar a quantidade de umidade presente na peneira molecular, uma vez que este material tem a propriedade de ter sua cor alterada (de azul-marinho para rosa) na presença de água. Todas as amostras foram deixadas no interior da câmara de ionização por 30 minutos, antes de cada medição ser efetuada.

A porção de peneira molecular que fica dentro da câmara de ionização foi trocada a por uma nova a cada três ensaios realizados, pois notamos que depois de três ensaios, ela já começava a ficar saturada de umidade, não desempenhando mais seu papel de desumidificador.

Segundo Zygmund, Curtiss e Iton [37], a peneira molecular, uma zeólita ${ }^{8}$, é um aluminosilicato, o qual tem uma estrutura porosa com cavidades e canais através dos quais moléculas de tamanhos e formas apropriados podem facilmente se difundir; assim, elas têm propriedades catalíticas.

8. Zeólita em Sueco significa "cachorro". Em 1756 um mineralogista sueco saiu para caminhar em companhia do seu cachorro, quando este desenterrou uma pedra, a qual levou o nome de zeólita ${ }^{9}$ [38].

9. Assunto melhor detalhado no Anexo III, página 129. 
Na figura 4.15 observa-se a peneira molecular utilizada, a qual tem $1 / 8^{\prime \prime}$ de tamanho e porosidade de $4 \AA^{10}$.

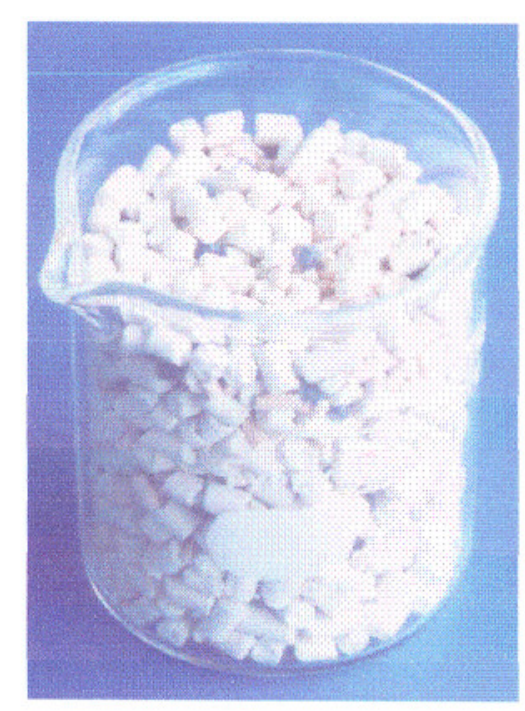

Figura 4.15: Peneira molecular

Logo após serem colocadas a amostra de revestimento têxtil e a porção de peneira molecular no interior da câmara de ionização, ela é rapidamente fechada; e temse um tempo de espera de 30 minutos para que se dê continuidade ao ensaio (tempo de espera detalhado no CAPÍTULO V). Aciona-se, então, o bloco para vibração do altofalante, ligando-se manualmente o oscilador.

As próximas fases da parte experimental são realizadas automaticamente pelo programa computacional AD32. Assim, para continuar com a parte experimental, é necessário que o usuário esteja no ambiente do programa $\mathrm{AD} 32$, mais precisamente na tela de caracterização da amostra.

10. $1 \AA=1 \times 10^{-8} \mathrm{~cm}$ ou $1 \AA=1 \times 10^{-10} \mathrm{~m}$. 
Para iniciar-se a fase de caracterização da amostra, deve-se pressionar o botão Caracterizar, sendo necessário que os parâmetros de tempo da configuração do sistema sejam previamente escolhidos. Esses parâmetros são: Tempo de Carregamento, Tempo de "Delay" e Tempo de Aquisição, como o mostrado anteriormente, na figura 4.9. Esses parâmetros foram configurados com os seguintes valores: Tempo de Carregamento-20 segundos. Tempo de "Delay"-500 milissegundos e Tempo de Aquisição-30 segundos.

Para determinar esses tempos, foram feitos vários testes.

Primeiro a fim de avaliar qual o tempo necessário para que a amostra se carregue, fazendo o carregamento do mesmo tipo de amostra várias vezes, mantendo a tensão de carregamento em $3 \mathrm{kV}$ e alterando o tempo de carregamento Percebe-se que aumentando-se o tempo de carregamento para um valor maior do que $20 \mathrm{~s}$, tem-se praticamente o mesmo valor de potencial adquirido com $20 \mathrm{~s}$.

Depois testou-se qual o tempo de atraso necessário entre o carregamento e a aquisição dos dados do carregamento para promover a segurança da placa de aquisição de dados, realizando-se várias aquisições para um mesmo tipo de amostra e comparando-se os ruídos gerados no carregamento adquirido pelo programa AD32.

$\mathrm{E}$, finalmente, determinou-se qual o tempo de aquisição necessário para que se tenha uma amostragem suficiente de dados para análise, também com várias análises realizadas em cima de dados obtidos de testes realizados.

Depois do acionamento do botão Caracterizar, o próprio programa computacional AD32 irá acionar o bloco para o carregamento da amostra, ou seja, a fonte de alta tensão para o carregamento corona, de acordo com o Tempo de Carregamento pré-fixado. Tanto o acionamento como o desligamento da fonte de alta tensão pelo programa AD32 são realizados via módulo de controle.

Após o carregamento, o programa dará um tempo de atraso entre a fase do carregamento da amostra e a aquisição de dados, de acordo com o Tempo de "Delay", também pré-fixado e também feito via módulo de controle. Esse tempo existe para promover uma maior segurança em relação à placa de aquisição de dados no que diz respeito à fuga de alta tensão para o computador. 
Terminado o Tempo de "Delay", também automaticamente, inicia-se a aquisição de dados do decaimento do potencial eletrostático adquirido pela amostra de revestimento têxtil, durante o seu carregamento, através de um comando vindo do programa $\mathrm{AD} 32$, pelo módulo de controle. Esse tempo de aquisição de dados depende do Tempo de Aquisição pré-fixado. Terminado o Tempo de Aquisição, deve-se desligar o oscilador pois não é mais necessário que o alto-falante fique vibrando.

Os dados são adquiridos pela placa por meio do método do capacitor vibrante, passando o sinal do decaimento eletrostático por um amplificador, antes de chegar na placa de aquisição LAB PC $\mathrm{PC}^{+}$.

Já na placa, os dados são tratados e apresentados na tela do computador na forma de onda mostrada na figura 4.16.

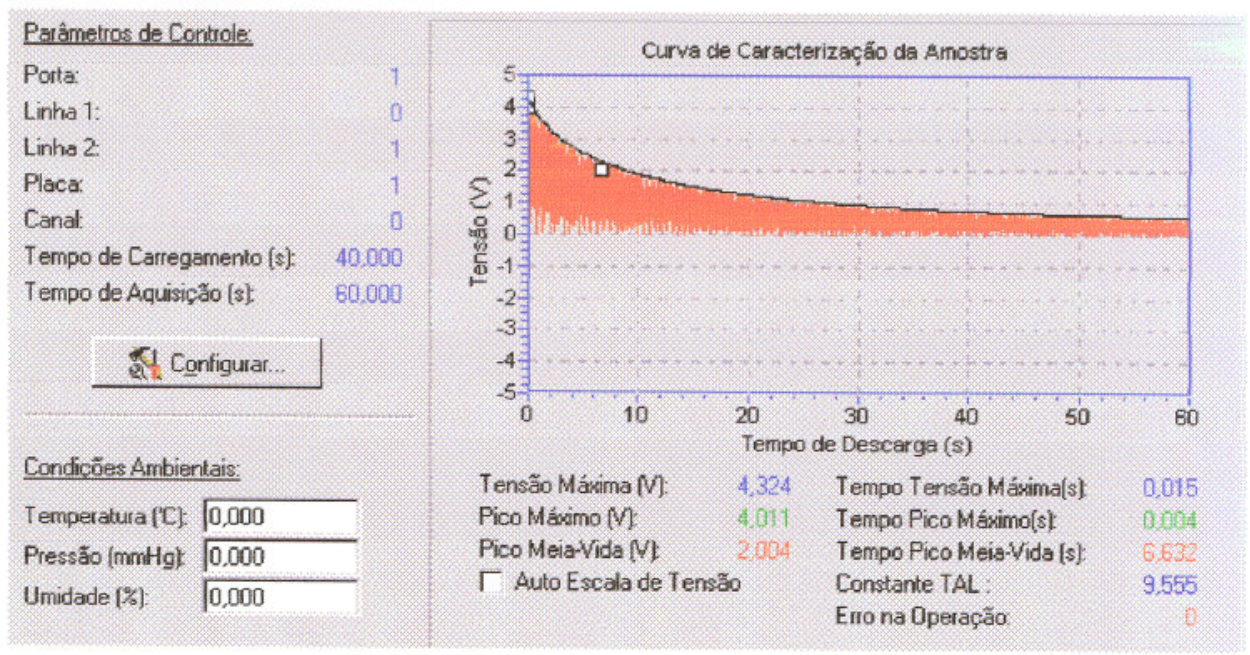

Figura 4.16: Exemplo de aquisição de dados pelo computador, gerenciado pelo programa $A D 32$

Nesta mesma tela do programa - na tela de Caracterização da amostra -, tem-se a constante TAL $(\tau)$ calculada, que corresponde ao tempo de decaimento eletrostático da amostra testada. Assim, tendo em mãos o valor do tempo de decaimento eletrostático e a capacitância da amostra estimada como sendo da ordem de $10^{-11} \mathrm{~F}$, através da equação: 


$$
C=\frac{\varepsilon \cdot A}{d}
$$

em que a permissividade é dada por $\varepsilon=\varepsilon_{0} . \varepsilon_{\mathrm{r}}$,

$\varepsilon_{\mathrm{r}} \approx 4$ (permissividade do Náilon) [43] $\mathrm{e}$

$\mathrm{A}=\pi \cdot \mathrm{r}^{2}=\pi \cdot(0,025)^{2}=1,96 \times 10^{-3} \mathrm{~cm}^{2}$

$\mathrm{d}$, a espessura da amostra, é de aproximadamente $0,52 \mathrm{~cm}$ (dependendo da amostra)

Utilizando-se agora a equação (4.1), tendo o valor do tempo do decaimento eletrostático e da capacitância, podemos estimar que a resistência volumétrica da amostra pode ser representada pela equação (4.2):

$$
R_{V} \approx \frac{\tau}{C}
$$

Dessa maneira, utilizam-se a equação (4.2), que relaciona a resistência volumétrica com a capacitância e o tempo de decaimento do material, e a Norma EIA 541 [22] para caracterizar materiais eletrostaticamente.

A Norma EIA 541 categoriza os materiais de acordo com a resistividade volumétrica deles. Citam-se a seguir, alguns trechos dessa norma referentes à resistividade volumétrica:

- Material com blindagem eletrostática: material capaz de atenuar um campo eletrostático, não permitindo o acúmulo de cargas eletrostáticas nele. A resistividade volumétrica, é menor do que $1 \times 10^{3} \Omega-\mathrm{cm}$ por milímetro de espessura. 
- Material condutivo: material condutivo tanto na sua superfície como no seu volume, sem essas duas partes estarem necessariamente interrelacionadas. É um material impregnado com metal, carbono ou outro material condutivo, isto é, sua superficie é tratada com tais tipos de material, por envernizamento, metalização ou pintura. Um material condutivo não é, necessariamente, antiestático. A resistividade volumétrica desse tipo de material é menor que $1 \times 10^{4} \Omega$-cm por milímetro de espessura.

- Material dissipativo: tipo de material que minimiza a formação de cargas eletrostáticas. Nesse material, a resistividade volumétrica se encontra entre $1 \times 10^{4}$ e $1 \times 10^{11} \Omega$-cm por milímetro de espessura.

- Material isolante: material que armazena as cargas eletrostáticas nele formadas, não as dissipando e, assim, tornando-se o pior tipo de material no que se refere às características eletrostáticas. No material isolante, a resistividade volumétrica é maior que $1 \times 10^{11} \Omega-\mathrm{cm}$ por milimetro de espessura.

A figura 4.17 apresenta um gráfico indicando os valores da resistividade volumétrica de acordo com as características eletrostáticas dos materiais.

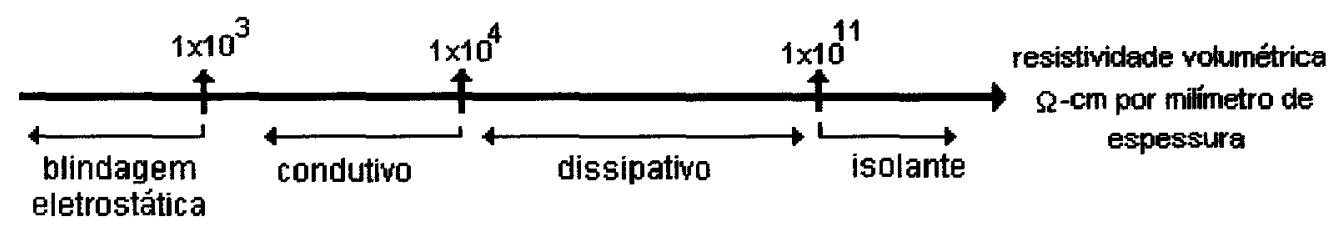

Figura 4.17: Resistividade volumétrica relacionada com as características eletrostáticas dos materiais,segundo a Norma EIA - 541 [22] 


\subsection{EQUACIONAMENTO DA CÂMARA}

Com a descrição da câmara de ionização feita no item 2.1 deste capítulo, pode-se obter o equacionamento do circuito equivalente da câmara de ionização, e, na figura 4.18 , tem-se, em primeira aproximação, o circuito elétrico correspondente da câmara de ionização.

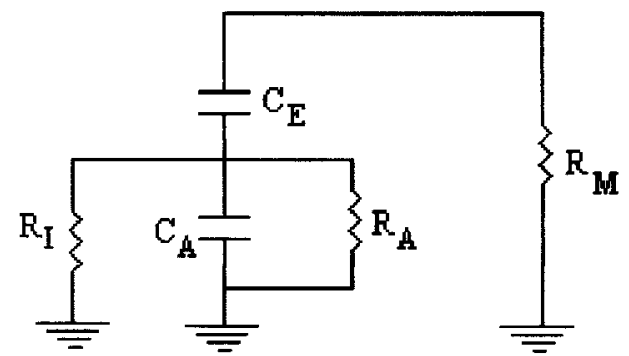

Figura 4.18: Circuito elétrico representando a câmara de ionização

Sendo: $\quad C_{E}=$ capacitância do espaço entre a placa vibratória e a placa responsável pelo carregamento da amostra $[\mathrm{F}]$ $\mathrm{C}_{\mathrm{A}}=$ capacitância da amostra $[\mathrm{F}]$ $\mathrm{R}_{\mathrm{A}}=$ resistência da amostra $[\Omega]$

$\mathbf{R}_{M}=$ resistência referente à medição [ $\left.\Omega\right]$ (osciloscópio) e $R_{I}=$ resistência de isolação [ $\left.\Omega\right]$

Nesse circuito, a amostra de tapete foi representada por uma capacitância em paralelo, $C_{A}$, com uma resistência em paralelo, $R_{A}$, cuja capacitância pode ser calculada como sendo um capacitor de placas paralelas, ou seja:

$$
C_{A}=\frac{A . \varepsilon}{h}
$$

em que: 

A é a área da amostra $\left(\mathrm{cm}^{2}\right)$,
$\varepsilon$, a permissividade da amostra $\left(\varepsilon=\varepsilon_{0} . \varepsilon_{\mathrm{r}}\right)$,
$\varepsilon_{0}$, a permissividade do vácuo $\left(8,85418 \times 10^{-12} \mathrm{~F} / \mathrm{m}\right)$,
$\varepsilon_{\mathrm{r}}$, permissividade relativa do material e
$\mathrm{h}$, a distância entre as placas do capacitor $(\mathrm{cm})$.

A resistência $R_{A}$, pode ser calculada por:

$$
R_{A}=\frac{L}{A \cdot g}(\Omega)
$$

Sendo: $L=$ espessura da amostra $(h$ - distância entre as placas do caoacitor $=L)$

$$
\begin{aligned}
& \mathrm{A}=\text { área superficial da amostra } \\
& \mathrm{g}=\text { condutividade elétrica }
\end{aligned}
$$

O circuito da figura 4.18 pode ser simplificado para o circuito mostrado na figura 4.19 , quando se considera a resistência da isolação $R_{I}\left(\sim 10^{15} \Omega\right)$ muito maior que a resistência da amostra $R_{A}\left(\sim 10^{12} \Omega\right.$.)

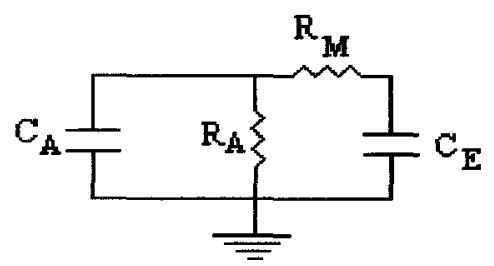

Figura 4.19: Circuito da figura 4.18 - modificado 
Analisando melhor o circuito da figura 4.19 pode-se escrever:

$$
\begin{aligned}
& C e q=C_{E}+C_{A}(F) \\
& C e q \approx C_{A}(F)
\end{aligned}
$$

porque a capacitância $\mathrm{C}_{\mathrm{E}}$ é extremamente pequena em relação à capacitância $\mathrm{C}_{\mathrm{A}}$, como se pode ver ao substituir-se os valores da equação:

$$
\tau=R . C
$$

que representa um capacitor de placas paralelas onde:

$$
\begin{aligned}
& \mathrm{A}=\text { área }=\pi r^{2}=1,257 \times 10^{-3} \mathrm{~m} ; \\
& \varepsilon=\varepsilon_{0} \cdot \varepsilon_{r}=\text { permissividade }=8,8594 \times 10^{-12} \mathrm{~F} / \mathrm{m} \mathrm{e} \\
& \mathrm{h}=\text { distância entre a placa vibratória e a placa do carregamento }=0,027 \mathrm{~m}, \\
& \text { tem-se então o valor de } \mathrm{C}_{\mathrm{E}}=4,1209 \times 10^{-13} \mathrm{~F} .
\end{aligned}
$$

Como $\mathbf{R}_{\mathrm{M}}(\sim 1 \mathrm{M} \Omega)<<\mathbf{R}_{\mathrm{A}}$, então, pode-se escrever que o tempo de decaimento eletrostático depende exclusivamente das características da amostra e é dado por:

$$
\tau=R_{A} \cdot C_{A}(s)
$$

Sendo: $\quad \tau=$ tempo de decaimento eletrostático [s]

$\mathrm{R}_{\mathrm{A}}=$ resistência da amostra [ $\left.\Omega\right]$

$\mathrm{C}_{\mathrm{A}}=$ capacitância da amostra $[\mathrm{F}]$

Contudo, neste equipamento, o tempo de decaimento é medido de forma indireta, medindo-se a taxa de decaimento das cargas superficiais pelo capacitor vibrante, obedecendo-se o equacionamento descrito no item subseqüente. 


\subsubsection{CONFIGURAÇÃO ELETRODO-AMOSTRA}

Neste estudo teórico, o sistema de eletrodos e a amostra de tapete ou carpete, localizada no interior da câmara de ionização, podem ser considerados como o mostrado na figura 4.20 , ou seja, tanto o eletrodo terra como o superior, estão em contato com a amostra.

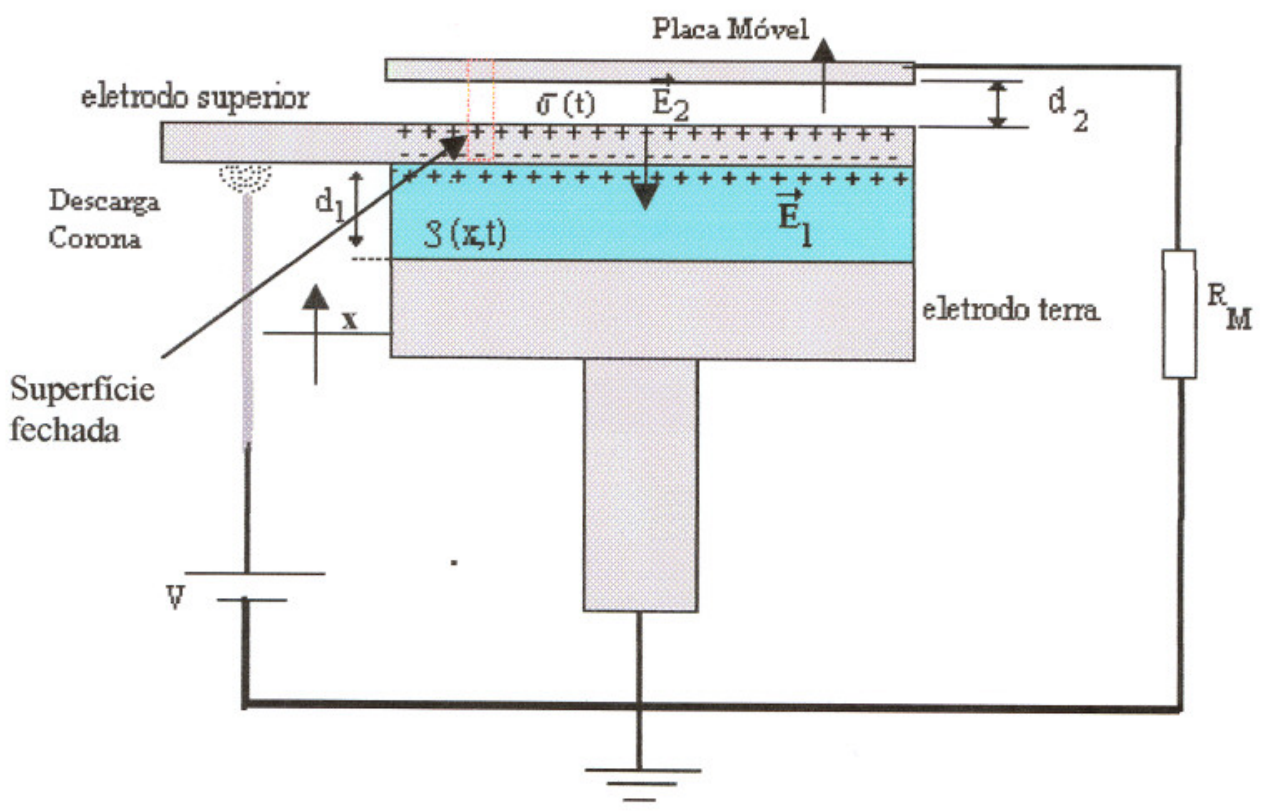

Figura 4.20: Diagrama esquemático da disposição dos eletrodos/ amostra, no interior da câmara de ionização.

$\mathrm{E}_{1}$ é o campo elétrico no interior da amostra $[\mathrm{V} / \mathrm{m}]$;

$\rho(\mathrm{x}, \mathrm{t})$ é a densidade volumétrica de cargas no material $\left[\mathrm{C} / \mathrm{m}^{3}\right]$;

$\mathrm{d}_{1}$ é a espessura do material $[\mathrm{m}]$;

$\mathrm{d}_{2}$ é a distância entre o eletrodo superior e a placa móvel, mantida fixa [m];

$\mathrm{V}$ é a diferença de potencial entre os eletrodos [V];

$\mathrm{E}_{2}$ é o campo elétrico no interstício $[\mathrm{V} / \mathrm{m}]$;

$\sigma(\mathrm{t})$ é a densidade superficial de cargas no material $\left[\mathrm{C} / \mathrm{m}^{2}\right]$. 
Após ter sido carregada a amostra, todo o circuito é colocado pela resistência $\mathbf{R}_{M}$ em curto-circuito. Nessa configuração, obedecendo a orientação do sistema de coordenadas indicado, tem-se:

$$
0=\int_{0}^{d_{1}} E_{1} \cdot d l-\int_{d_{1}}^{d_{2}} E_{2} \cdot d l
$$

Ou também

$$
E_{1} \cdot d_{1}=E_{2} \cdot d_{2}
$$

Agora, aplicando a lei de Gauss na superfície fechada indicada na figura 4.20, pode-se escrever

$$
\oint_{S} \vec{D} \cdot d \vec{s}=Q \Rightarrow D_{2}+D_{1}=\sigma(t) \Rightarrow \varepsilon_{0} E_{2}+\varepsilon \cdot E_{1}=\sigma(t)
$$

Usando-se, as equações (4.10) e (4.11), tem-se

$$
E_{1}=\frac{\frac{\sigma(t)}{\varepsilon_{0}}}{\frac{d_{1}}{d_{2}}+\frac{\varepsilon}{\varepsilon_{0}}}
$$

$\mathrm{Na}$ equação (4.12) a densidade superficial de cargas $\sigma(t)$ é determinada aplicando-se na mesma superficie fechada a equação da continuidade

$$
\nabla . \vec{J}=-\frac{\partial \sigma(t)}{\partial t} \Rightarrow \nabla \cdot \frac{\vec{E}}{\rho}=-\frac{\partial \sigma(t)}{\partial t} \Rightarrow \frac{d \sigma(t)}{d t}=-\frac{1}{\varepsilon \rho} \sigma(t)
$$

cuja solução é dada por

$$
\sigma(t)=\sigma_{o} e^{-\frac{t}{\tau}}
$$

em que $\tau$ é igual a $\tau=\rho \varepsilon$, ou pode ser dado também pela equação (4.8) 
De posse do campo elétrico $\vec{E}_{1}$ dado pela equação (4.12), a diferença de potencial entre o eletrodo superior e o eletrodo terra pode ser determinada por:

$$
V_{1}(t)=d_{1} E_{1}=\frac{\frac{\sigma(t) d_{1}}{\varepsilon_{0}}}{\frac{d_{1}}{d_{2}}+\frac{\varepsilon}{\varepsilon_{0}}}
$$

Com esta equação, o circuito torna-se igual àquele descrito pela figura 4.21:

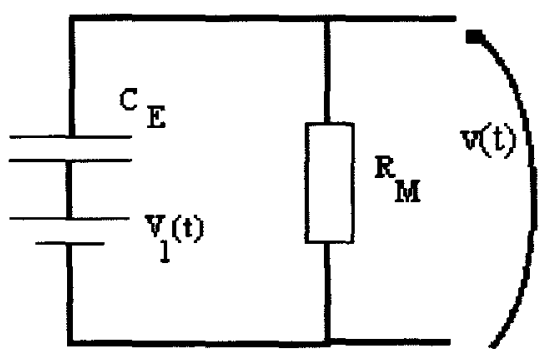

Figura 4.21: Circuito equivalente da Câmara contendo uma amostra carregada, onde o $C_{E}$ é o capacitor vibrante.

$\mathrm{O}$ movimento senoidal de uma das placas do capacitor vibrante $\mathrm{C}_{\mathrm{E}}$ altera a distância $d_{2}$ permitindo escrever:

$$
d_{2}=d_{0}-d_{3} \operatorname{sen}(w t)
$$

onde $d_{0}$ é a distância média entre as placas e $d_{3}$ é a amplitude máxima da oscilação.

Dessa forma tem-se a capacitância $\mathrm{C}_{\mathrm{E}}$, ou seja, $C_{E}=\frac{A \cdot \varepsilon_{0}}{d_{2}}$; expandindo o denominador como um binômio até o terceiro termo, tem-se, segundo Anderson [39]:

$$
C_{E}=C_{0}+C_{1} \operatorname{sen}(w t)+C_{2} \cos (2 w t)+C_{3} \operatorname{sen}(3 w t) \ldots
$$


em que as constantes $\mathrm{C}_{0}, \mathrm{C}_{1}, \mathrm{C}_{2}$ e $\mathrm{C}_{3}$ podem ser expressas em termos de $d_{3}, d_{0}, \varepsilon_{0}$ e $\mathrm{A}$. Para uma situação em que $d_{3}<<d_{0}$, tem-se que $C_{E}$ varia senoidalmente, e a equação (4.16) pode ser escrita da seguinte maneira:

$$
\mathrm{C}_{\mathrm{E}}=\mathrm{C}_{0}+\mathrm{C}_{1} \operatorname{sen}(\mathrm{wt})
$$

Nessa situação, o circuito da figura 4.20 foi solucionado por Wente [40], em 1917, determinando-se a tensão $v(t)$, ou seja:

$$
\frac{v(t)}{V_{1}(t)}=\frac{R_{M} C_{1} \operatorname{sen}\left(w t+\varphi_{1}\right)}{C_{0} \sqrt{\left(\frac{1}{C_{0 w}}\right)^{2}+R_{M}^{2}}}
$$

Em que $\varphi_{1}=\tan ^{-1}\left(\frac{1}{R_{M} C_{0} w}\right)$. Quando se faz $R_{M}{ }^{2} \gg \frac{1}{C_{0} w}$, a equação (4.19) reduz-se $\mathrm{a}:$

$$
\frac{v(t)}{V_{1}(t)}=\frac{C_{1} \operatorname{sen}\left(w t+\varphi_{1}\right)}{C_{0}}
$$

ou, ainda, como $d_{3}<<d_{0}$, em:

$$
\frac{v(t)}{V_{1}(t)}=\frac{d_{3} \operatorname{sen}\left(w t+\varphi_{1}\right)}{d_{0}}
$$

Da equação (4.21) e da equação (4.15) escreve-se:

$$
v(t)=\frac{\frac{\sigma(t) d_{1}}{\varepsilon_{0}}}{\frac{d_{1}}{d_{2}}+\frac{\varepsilon}{\varepsilon_{0}}} \frac{d_{3}}{d_{0}} \operatorname{sen}\left(w t+\varphi_{1}\right)
$$


Finalmente, substituindo a equação (4.14) em (4.22) pode-se escrever:

$$
v(t)=v_{0} e^{-\frac{t}{\tau}} \operatorname{sen}\left(w t+\varphi_{1}\right)
$$

com $v_{o}$ constante dado por:

$$
v_{0}=\frac{\frac{\sigma_{0} d_{1}}{\varepsilon_{0}}}{\frac{d_{1}}{d_{2}}+\frac{\varepsilon}{\varepsilon_{0}}} \frac{d_{3}}{d_{0}}
$$

Como se observa, a equação (4.23) fornece informações sobre o tempo de decaimento $\tau$ das amostras. Dessa forma, neste trabalho, a determinação de $\tau$ foi feita, primeiramente, adquirindo-se os valores da equação (4.23) no tempo e depois determinando-se sua envoltória. De posse da equação da envoltória, que consiste basicamente em:

$$
v(t)^{\prime}=v_{0} e^{-\frac{t}{\tau}}
$$

a determinação de $\tau$ pôde ser feita conhecendo-se apenas dois valores de $v(t)$ ' e seus respectivos tempos:

$$
\frac{v_{1}^{\prime}}{v_{2}^{\prime}}=e^{\frac{-\left(t_{1}-t_{2}\right)}{\tau}} \Rightarrow \tau=\frac{t_{1}-t_{2}}{\ln \frac{v_{2}^{\prime}}{v_{1}^{\prime}}}
$$

Da equação (4.26) também pode-se observar que, neste processo para a determinação do tempo de decaimento, o efeito do carregamento é praticamente eliminado.

Assim, mesmo que não tivesse sido tomado o cuidado de manterem-se as amostras por um igual período de tempo de carregamento, ainda, por esse método, tornase possível medir o tempo de decaimento. 


\title{
CAPÍTULO V
}

\section{COMPORTAMENTO DO PROTÓTIPO PARA CARACTERIZAÇÃO DE REVESTIMENTOS TÊXTEIS - PCRT}

\author{
Procurando estudar o comportamento do \\ protótipo para a caracterização de revestimentos \\ têxteis-PCRT, foram desenvolvidos, ao longo do \\ trabalho, inumeros experimentos laboratoriais. Neste \\ capitulo, eles são descritos, bem como seus \\ resultados e suas conclusões.
}

\subsection{CONSIDERAÇÕES INICIAIS}

Em uma nova metodologia de medição, como é o caso da aqui apresentada, as influências de inúmeros parâmetros precisam ser conhecidas e analisadas. Muitas delas podem ser desprezadas, em razão de seus diminutos valores, mas outras tornam-se tão importantes que comprometem todo o sistema proposto. Visando determinar e analisar os parâmetros que atuam sobre o protótipo-PCRT, foram desenvolvidos inúmeros experimentos laboratoriais que encontram-se descritos nos itens subseqüentes. Alguns desses parâmetros, como é o caso da umidade, já foram parcialmente apresentados no capítulo IV, mas aqui são melhor descritos. 


\subsection{INFLUÊNCIA DA UMIDADE}

Como mostrado no capítulo IV, a solução encontrada para um dos principais problemas deste protótipo, ou seja, para a influência da umidade no processo de medição, foi a colocação de uma porção de peneira molecular juntamente com sílica-gel, no interior da câmara de ionização fazendo-se necessária a espera de 30 minutos, estando a amostra já no interior da câmara, antes de se realizar o carregamento. A função desses materiais é a de adsorver a maior parte da umidade presente no interior da câmara ${ }^{8}$. Já, o tempo padronizado de espera por 30 minutos foi obtido a partir da análise dos valores das tensões iniciais fornecidas pelo sistema, correspondentes ao potencial de superfície de diferentes amostras de tapetes. Um gráfico mostrando a influência da umidade no potencial de superficie de amostras de tapete ou carpete encontra-se na figura 5.1.

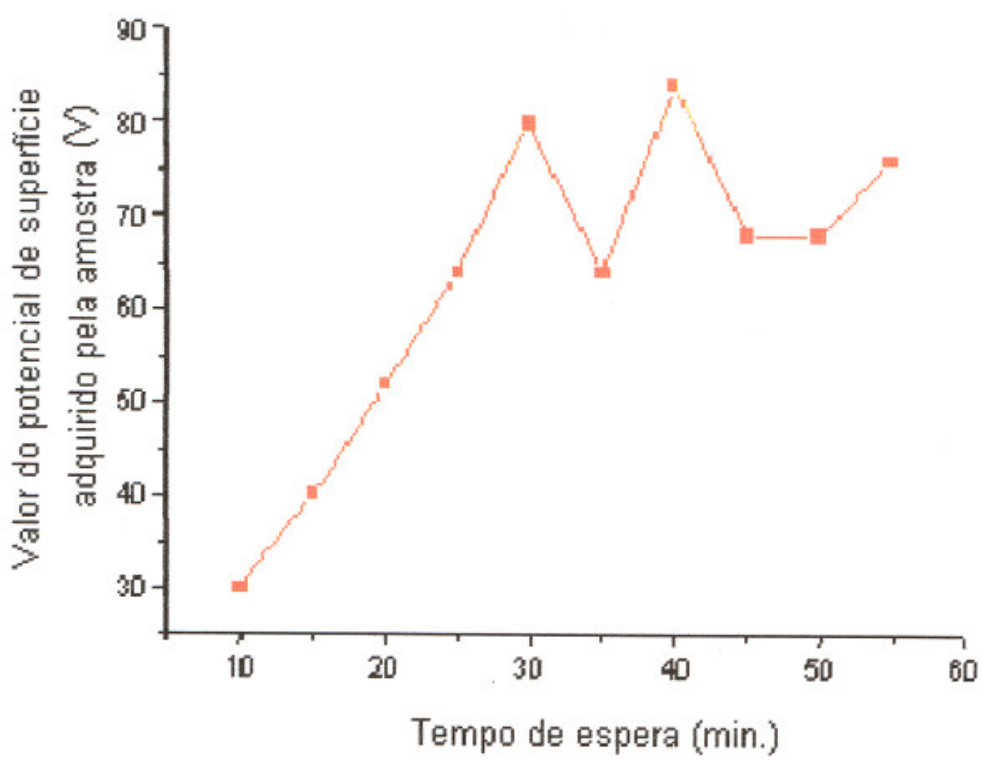

Figura 5.1: Gráfico mostrando a influência da umidade no carregamento de amostras de tapetes e carpetes

8. De acordo com os experimentos de carregamento por corona realizados nesse projeto, percebe-se que o carregamento acontece com um baixo valor de umidade, por volta de $20 \%$ de URA. 
A partir do gráfico mostrado na figura 5.1, pode-se observar que, depois de 30 minutos de espera para a realização do carregamento da amostra de revestimento têxtil, tem-se praticamente uma estabilização do valor do potencial de superfície adquirido pela amostra. Nota-se que se o tempo de espera for aumentado para um valor superior a 30 minutos, ocorre uma pequena variação no valor do potencial de superfície da amostra, não ocorrendo um aumento considerável desse valor como no caso do tempo de espera inferior a 30 minutos.

\subsection{ESTUDOS PARA A DETERMINAÇÃO DA GEOMETRIA DOS ELETRODOS}

A geometria dos eletrodos irá possibilitar que diferentes espessuras de amostras sejam caracterizadas e também fazer com que muitos fenômenos de descargas elétricas espúrias sejam evitados.

A primeira pergunta formulada e que necessitava ser respondida era " $\mathrm{O}$ sistema corona de alta tensão está carregando as amostras devidamente? O que poderia estar ocorrendo, como ilustra a figura 5.2, era que, quando terminado o carregamento corona, as cargas elétricas do eletrodo superior poderiam estar escoando pela distância, $\mathrm{d}_{3}$, entre a ponta corona e o eletrodo superior. A distância $d_{3}$ foi inicialmente fixada em $3 \mathrm{~mm}$.

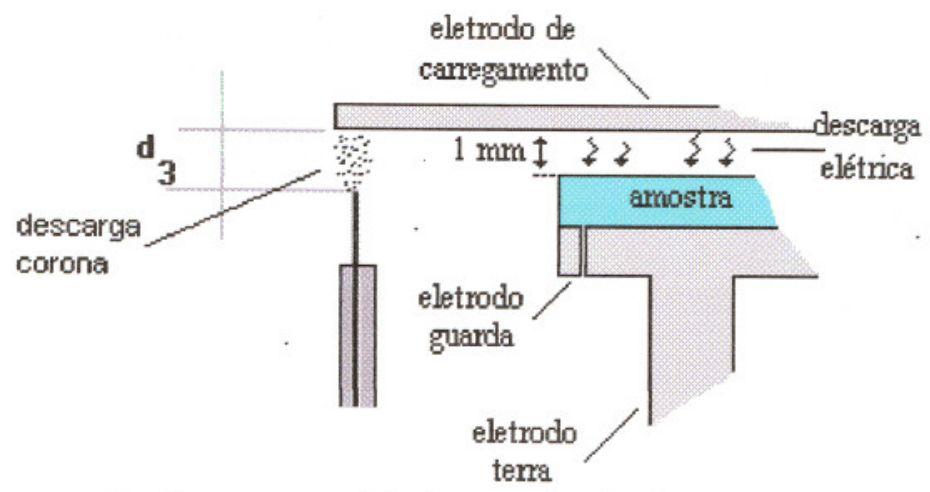

Figura 5.2: Escoamento das cargas elétricas pela distância entre a ponta corona e o eletrodo superior 
Realizando-se vários testes de carregamento e medição de decaimento eletrostático, com e sem amostras, utilizando filmes de Teflon FEP $50 \mu \mathrm{m}$, conseguiu-se definir essa distância como padrão para esse equipamento. $\mathrm{O}$ Teflon foi escolhido porque carrega-se facilmente na presença de descarga corona e, quando não descarregado, mantém sua carga por longos períodos de tempo (aproximadamente 500 anos), formando um eletreto. Também para comparar com os dados recolhidos pelo programa $\mathrm{AD} 32$, os testes foram cronometrados manualmente.

\subsubsection{RESULTADO DOS TESTES COM AMOSTRAS DE FILME TEFLON FEP}

Numa primeira série de testes foram empregadas amostras com filme de Teflon FEP $50 \mu \mathrm{m}$ presos a um bastidor circular de $5 \mathrm{~cm}$ de diâmetro (externo). A distância entre a amostra de teste e o eletrodo superior de carregamento foi mantida em $1 \mathrm{~mm}$, e o tempo de carregamento de 1minuto, com tensão de $3 \mathrm{kV}$. Foi observado que a placa foi carregada por corona e as amostras, por descarga elétrica completa, ficando as cargas presas nas armadilhas superficiais do material [15], formando, assim, um eletreto.

A figura 5.3 ilustra o fenômeno ocorrido.

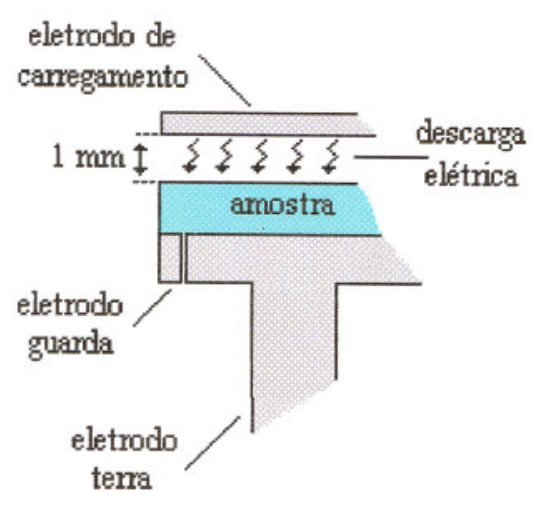

Figura 5.3: Carregamento da amostra por descarga elétrica 
Em testes com a amostra de Teflon encostada no eletrodo de carregamento, mantendo o eletrodo guarda sempre aterrado e mantendo-se também, o mesmo tempo de carregamento e a mesma tensão, observou-se um carregamento nulo de amostra. Uma explicação plausível para o fato são as ocorrências de descargas laterais entre o eletrodo superior e o eletrodo terra e a descarga de retorno ("back discharge")[44] entre o eletrodo de carregamento e a superfície da amostra que podem ocorrem após o final dos testes. A figura 5.4 procura ilustrar o ocorrido.

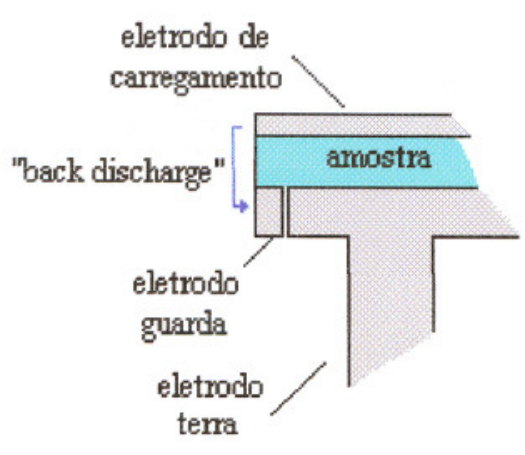

Figura 5.4: Descarregamento da amostra por descarga de retorno e descarga lateral

Esses dois testes permitem concluir que, em testes de filmes finos e tapetes com espessuras inferiores a $1 \mathrm{~mm}$, o eletrodo superior necessita sofrer algumas modificações em sua geometria, como o indicado na figura 5.5, evitando as descargas laterais e as descargas de retorno.

Embora a sugestão dessa nova geometria para os eletrodos não tenha sido testada, a distribuição de cargas o modelamento matemático e os testes nesse novo modelo de eletrodos, fica como sugestão para novas pesquisas, geradas pelo presente trabalho. 


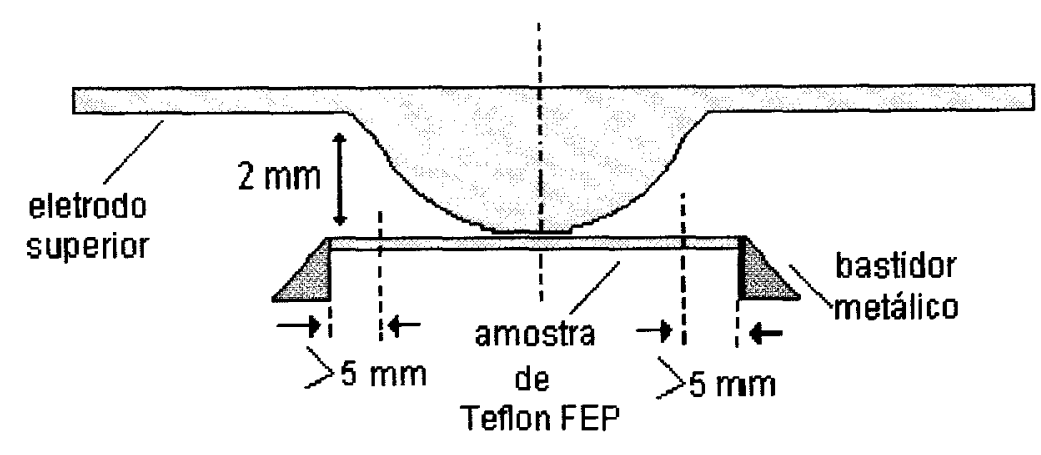

Figura 5.5: Eletrodo superior para filmes finos e tapetes com espessuras menores do que $1 \mathrm{~mm}$

\subsection{INFLUÊNCIA DA RESISTÊNCIA PARASITA DA CÂMARA DE IONIZAÇÃO}

Para determinar a resistência parasita da câmara de ionização e

o tempo de decaimento do sistema foram realizados testes de carregamento sem a presença de amostras em seu interior. Inicialmente mantendo uma distância de $1 \mathrm{~mm}$ entre o eletrodo de carregamento e o eletrodo terra, observaram-se baixos valores de carregamento, com rápido descarregamento posterior, mostrando que o sistema descarregava-se através de descargas elétricas para o terra. A figura 5.6 ilustra o fenômeno que pode ter ocorrido.

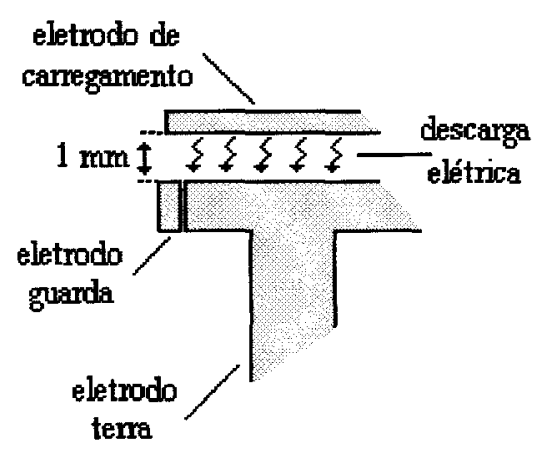

Figura 5.6: Descarregamento do sistema pelo eletrodo terra 
Mudando-se a distância entre o eletrodo superior e o eletrodo terra para $2,5 \mathrm{~cm}$ obteve-se um alto carregamento, com pequeno descarregamento posterior. Os resultados do carregamento $\left(\mathrm{mV}_{\mathrm{pp}}\right)$ pelo tempo (s) encontram-se nas figuras 5.7, 5.8 e 5.9.

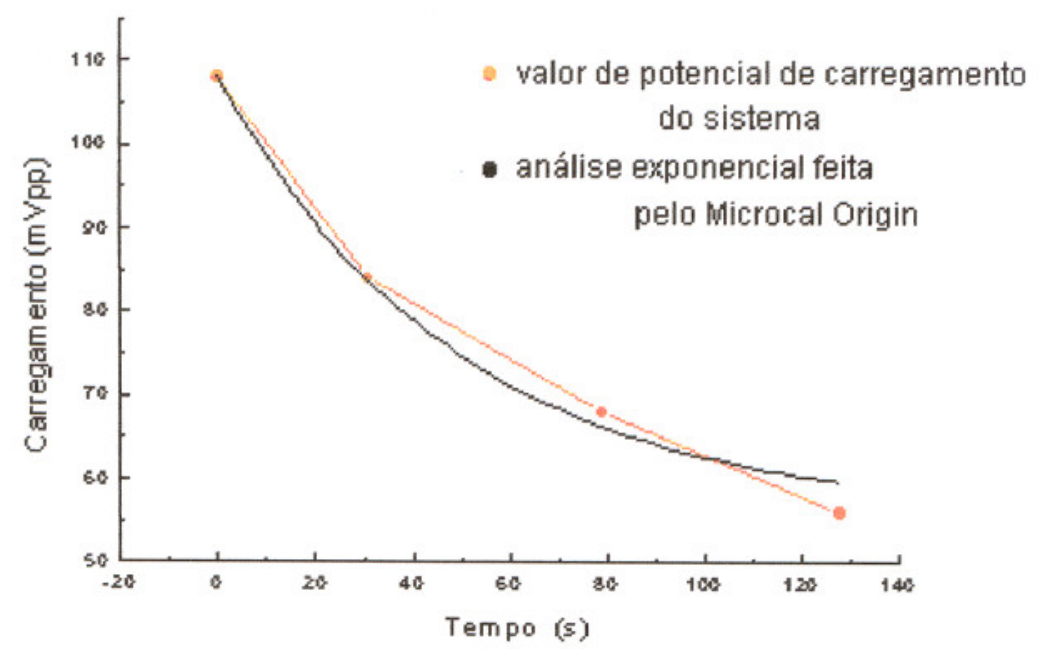

Figura 5.7: Potencial de carregamento, sem amostra, em função do tempo

Quando se fez uma análise exponencial de primeira ordem do gráfico da figura 5.7, pelo programa computacional Microcal Origin, obteve-se a equação:

$$
f(x)=y_{0}+A_{1} \cdot e^{\frac{-\left(x-x_{0}\right)}{t_{1}}}
$$

Em que pôde-se obter o tempo de decaimento do sistema $\left(\mathrm{t}_{1}\right)-48$ segundos. Fazendo-se a mesma análise para os gráficos das figuras 5.8 e 5.9, obtiveram-se os tempos de 56 e 59 segundos, respectivamente. 


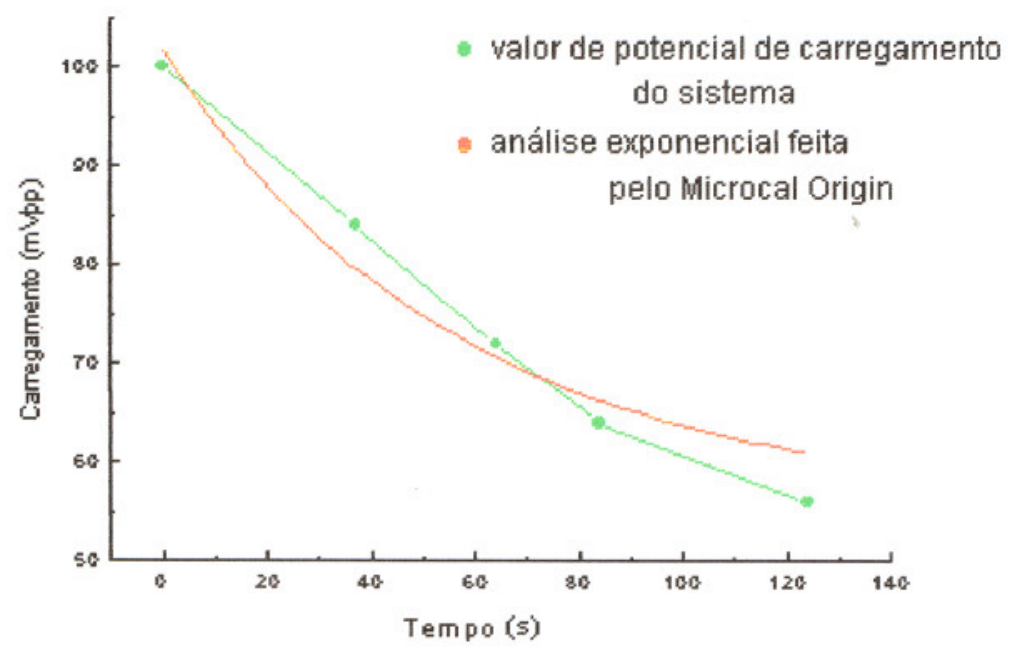

Figura 5.8: Tempo de decaimento do sistema

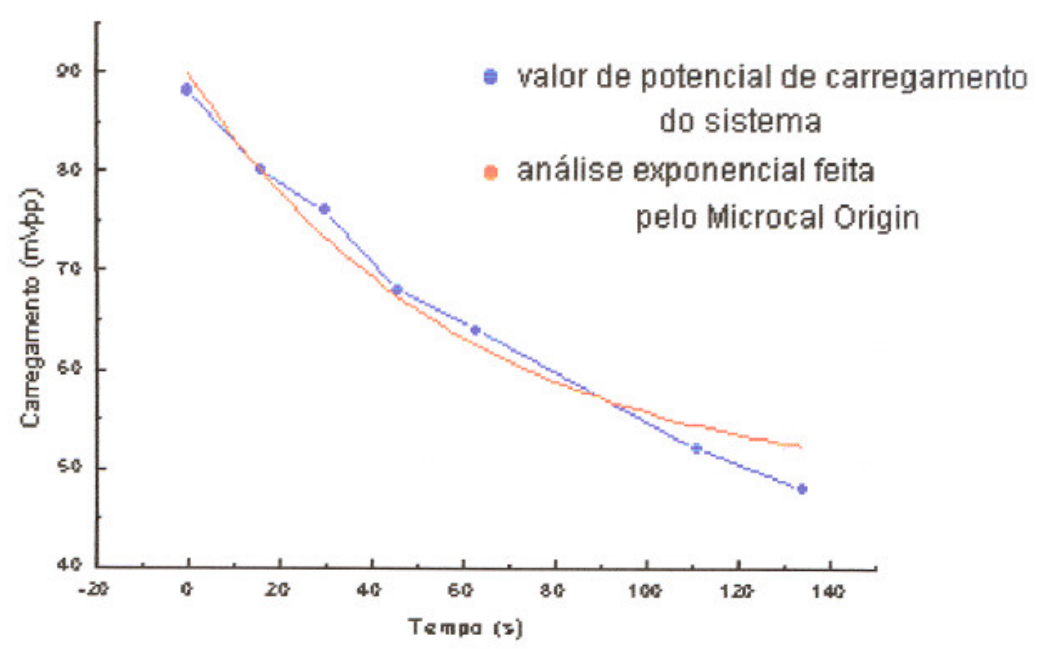

Figura 5.9: Tempo de decaimento do sistema

Assumindo-se o menor tempo de descarregamento encontrado, ou seja, 48 segundos, pôde-se determinar a isolação do sistema pela seguinte expressão: 


$$
\tau=R_{s} \cdot C_{0}
$$

sendo: $\quad \tau=$ tempo de decaimento do sistema

$\mathrm{R}_{\mathrm{S}}=$ resistência de isolação da câmara de ionização $\mathrm{e}$

$\mathrm{C}_{0}=$ capacitância do ar, ou seja, capacitância entre eletrodos

com $\mathrm{C}_{0}$ expresso por:

$$
C_{0}=\frac{\varepsilon_{0} \cdot A}{d}
$$

sendo: $\quad \varepsilon_{0}=$ permissividade dielétrica $\left(8,85 \times 10^{-12} \mathrm{~F} \mathrm{~m}^{-1}\right)$

$\mathrm{A}=$ área da superficie da placa $\left(\pi \cdot \mathrm{r}^{2}\right) \mathrm{m}^{2}$

$d$ = distância entre as placas do capacitor, ou seja, distância entre os eletrodos $\left(2,5 \times 10^{-2} \mathrm{~m}\right)$

Portanto, conseguiu-se calcular a resistência da câmara de ionização, apenas substituindo-se os valores anteriormente relacionados.

$$
\begin{gathered}
R_{S}=\frac{48.2,5 \times 10^{-2}}{8,85 \times 10^{-12} \cdot \pi\left(2,5 \times 10^{-2}\right)^{2}} \Rightarrow R_{s}=57,5 \times 10^{12} \Omega \\
R_{s}=6 \times 10^{13} \Omega
\end{gathered}
$$

O valor encontrado é bem elevado e satisfaz nossas exigências de isolação para o sistema. 


\subsection{TESTES UTILIZANDO AMOSTRAS DE TAPETES E CARPETES}

Utilizando-se a preparação das amostras citada no item 2.13 do capítulo IV, foram realizados seis testes de carregamento, com 20 amostras de tapete e medição do tempo de decaimento pelo Programa AD32.

Os resultados obtidos com esses testes estão apresentados na tabela 2 .

Como se observa, existe uma razoável repetitividade entre os resultados de um mesmo material, considerando-se que, para este tipo de caracterização, o aspecto mais importante é a determinação da ordem de magnitude dos resultados.

Tabela 2: Tempo de decaimento" $\tau$ "

\begin{tabular}{||c|c||}
\hline AMOSTRA & $\tau(\mathbf{s})$ \\
\hline 10 & 16,83608 \\
\hline 10 & 15,13588 \\
\hline 10 & 16,09303 \\
\hline 10 & 17,03965 \\
\hline 10 & 12,56168 \\
\hline 10 & 15,93328 \\
\hline 4 & 11,59511 \\
\hline 4 & 10,31176 \\
\hline 4 & 16,28613 \\
\hline 4 & 17,16588 \\
\hline 4 & 12,92557 \\
\hline & \\
\hline 1 & 18,84201 \\
\hline 1 & 18,35263 \\
\hline 1 & 13,44263 \\
\hline 1 & 10,64646 \\
\hline 1 & 13,31085 \\
\hline & \\
\hline 15 & 17,77561 \\
\hline 15 & 28,03544 \\
\hline 15 & 21,27908 \\
\hline 15 & 26,88632 \\
\hline
\end{tabular}


A seguir são descritas algumas características ${ }^{11}$ dos tipos de tapetes citados na tabela 2 .

AMOSTRA NÚMERO 10: amostra de construção em veludo "tufting" tipo "shag", filamento contínuo de náilon 6.6 singelo, tela urdida de polietileno. "compound" de látex sintético de estirenobutadieno, carga mineral (carbonato) e pigmento preto.

AMOSTRA NÚMERO 15: amostra de construção "loop tufting", $100 \%$ poliamida, sobre tela de polipropileno; base "compound"de látex sintético de estireno butadieno, carga mineral (carbonato) e negro de fumo semicondutivo.

AMOSTRA NÚMERO 4: amostra com construção em veludo "tufting" tipo "shag", filamento contínuo de náilon 6.6 singelo, tela urdida de polietileno; base dublada com tela "rachel", poliésteralgodão, "compound" de látex sintético de estirenobutadieno, carga mineral (carbonato) e pigmento preto.

AMOSTRA NÚMERO 1: características idênticas às da amostra de número 4, diferenciando-se apenas pela cor e o peso, que no caso é mais densa.

11. Essas informações foram fornecidas pelo Supervisor - Tinturaria/Laboratório da Tapetes São Carlos, Sr. Altair Francisco. 


\title{
CAPÍTULO VI
}

\section{PROPOSTA DE MODELAGEM DE REVESTIMENTOS TÊXTEIS}

\author{
Neste capitulo, encontra-se uma proposta \\ para modelagem do comportamento eletrostático \\ de revestimentos têxteis, através da associação \\ dos circuitos elétricos equivalentes, que \\ representam suas fibras individuais.
}

\subsection{CONSIDERAÇÕES GERAIS}

$\mathrm{Na}$ metodologia apresentada no capítulo IV a caracterização eletrostática de revestimentos têxteis foi baseada na Norma EIA-541 [22], considerando-se basicamente a resistência volumétrica de uma dada amostra associada em paralelo a sua capacitância. Entretanto, foi também observado uma influência marcante da umidade nas medições, muito superior àquela esperada nesses casos. Embora a umidade também interfira nas medições de resistência volumétrica, sua maior atuação ocorre nas medidas de resistência superficial, segundo a Norma ASTM [41]. Essa observação, aliada a uma análise do formato dos revestimentos têxteis, leva à conclusão de que uma melhor modelagem desses materiais pode ser conseguida se estes forem considerados como compostos por inúmeras fibras associadas em paralelo, permeadas pelo ar, nas condições climáticas do ambiente considerado. 


\subsection{MODELAGEM DE UM REVESTIMENTO TÊXTIL}

Nesta nova abordagem, a resistência volumétrica dos revestimentos têxteis pode ser encarada como uma associação em paralelo das resistências volumétricas, $\mathbf{R}_{\mathrm{Vi}}$, e superficiais, $\mathbf{R}_{\mathbf{S i}}$, das inúmeras fibras que os compõem. Isso também possibilita, de maneira análoga, considerar a capacitância total da amostra, $\mathrm{C}_{\mathrm{a}}$, como uma associação em paralelo das capacitâncias, $\mathrm{C}_{\mathrm{i}}$, de suas fibras individuais, como o mostrado na figura 6.1.

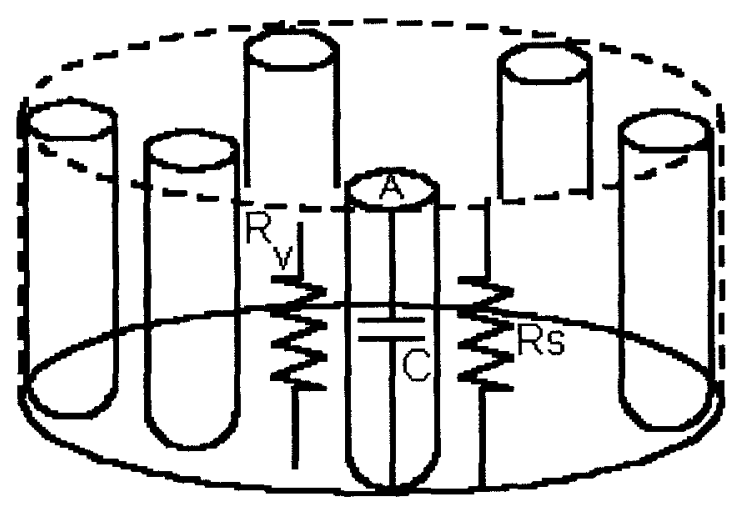

(a)

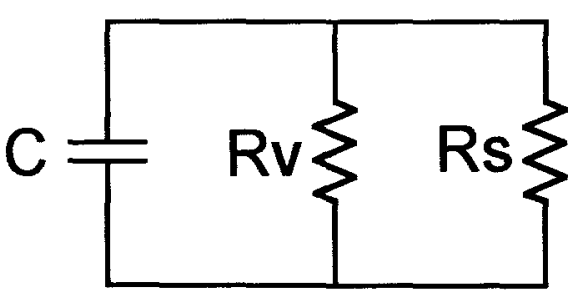

(b)

Figura 6.1:(a) Revestimento têxtil; (b) Circuito elétrico equivalente de uma fibra

Assim, pode-se escrever a resistência volumétrica total da amostra como sendo:

$$
\frac{1}{R_{v}}=\Sigma\left(\frac{1}{R_{v i}}+\frac{1}{R_{s i}}\right)
$$

ou melhor,

$$
R_{v}=\frac{1}{\sum \frac{1}{R_{v i}}+\sum \frac{1}{R_{s i}}}
$$


Supondo que a condutividade volumétrica da fibra seja análoga a de um metal, então podemos escrever que as resistências volumétricas $R_{v i}$ podem ser facilmente encontradas pela equação:

$$
R_{v i}=\rho_{v} \frac{l}{A}
$$

em que $\rho_{v}$ é a resistividade volumétrica,

$l$ é o comprimento efetivo da fibra e

A, a área desta.

Já as resistências superficiais são definidas segundo a Norma EIA-541 [22], como a razão da tensão DC pela corrente que atravessa a superficie de uma amostra. Dessa forma, elas podem ser determinadas aplicando-se uma corrente $\mathrm{I}_{0}$ constante entre as duas extremidades da fibra. Nessa condição, tem-se que a densidade superficial de corrente $\overrightarrow{\mathrm{k}}$ pode ser determinada por:

$$
\vec{k}=-\frac{I_{0}}{2 \pi r} \vec{a} z
$$

considerando-se o sistema de coordenadas posicionado conforme ilustrado na figura 6.2 e $r$, o raio da fibra.

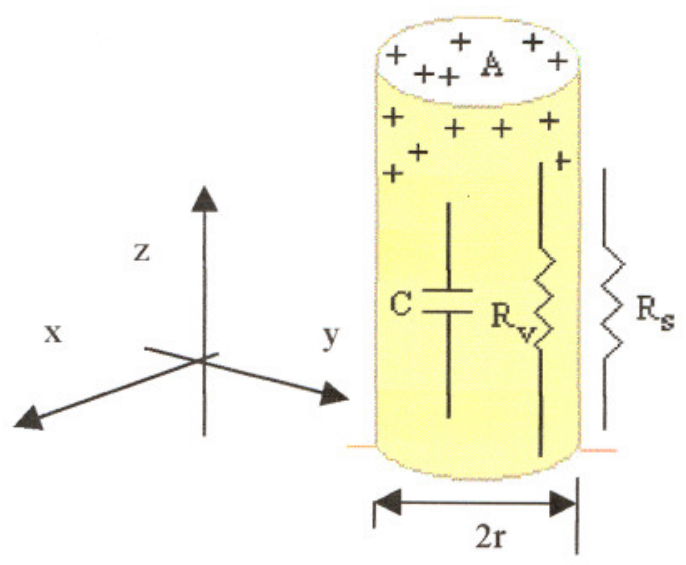

Figura 6.2: Modelo para a fibra de tapete ou de carpete 
Como

$$
\overrightarrow{\mathbf{k}}=\sigma_{\mathrm{s}} \cdot \overrightarrow{\mathrm{E}}
$$

e $\quad \sigma_{\mathrm{s}}=\frac{1}{\rho_{\mathrm{s}}}$

então,

$$
\vec{E}=-\frac{1}{\sigma_{s}} \cdot \frac{I_{0}}{2 \pi r} \vec{a} z
$$

Assim, pode-se calcular o potencial elétrico dado por:

$$
V_{A B}=-\int_{0}^{l} \vec{E} \cdot d \vec{l}
$$

portanto:

$$
V_{A B}=\int_{0}^{l}\left(\frac{I_{0}}{2 \pi r} \cdot d z\right)
$$

então,

$$
V_{A B}=\frac{I_{0}}{\sigma_{s} \cdot 2 \pi r} l
$$

Ou seja, a resistência superficial pode ser expressa por:

$$
R_{s i}=\frac{V_{A B}}{I_{0}}=\frac{1}{\sigma_{s} \cdot 2 \pi r} l
$$

Considerando-se agora a capacitância $\mathrm{C}_{\mathrm{a}}$ da amostra, tem-se:

$$
C_{a}=\sum_{i=1}^{N} C_{i}=\sum_{i=1}^{N} \frac{\varepsilon A_{i}}{l} \approx \frac{\varepsilon A_{\text {total }}}{l}
$$


$\mathrm{Na}$ ausência de umidade, a consideração dos revestimentos têxteis como uma associação de suas fibras, na verdade, conduz aos mesmos resultados apresentados no capítulo IV. Contudo, quando a umidade do ar se encontra presente, a resistência volumétrica e capacitância de suas fibras praticamente não se alteram; mas não é o caso da resistência superficial, que tem seu valor extremamente reduzido, tornando-se o elemento que mais influencia o modelo.

$\mathrm{Na}$ presença de umidade, o processo de dissipação de cargas elétricas ocorre através da dissociação das moléculas em íons $\mathrm{H}^{+}$e $\mathrm{OH}^{-}[41]$. $\mathrm{O}$ que acontece nas fibras do tapete ou do carpete é que suas camadas da superficie adsorvem grande quantidade de água com o aumento da umidade relativa. Dessa maneira, o decréscimo da resistividade superficial, com o aumento da umidade relativa, é atribuído ao aumento de mobilidade das moléculas aquosas nas camadas superiores da fibra. Dados experimentais demostram que tendo-se um aumento da umidade relativa em $20 \%$, a resistividade superficial cai para aproximadamente um décimo de seu valor inicial [41].

Assim, na presença de umidade, a resistência superficial das fibras tem seu parâmetro de resistividade fortemente alterado, não mais permanecendo constante, devendo ser escrita como:

$$
R_{s i}=\rho_{s}(U R A \%) \cdot \frac{l}{2 \pi r}
$$

Existem, na literatura, poucos estudos sobre o comportamento da resistividade superficial de materiais em relação à umidade. Um desses estudos deve-se a Tadashi, Sato, Sakada e Okada [41], que mediram o decaimento da resistividade superficial do vidro na presença de umidade. Seus resultados encontram-se ilustrados na figura 6.3. 


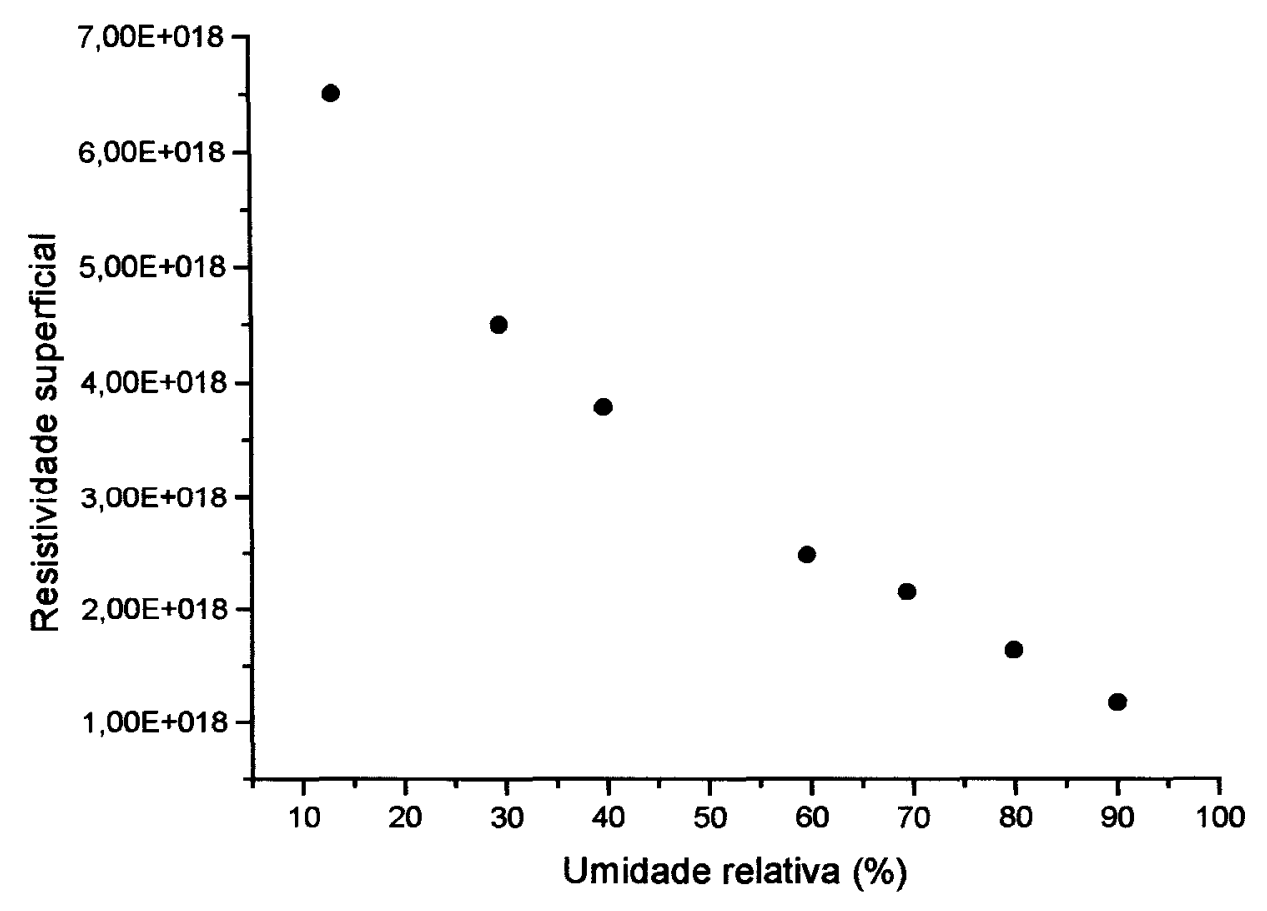

Figura 6.3: Gráfico do comportamento da resistividade superficial na presença de umidade, de uma amostra de vidro [41]

Assumindo, em primeira aproximação que os polímeros e, por conseqüência, as fibras dos tapetes e carpetes tenham um comportamento semelhante ao do vidro, pode-se determinar da figura 6.4 que a resistividade superficial tem a forma exponencial dada por:

$$
\rho_{s}(U R A \%)=\rho_{s 0}+A_{1} \cdot e^{\left(-\left(U R A \%-U R A_{0} \%\right) / T_{0}\right)}
$$

com $\rho_{s o}, A_{l}$ e URA $A_{0}$ constantes características de cada material e $\mathrm{T}_{0}$ o tempo de decaimento de cargas. 


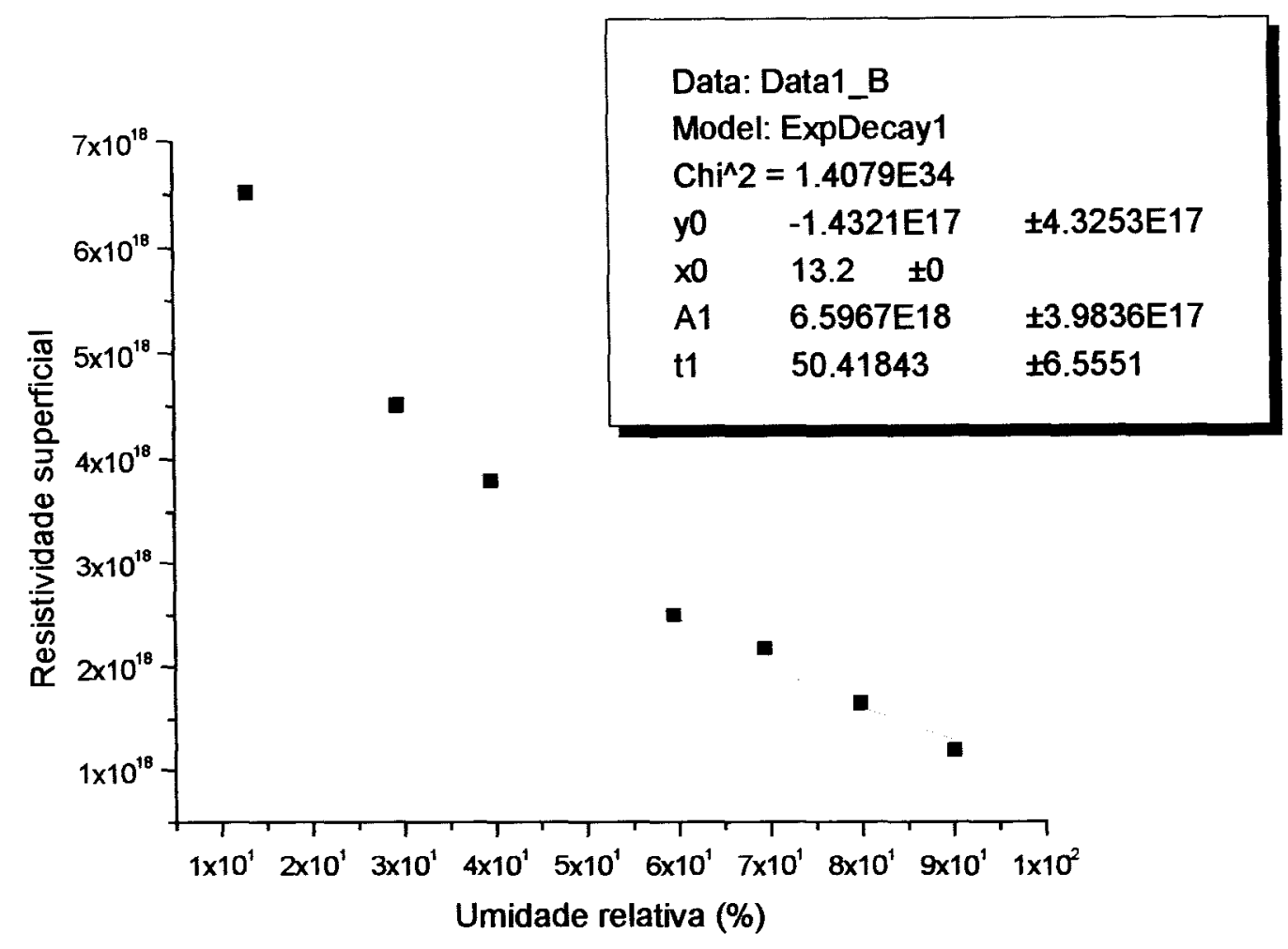

Figura 6.4: Análise exponencial de primeira ordem do gráfico da figura 6.3, com

$$
f(x)=y_{0}+A_{1} \cdot e^{\left(-\left(x-x_{0}\right) / t_{1}\right)}
$$

Substituindo (6.14) em (6.13):

$$
R_{s i}=\left(\rho_{s 0}+A_{1} \cdot e^{\left(-\left(U R A \%-U R A_{0} \%\right) / T_{0}\right)}\right) \cdot \frac{l}{2 \pi r}
$$

Como, na expressão (6.2), as resistências volumétricas das fibras são muito elevadas, a resistência volumétrica da amostra passa a ser função apenas das 
resistividades superficiais das fibras. Portanto, substituindo-se a expressão (6.15) em (6.2), tem-se uma expressão que permite estimar a resistência volumétrica das amostras em função da umidade:

$$
R_{y} \approx \frac{\left(\rho_{s 0}+A_{1} \cdot e^{\left(-\left(U R A \%-U R A_{0} \%\right) / T_{0}\right)}\right) l}{2 \pi r N}
$$

sendo $\mathrm{N}$ o número total das fibras da amostra.

Com a expressão (6.16) torna-se fácil entender a grande influência da umidade nas medições efetuadas e, também, o processo físico envolvido nos processos antiestáticos, que empregam a umidificação de ambientes e também o tratamento químico dos revestimentos têxteis. Torna-se também possível compreender porque revestimentos com base condutora são muito mais eficientes que os de base isolante. Nos últimos, as cargas elétricas, escoando superficialmente pelas fibras, ficam retidas em sua base isolante, o que não ocorre com os de base condutora. Contudo, ainda é preciso melhor validar a expressão (6.16), o que dá margem para futuros trabalhos.

Tomando-se como exemplo a amostra de tapete de número 10 , com $\tau=17 \mathrm{~s} \mathrm{e}$ fazendo-se:

$$
\tau=R . C
$$

e ainda,

$$
C=\frac{\varepsilon \cdot \varepsilon_{0} \cdot A}{d}
$$

sendo:

$$
\begin{aligned}
& A=\pi \cdot r^{2}=\text { área da amostra }=\pi \cdot\left(2,25 \times 10^{-2}\right)^{2} ; \\
& d=\text { espessura da amostra }=0,52 \mathrm{~cm} \\
& \therefore \mathrm{C}=1,35 \times 10^{-11} \mathrm{~F} .
\end{aligned}
$$

e $R_{v}=1,5 \times 10^{11} \Omega$. 
Estimando-se a resistividade volumétrica pela expressão (6.19) tem-se:

$$
R_{v}=\rho_{v} \cdot \frac{l}{2 . \pi \cdot r \cdot N}
$$

sendo: $\quad l=$ comprimento da fibra $-0,52 \mathrm{~cm}$;

$$
r=\text { raio da fibra }=0,02 \times 10^{-3} \mathrm{~m} \text {, }
$$$$
N=\text { número de fibras na amostra }=100.000 \text { fibras }
$$

obtém-se : $\quad \rho_{v}=5,2 \times 10^{11} \Omega$ m, caracterizando o material como isolante de acordo com a figura 6.5 .

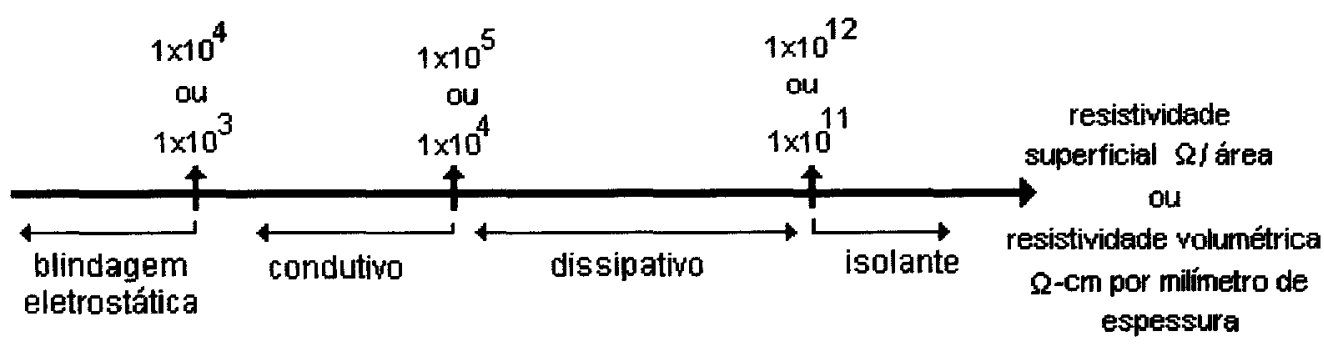

Figura 6.5: Resistividade superficial ou resistividade volumétrica, relacionada com as características eletrostáticas dos materiais,segundo a Norma EIA - 541 [22]

Utilizando-se a equação (6.16) com o valor de $R_{v}=1,5 \times 10^{11} \Omega$ e admitindo-se um aumento de $10 \%$ na URA, o valor da resistividade superficial das fibras é $4 \times 10^{15} \Omega / a ́ r e a$, o que remete a um valor de $R_{v}$ de $10^{10}$, que já está na faixa de material dissipativo.

Com esse exemplo conclui-se que diferentemente da resistividade volumétrica, nos tapetes, a resistividade superficial sofre uma influência muito maior do que a indicada na figura 6.5, no caso do vidro, ou seja, a curva exponencial apresentada na figura 6.5, tende a ser muito mais íngreme para o caso das fibras de tapete, dada a maior influência da umidade, sofrida pelas suas fibras. A resistividade superficial decai acima de dez mil vezes, com um aumento de $50 \%$ na URA. 


\title{
CAPÍTULO VII
}

\section{CONCLUSÃO}

\author{
Neste capitulo, estão descritas as \\ vantagens de se empregar o método \\ proposto neste trabalho para a caracterização \\ eletrostática de tapetes e carpetes.
}

Neste trabalho foi desenvolvida uma nova metodologia para a caracterização eletrostática de revestimentos têxteis, incluindo um protótipo laboratorial.

Desse protótipo destaca-se sua câmara de ionização e de medição, totalmente diferente daquelas anteriormente propostas, no que se refere à configuração eletrodos/amostra, carregamento, isolação elétrica e controle de umidade no seu interior.

Desenvolveu-se também um programa computacional para o controle de todas as partes do equipamento e processo de medição. Dessa forma, o protótipo possibilita que medidas sejam efetuadas praticamente sem qualquer manipulação humana, sendo esta concentrada apenas na preparação e colocação das amostras no interior da câmara de ionização.

Quanto aos processos de medição, o programa determina inicialmente o tempo de decaimento de cargas elétricas geradas por descarga corona e depositadas nas amostras.

Depois, considerando as capacitâncias das amostras como sendo da ordem de $10^{-11} \mathrm{~F}$, tornou-se possível a determinação da ordem de grandeza das resistências volumétricas das amostras e, com isto, classifica-las conforme procedimentos da Norma STANDARD EIA 541 [22], em material condutivo, isolante ou dissipativo.

A classificação empregando a ordem de grandeza é uma das grandes contribuições deste trabalho, porque torna a metodologia robusta e possibilita que pequenos desvios entre valores medidos em uma mesma amostra sejam perfeitamente tolerados. 
Esta metodologia apresenta, também, outras vantagens: permite eliminar a sala climatizada e os procedimentos trabalhosos definidos por normas internacionais para este tipo de caracterização; possui dimensões reduzidas; e baixíssimo custo.

Também fez parte deste trabalho o equacionamento completo da câmara de ionização e de medição, o que possibilitou não só melhor visualização de todos os fenômenos envolvidos, mas também solucionar muitos dos problemas encontrados.

Foi também apresentada, no capítulo VI, uma nova modelagem dos revestimentos têxteis através da associação em paralelo dos circuitos equivalentes representativos de suas fibras poliméricas.

A principal contribuição dessa abordagem é a de permitir incluir nos equacionamentos a influência da umidade nos processos de medição. Usando essa modelagem, é possível também, explicar os fenômenos físicos dos tratamentos anti-estáticos de revestimentos têxteis, como é o caso do tratamento químico de suas fibras e da umidificação do ambiente.

Embora tenham sido concluídos todo o protótipo e a metodologia de caracterização, muito ainda necessita ser feito. Dentre os trabalhos futuros podem-se citar:

- empregar a tecnologia dos microcontroladores para tornar o sistema computacional totalmente dedicado e muito mais amigável aos usuários,

- projetar novas câmaras, que facilitem a colocação de amostras em seu interior e que sejam silenciosas, utilizando um mecanismo diferente do alto-falante para promover a suspensão necessária para a vibração senoidal do capacitor vibrante; $\mathrm{e}$

- melhor validar a expressão 6.16 quanto à influência da umidade, através de ensaios e grande quantidade de amostras de revestimentos têxteis. 


\section{ANEXO I}

\section{MANUAL DO USUÁRIO DO PROGRAMA COMPUTACIONAL AD32}

\section{INTRODUÇÃO}

\section{I.1. PROGRAMA AD32}

O Programa Computacional AD32 foi desenvolvido por Canova [35] com o objetivo de obter todas as operações desejadas e disponíveis na placa de aquisição de dados $\mathrm{LAB} \mathrm{PC}^{+}$, de maneira fácil e rápida, tornando a interface entre o usuário e o equipamento para medição do decaimento eletrostático de tapetes e carpetes dependente exclusivamente do programa computacional.

Na figura I.1 tem-se o ícone do programa AD32, disponível em ambiente Windows.

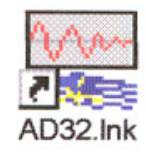

Figura I.1: Ícone do programa computacional AD32 


\section{I.2. PLACA LAB PC ${ }^{+}$}

A placa $\mathrm{AD}$ utilizada foi a modelo $\mathrm{LAB} \mathrm{PC}^{+}$fabricada pela National Instruments Corporate Headquarters, a qual é instalada internamente no microcomputador, propiciando uma forma prática e acessível de implementação de um sistema analógico/digital (A/D) de medição e aquisição de dados, utilizando um microcomputador para as medições e análise dos dados.

\section{I.3. OBJETIVOS}

O programa $\mathrm{AD} 32$ tem como metas:

1 - Controlar todas as etapas de funcionamento do equipamento para medição do decaimento do potencial eletrostático de tapetes e carpetes;

2 - Facilitar a utilização do equipamento, bem como promover a segurança do usuário no que se refere à etapa que ocorre com a presença de alta tensão, durante o carregamento;

3 - Utilizar o computador como instrumento de medição, aquisição e análise dos dados obtidos com os testes realizados.

\section{I.4. CONFIGURAÇÃO MÍNIMA}

A configuração mínima necessária para a perfeita operação do programa computacional $\mathrm{AD} 32$ é:

1 - Pentium I - 100MHz;

2 - $32 \mathrm{Mb}$ de memória RAM;

3 - HD de 4.3G;

4 - Windows 95. 


\section{I.5. ESPECIFICAÇÃO DO PROGRAMA AD32}

O programa computacional AD32 disponibiliza as seguintes opções:

\section{- Entrada do programa:}

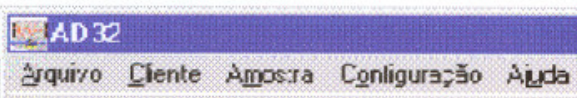

Figura I.2: Entrada do programa

Nesta tela é iniciada a utilização, pelo usuário, do programa computacional AD32, com as opções de Arquivo, Amostra, Configuração e Ajuda, que serão apresentadas no item II. CONTEÚDO.

\section{- Arquivo:}

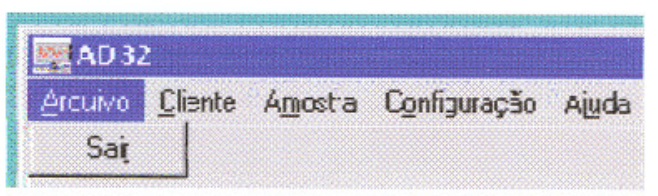

Figura I.3: Opção arquivo

Essa opção dá acesso à saída do programa AD32. 


\section{- Cliente:}

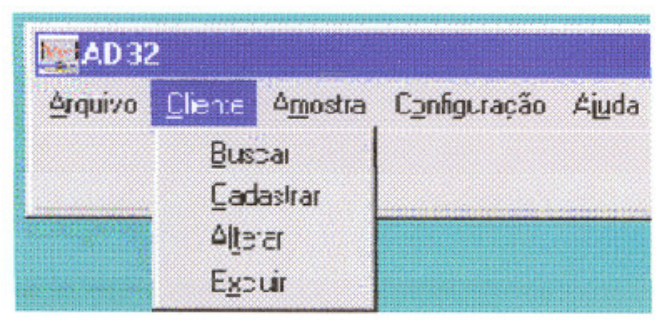

Figura I.4: Opção cliente

A opção Cliente permite ao usuário obter todas as informações, já cadastradas, sobre os clientes como, por exemplo, nome, endereço, CIC e RG.

Nesse mesmo campo (Cliente), existe a opção Cadastrar, através da qual temos acesso à ficha para cadastro de um novo cliente.

Quando a opção Alterar é acionada, tem-se acesso à ficha de alteração dos dados de um cliente já cadastrado, para que se possa, então, alterar algum dado já existente, por exemplo, o endereço.

É por meio do comando Excluir que um cliente é excluído do banco de dados.

- Amostra:

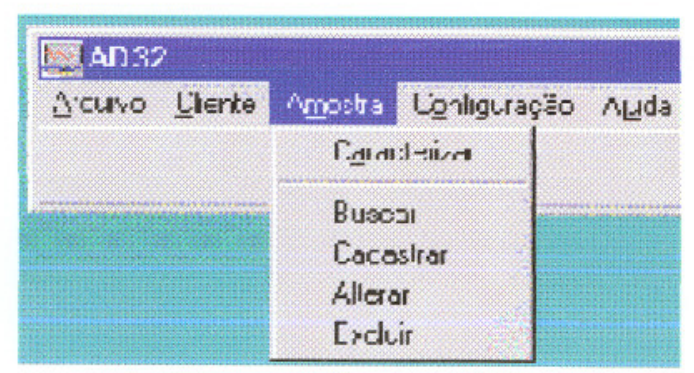

Figura I.5: Opção amostra 
Nesta tela, o usuário terá acesso ao comando de caracterização da amostra a ser testada por meio da opção Caracterizar, pela qual se abre a tela para a aquisição da forma de onda do decaimento eletrostático da amostra. Também fazem parte desta tela as opções Buscar, por meio da qual pode-se buscar os dados de uma amostra já cadastrada e já caracterizada; Cadastrar, para cadastro de uma nova amostra; Alterar, opção que dá acesso à ficha cadastral das amostras previamente cadastradas, para uma eventual mudança de dados e Excluir, opção pela qual uma amostra pode ser excluída do banco de dados do programa.

\section{- Configuração:}

A opção Configuração dá acesso aos parâmetros de controle do sistema, como será detalhado no item II. CONTEÚDO.

- Ajuda:

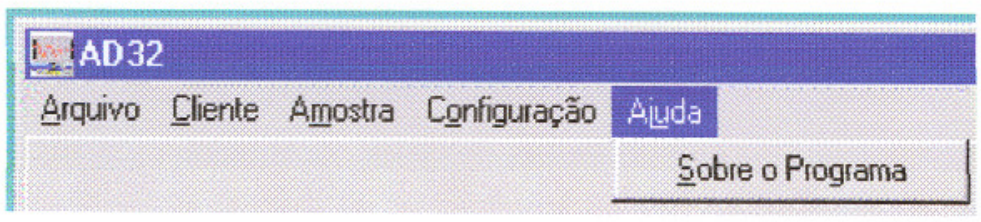

Figura I.6: Opção ajuda

Na opção Ajuda o usuário obterá todas as respostas para eventuais dúvidas que surgirem no decorrer do processo de utilização do programa computacional AD32. 


\section{I.6. RECURSOS UTILIZADOS}

1 - Sistema operacional Windows 95X;

2 - Linguagem Delphi 4.0.

\section{I.7. INSTALAÇÃO}

Ao entrar no ambiente Windows, insira o disco ou o CD de instalação, contendo o programa computacional AD32, no respectivo drive $\mathrm{e}^{12}$, clique no menu Iniciar do Windows; em seguida, clique em Executar e digite a: $\backslash$ Setup (se o disco ou o CD de instalação estiver no drive a). Feito isso, siga as instruções que aparecerão na tela.

Para inicializar o programa, dê duplo clique no ícone AD32.

\section{CONTEÚdO}

Neste item descrevem-se todos os comandos existentes em cada tela do programa computacional AD32.

\section{I.1. ENTRADA DO PROGRAMA}

Ao dar um duplo clique no ícone AD32, aparecerá a tela mostrada na figura I.7, com as opções Arquivo, Cliente, Amostra, Configuração e Ajuda, como será descrito a seguir.

12. Drive é a entrada, para o disco ou $\mathrm{CD}$, existente no microcomputador. 
Figura I.7: Tela de entrada do programa AD32

\section{II.2. ARQUIVO}

Quando a opção Arquivo é acionada, como mostra a figura I.8, tem-se acesso à saída do programa.

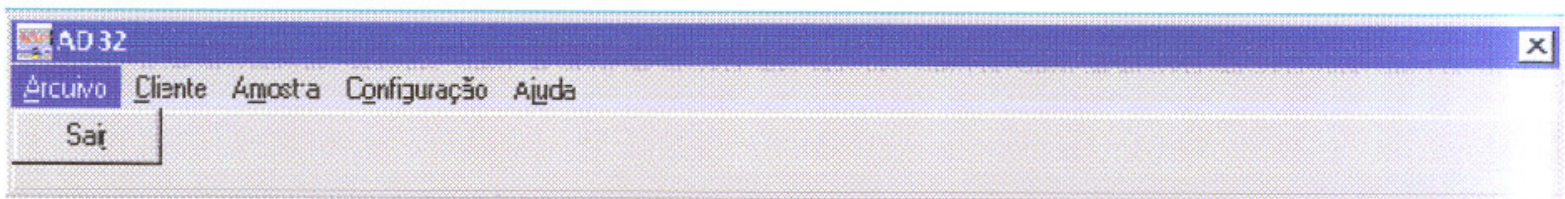

Figura I.8: Opção para sair do programa AD32

Para sair, basta dar um clique em Sair, e a tela apresentada na figura I.9 aparecerá.

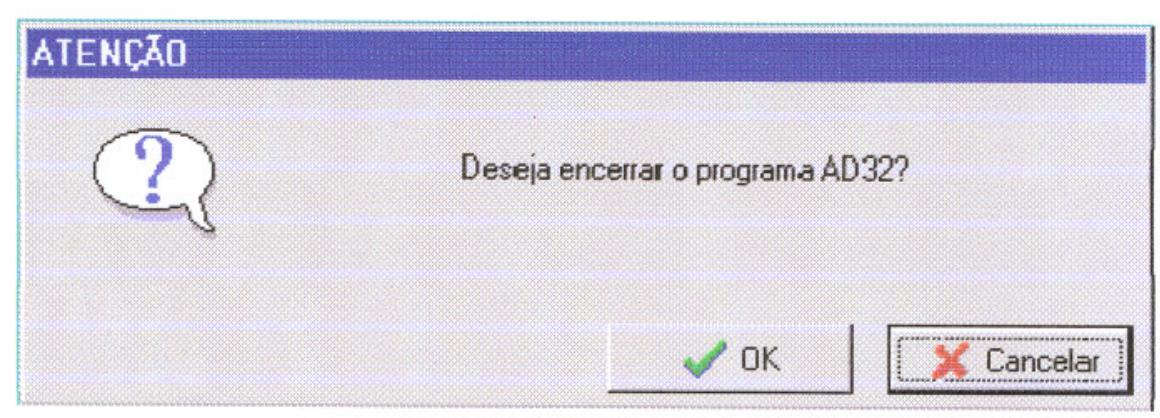

Figura I.9: Tela para finalizar o uso do programa AD32 
Optando-se por OK, na tela de saída apresentada na figura I.9, acontece a saída do programa; optando-se por Cancelar, volta-se para a tela de entrada do programa.

\section{II.3. CLIENTE}

Na opção Cliente, mostrada na Figura I.10, encontram-se também disponíveis as opções Buscar, Cadastrar, Alterar e Excluir.

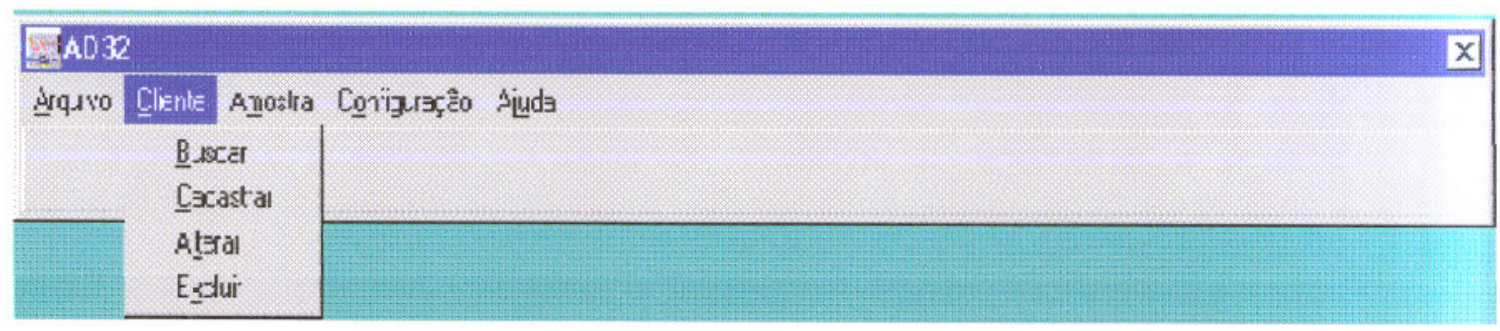

Figura I.10: Tela da opção Cliente

Clique em Buscar, caso queira ter acesso aos dados de um cliente previamente cadastrado; aparecerá então, a tela mostrada na figura I.11.

Selecione o tipo de busca, ou seja, se a busca será efetuada pelo código do cliente, pelo CIC ou RG, pelo RG/ Inscrição Estadual ou pelo nome e endereço, e clique em Buscar; assim, aparecerão os dados do cliente procurado.

Para fazer outra busca, basta dar um clique em OK, e para cancelar esta busca, clique em Cancelar.

Clique em Amostras para saber de que amostra o cliente buscado é fornecedor. 


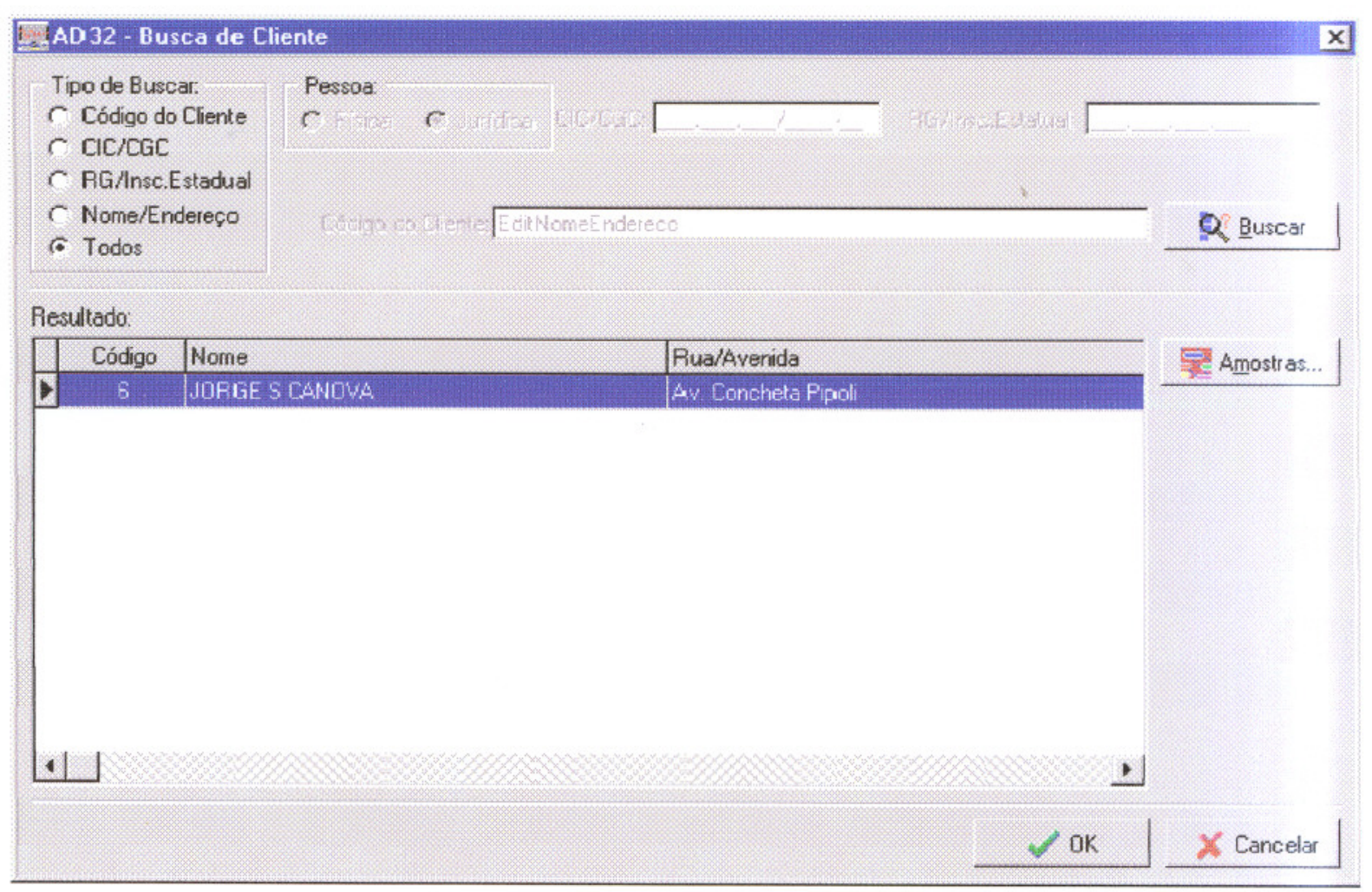

Figura I.11:Tela de busca do cliente

Clique em Cadastrar para que apareça a tela apresentada na figura I.12, destinada ao cadastro de um novo cliente. Basta digitar as informações solicitadas nos devidos campos e, para que esta ficha fique disponível no banco de dados, clicar em Cadastrar.

Clique em Restaurar para voltar ao início da Ficha de Cadastro do mesmo cliente.

Clique em Buscar para ter acesso à tela anterior, de Busca de Cliente.

Clique em Cancelar para retornar à tela de entrada do programa. 


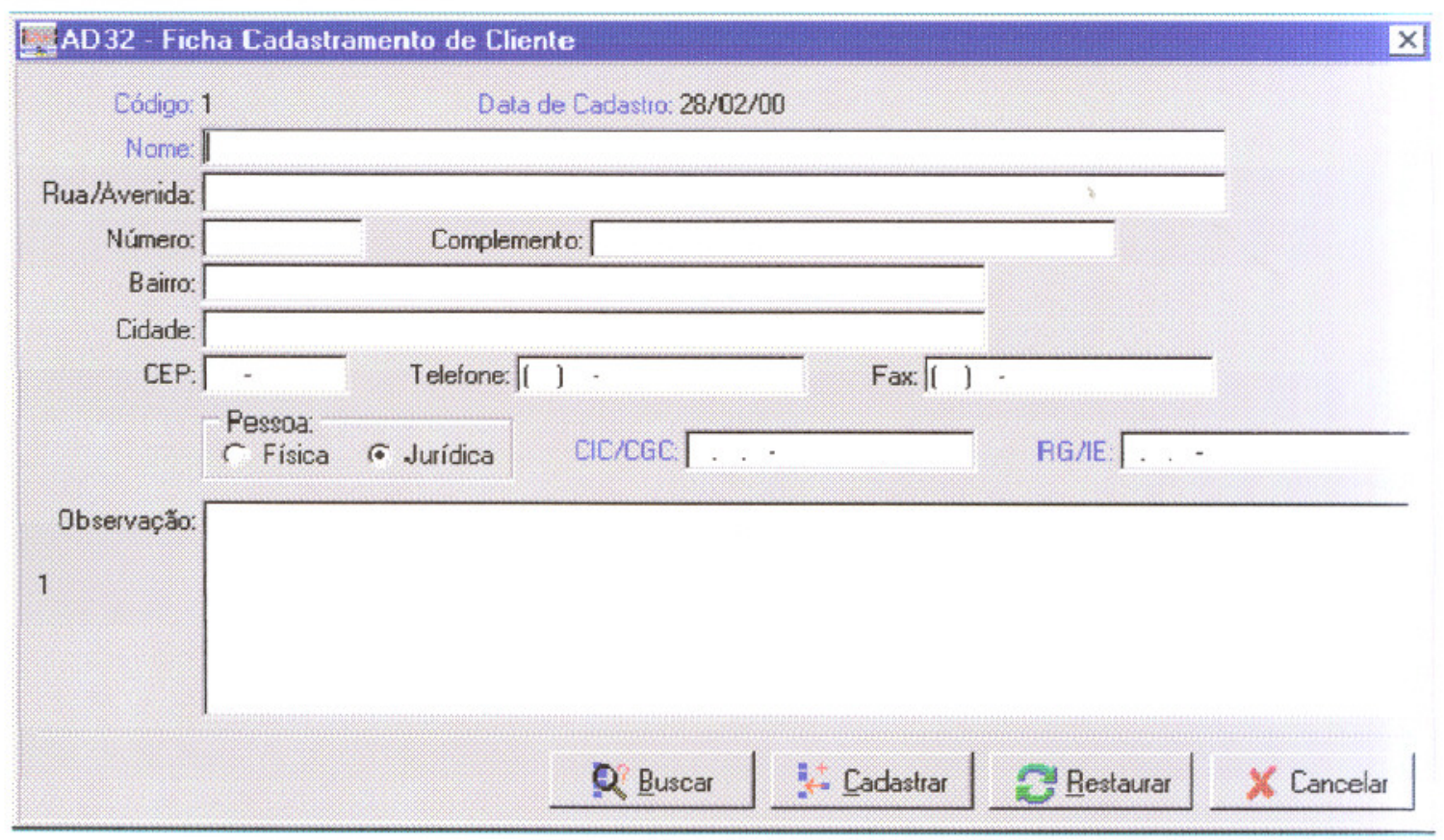

Figura I.12: Cadastro do cliente

Clique em Alterar, na tela de opção Cliente, para ter acesso à Ficha de Alteração de dados de Cliente, cuja tela é mostrada na figura I.13.

Marque os dados a serem alterados e os digite novamente no campo correspondente. Clique em Alterar, para que sejam gravadas as novas informações no banco de dados.

Clique em Restaurar para voltar ao campo inicial, ou seja, Nome.

Clique Buscar para retornar à tela de Busca do Cliente.

Clique em Cancelar para retornar à tela de entrada do programa. 


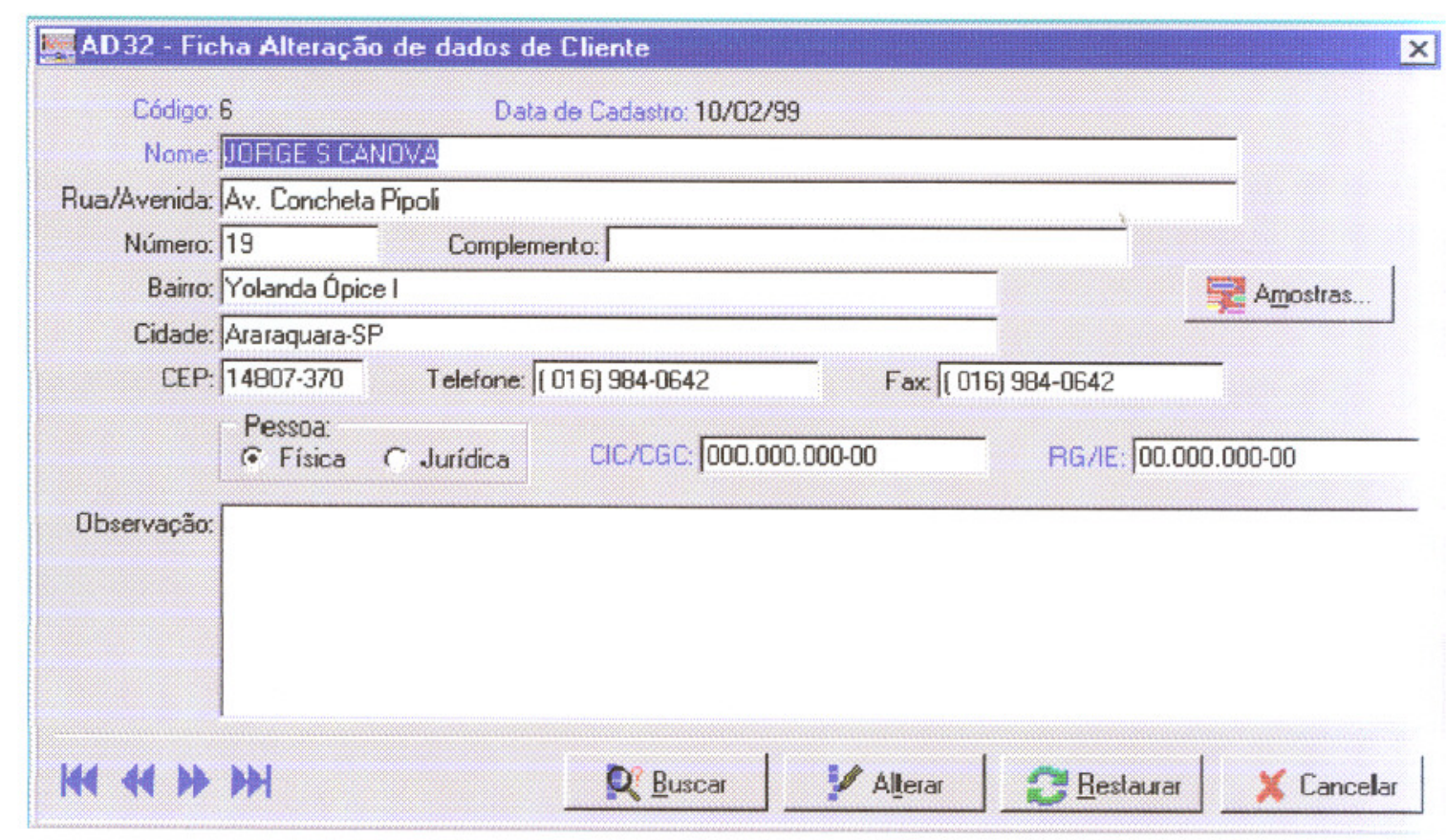

Figura I.13: Alteração dos dados de um cliente

Na figura I.15 pode-se ver a tela de acesso à opção Ficha de Exclusão de Cliente.

A partir da tela da opção Cliente, clique em Excluir e usando a tela apresentada na figura I.15, clique em Avançar ou Voltar - procura lenta, ou Avançar e Voltar procura rápida, cujo símbolo está representado na figura I.14, para escolher o cliente a ser excluído.

Clique em Amostras para saber de que amostra o cliente a ser excluído é fornecedor.

\section{IH 4 W}

Figura I.14: Botões para procura de cliente - procura lenta e rápida 


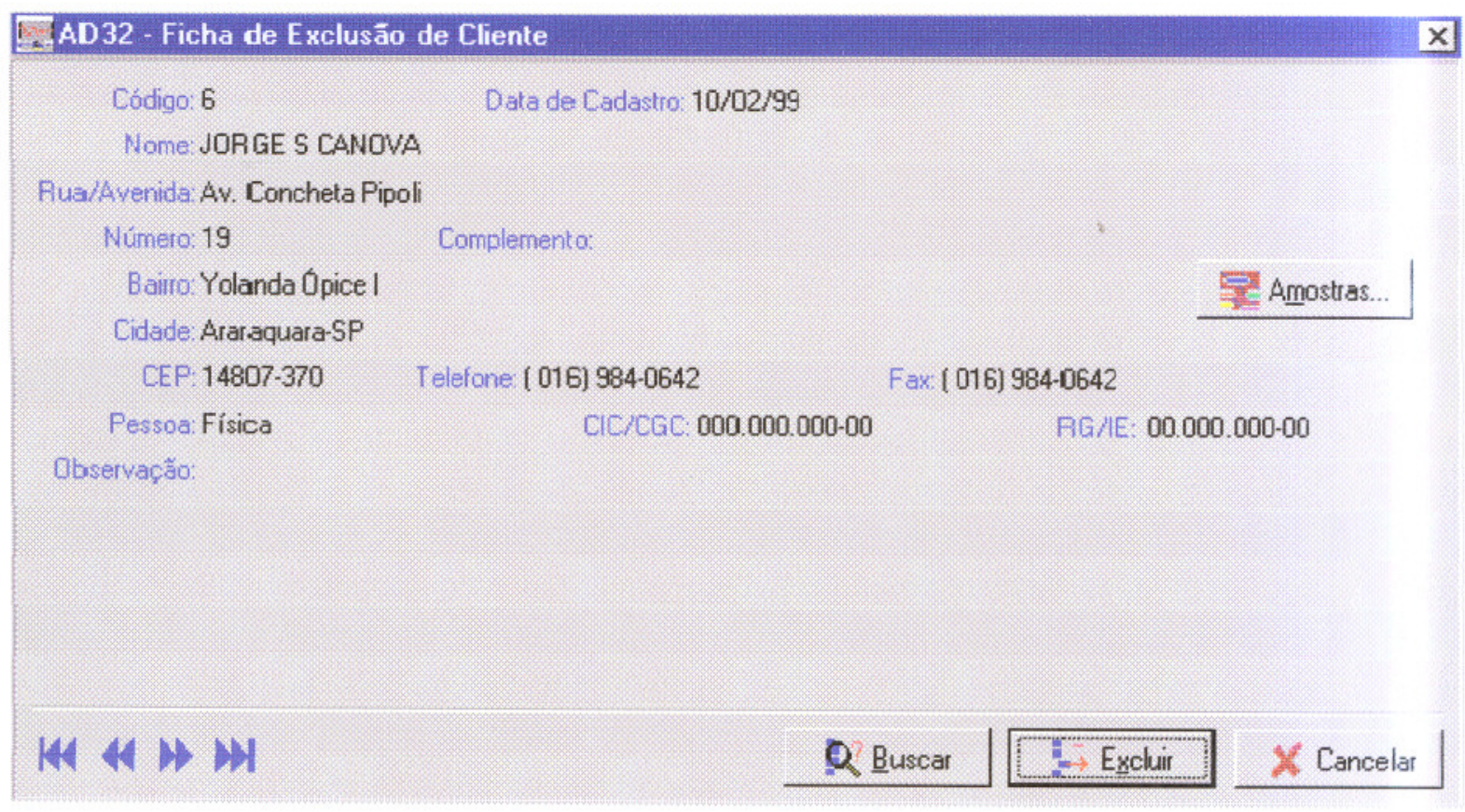

Figura I.15: Excluir os dados de um cliente

\section{II.4. AMOSTRA}

Na opção Amostra, mostrada na figura I.16, tem-se acesso às opções Buscar, Cadastrar, Alterar e Excluir, como será citado a seguir.

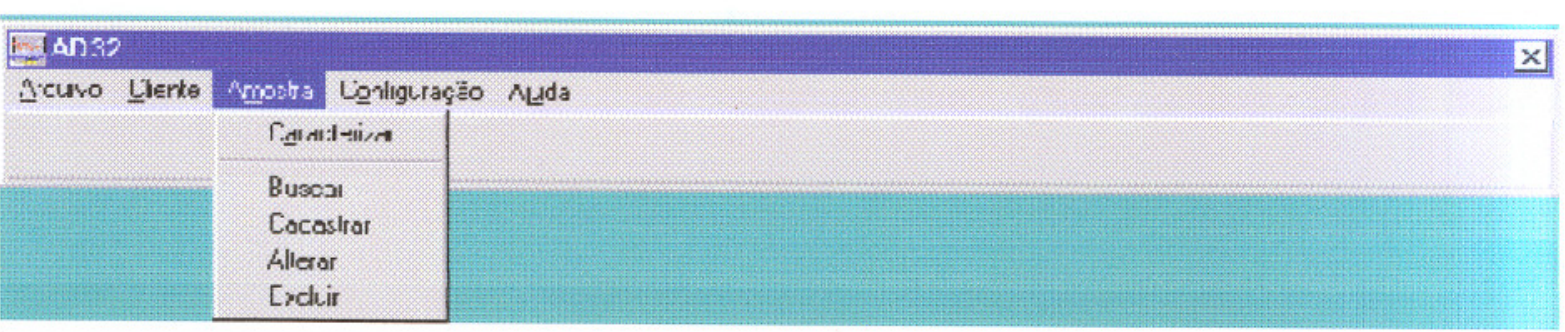

Figura I.16: Amostra 


\section{II.5. CARACTERIZAÇÃo dA AMOSTRA}

Por meio do comando Caracterizar, tem-se acesso à tela para Caracterização da Amostra, (figura I.17).

Clique em Caracterizar para acionar o carregamento da amostra e a aquisição dos dados do carregamento dela.

Clique em Copiar Curva para copiar a forma de onda do decaimento eletrostático adquirido pela placa de aquisição de dados utilizada. Para copiá-la, basta estar num aplicativo do Windows do tipo Paint Brush, por exemplo, e clicar em Editar e depois Colar.

Clique em Limpar Dados para começar uma nova caracterização de amostra.

Clique em Salvar para guardar os dados da forma de onda do decaimento eletrostático, num determinado arquivo.

Clique em Cancelar para voltar à tela de entrada do programa AD32.

Clique em Configurar para ter acesso à tela com os comandos para a configuração da temporização do sistema, ou seja, tempo de carregamento, tempo de aquisição e tempo de atraso. A tela de Configuração do Sistema é mostrada na figura I. 22 .

Nos campos Temperatura, Pressão e Umidade, podem-se escrever os dados relativos às condições ambientais em que o ensaio está sendo realizado; para tanto, apenas coloque o cursor sobre o campo desejado, dê um clique e escreva a informação desejada.

No campo Auto Escala de Tensão tem-se a opção de ajuste da curva do decaimento eletrostático adquirida.

É nessa tela que se obtêm os dados da tensão referentes ao Pico Máximo e Pico de Meia-Vida, bem como os dados dos tempos de Tensão Máxima, de Pico Máximo, de Meia-Vida e o valor da constante de decaimento $(\tau)$ da amostra testada. 


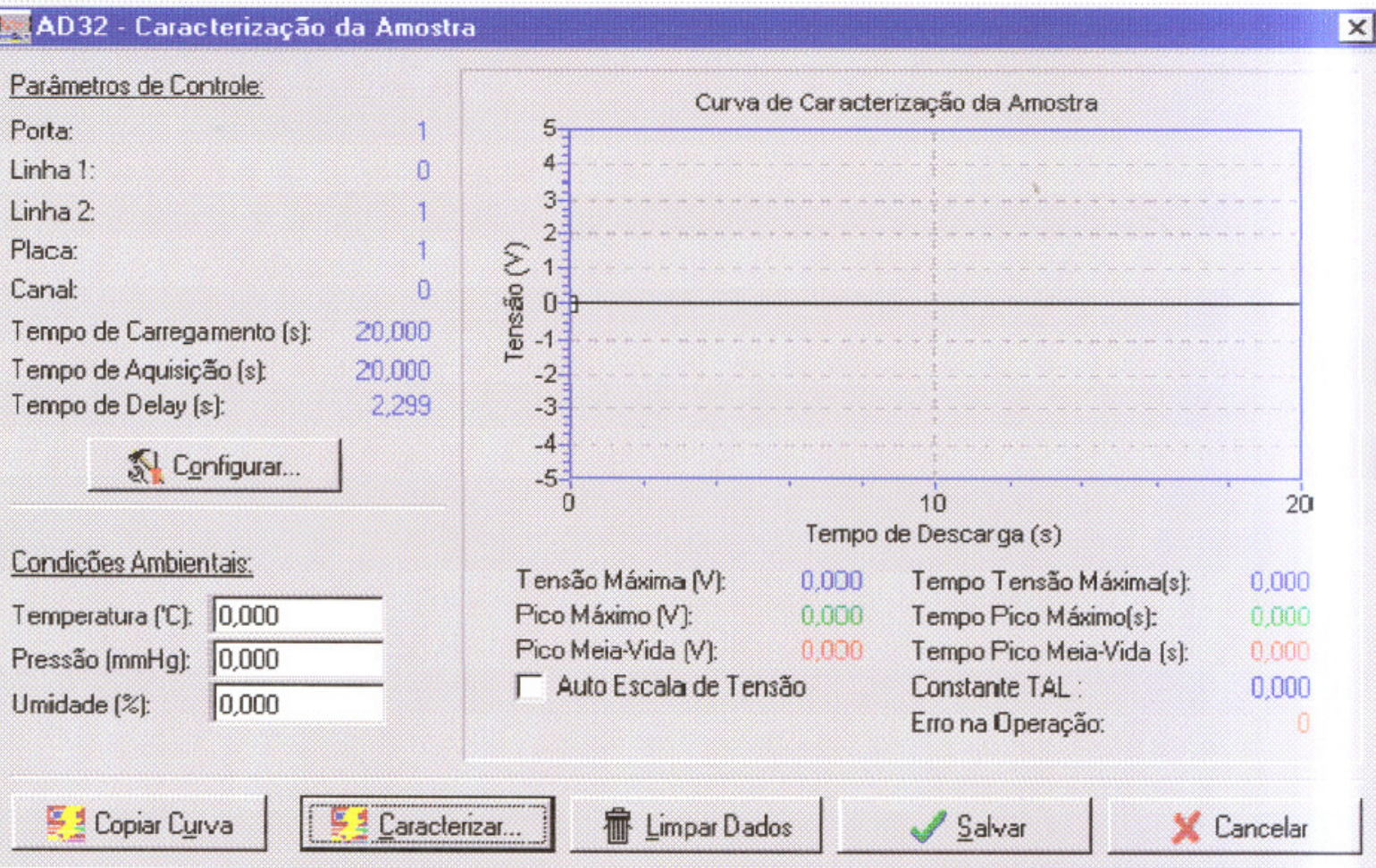

Figura I.17: Tela da caracterização das amostras

Na figura I.18 é mostrada a tela de Busca de Amostra previamente cadastrada.

Selecione o Tipo de Busca por Código do Cliente, Data da Caracterização, Caracterizadas, Não Caracterizadas, Descrição, condições ambientais, Tensão, Tempo ou todas. Preencha o campo respectivo ao tipo de busca selecionado.

Clique em Buscar para obter os dados da amostra procurada.

Clique em OK para sair do programa.

Clique em Cancelar para voltar à tela de entrada do programa AD32. 
Tipo de Buscar:

(c) Código do Cliente

C. Data da Caracterização

$r$ Caracterizadas

C Não Caracterizadas

C Descrição

C Pressão (mmHg)

(C) Temperatura [' $\mathrm{C}]$

C Tensão $(\mathrm{V})$

C Tempo (s)

$r$ Umidade [\%]

C Todas
Cádigo do Cliente: $\longdiv { \text { EditCodigoClien } }$
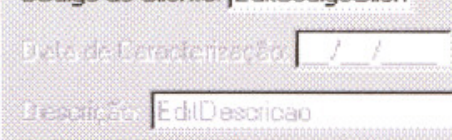

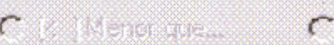

Resultado.

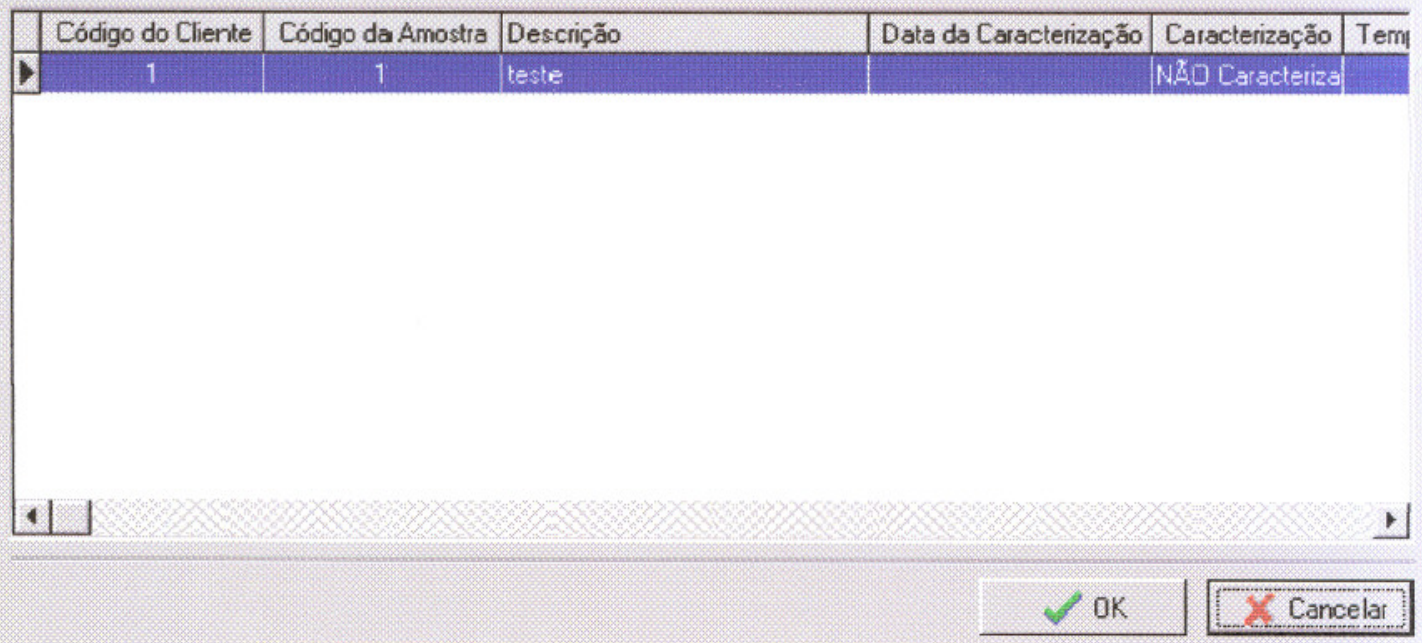

Figura I.18: Busca de uma amostra cadastrada

Por meio do comando Cadastrar, mostrado na figura I.16, tem-se acesso à Ficha de Cadastramento da amostra, mostrada na figura I.19.

Selecione, com um clique nos campos Não Caracterizada ou Caracterizada, a situação da amostra a ser cadastrada.

Preencha o campo Descrição com os dados descritivos da amostra.

Preencha os campos dos dados sobre a caracterização da amostra.

Clique em Cliente para acessar a Ficha de Cadastramento de Cliente, com a qual a amostra se relaciona. 
Clique em Cadastrar para gravar os dados da amostra no banco de dados do programa AD32.

Clique em Restaurar para voltar o cursor ao campo inicial (Descrição).

Clique em Buscar para voltar à tela de Busca de Amostra, mostrada na figura I. 18

Clique em Cancelar para voltar à tela de entrada do programa AD32.

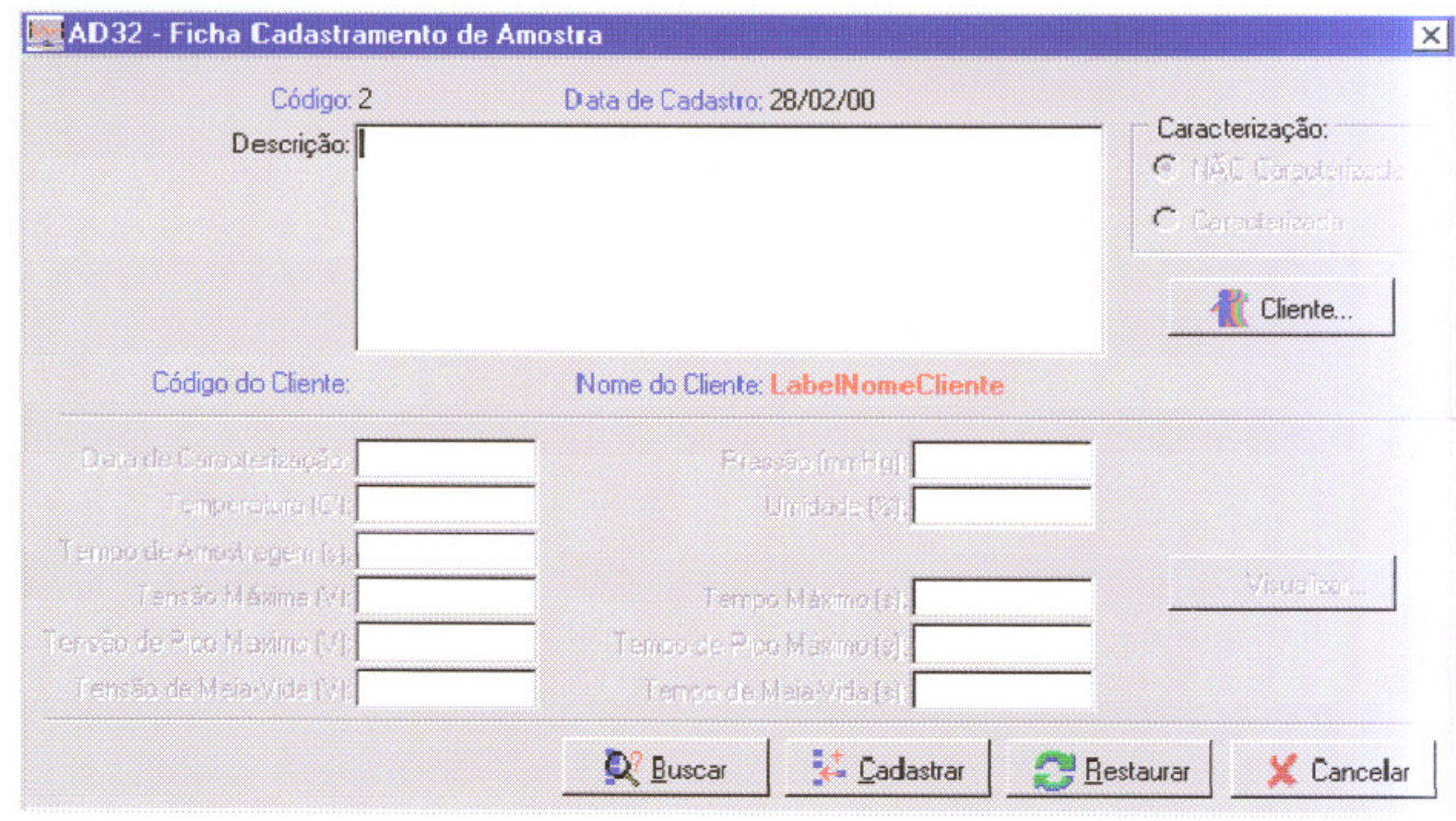

Figura I.19: Cadastro de uma nova amostra

Selecionando a opção Alterar da figura I.16, tem-se acesso à Ficha de Alteração de dados da Amostra, mostrada na figura I.20.

Apague os dados a serem alterados e digite-os novamente, já corrigidos.

Clique em Alterar para que sejam gravadas as novas informações no banco de dados. 
Utilize Avançar ou voltar - procura lenta, ou Avançar ou voltar - procura rápida, cujo símbolo está representado na figura I.14, para escolher a amostra a ser alterada.

Clique em Restaurar para voltar ao campo inicial, ou seja, Descrição.

Clique em Buscar para retornar à tela de Busca de amostra.

Clique em Cancelar para retornar à tela de entrada do programa AD32.

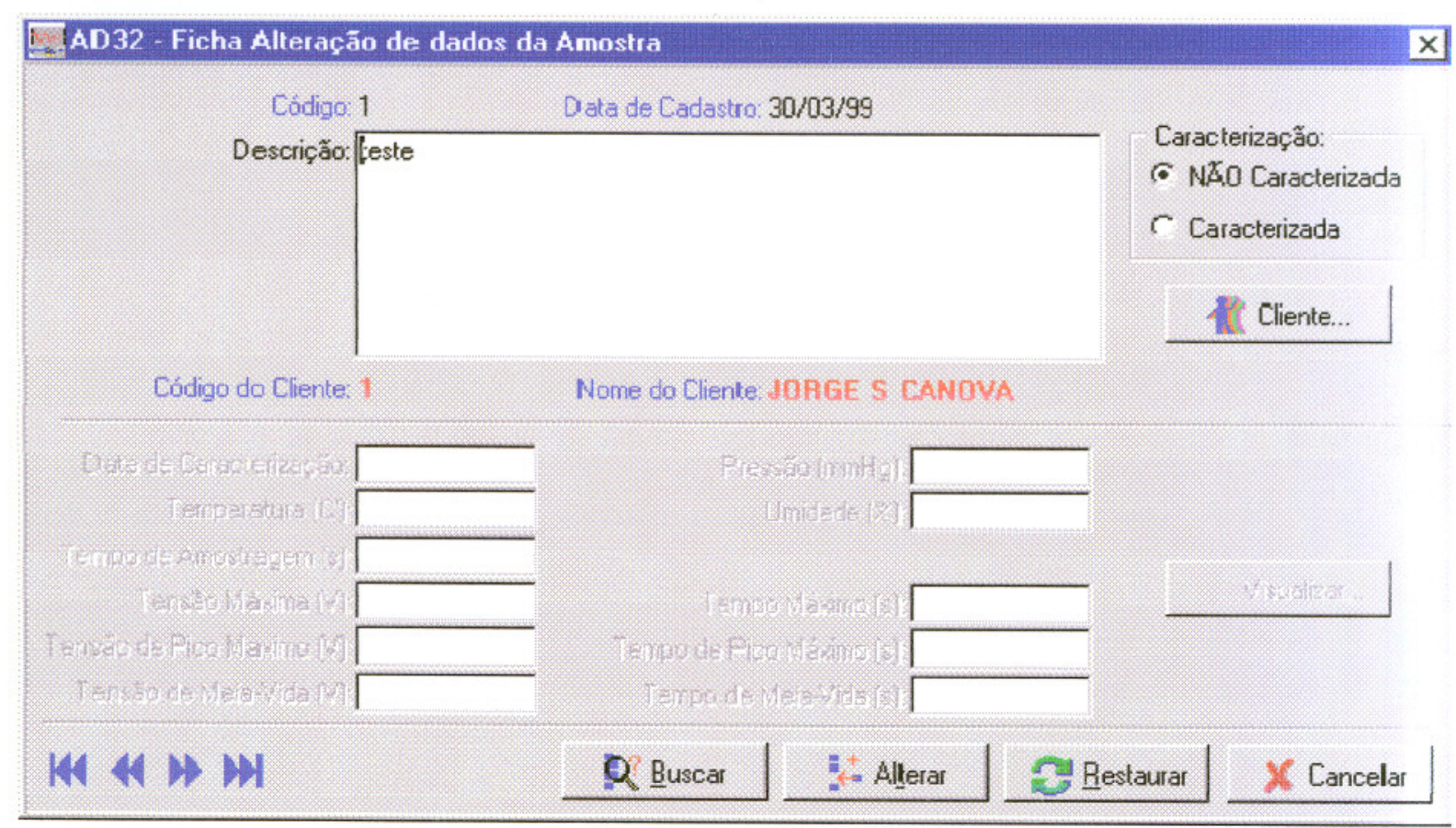

Figura I.20: Tela para alteração dos dados de uma amostra previamente cadastrada

Na figura I.21, pode-se ver a tela de acesso à opção Ficha de Exclusão de Amostra.

A partir da tela da opção Amostra, clique em Excluir e utilizando a tela apresentada na figura I.21, clique em Avançar ou Voltar - procura lenta, ou Avançar e Voltar - procura rápida, cujo símbolo está representado na figura I.14, para escolher a amostra a ser excluída. 
Clique em Cliente para saber a qual cliente pertence a amostra a ser excluída

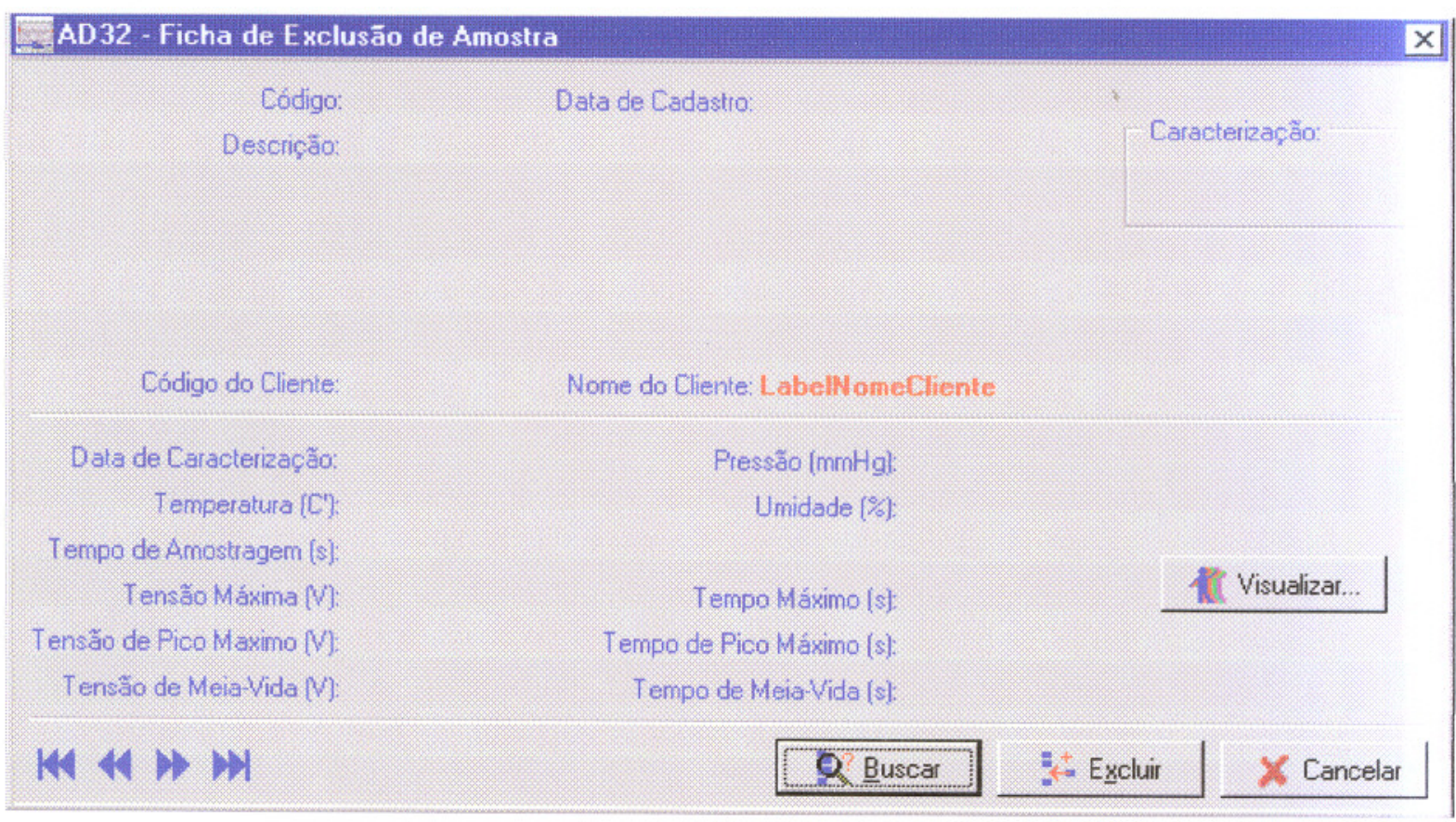

Figura I.21: Tela para excluir uma amostra do banco de dados

\section{II.6. CONFIGURAÇÃO DO SISTEMA}

A partir da tela de entrada do programa AD32, mostrada na figura I.7, selecione a opção Configuração para ter acesso à tela de configuração do programa computacional AD32, mostrada na figura I.22.

Selecione um dos parâmetros de controle do módulo de carregamento, ou seja, uma das portas $\mathrm{P}_{\mathrm{A}}, \mathrm{P}_{\mathrm{B}}$ ou $\mathrm{P}_{\mathrm{C}}$ como entrada de dados para a placa LAB $\mathrm{PC}^{+}$(na tela da figura I.21 foi selecionada a porta $\mathrm{P}_{\mathrm{B}}$ ).

Selecione duas linhas para habilitar as entradas da porta selecionada (na tela da figura I.21 foram selecionada as linhas $\mathrm{L}_{0}$ e $\mathrm{L}_{1}$, sendo habilitadas as entradas $\mathrm{P}_{\mathrm{B} 0}$ e $\mathrm{P}_{\mathrm{B} 1}$ ). 
Selecione agora os parâmetros de controle do processo de aquisição de dados, ou seja, a Placa (na tela da figura I.21 foi selecionado a placa 1, pois só dispomos de uma placa de aquisição de dados), e o Canal para a entrada do sinal do potencial eletrostático (foi ativado o $\mathrm{B}_{\mathrm{CHO} 1 \mathrm{IN}}$ ).

Selecione o Tempo de Carregamento, Tempos de Aquisição, sendo o último necessário para que não haja ruídos na aquisição dos dados do sistema.

Clique em OK para gravar os dados da configuração do sistema.

Clique em Cancelar para manter a configuração anteriormente escolhida.

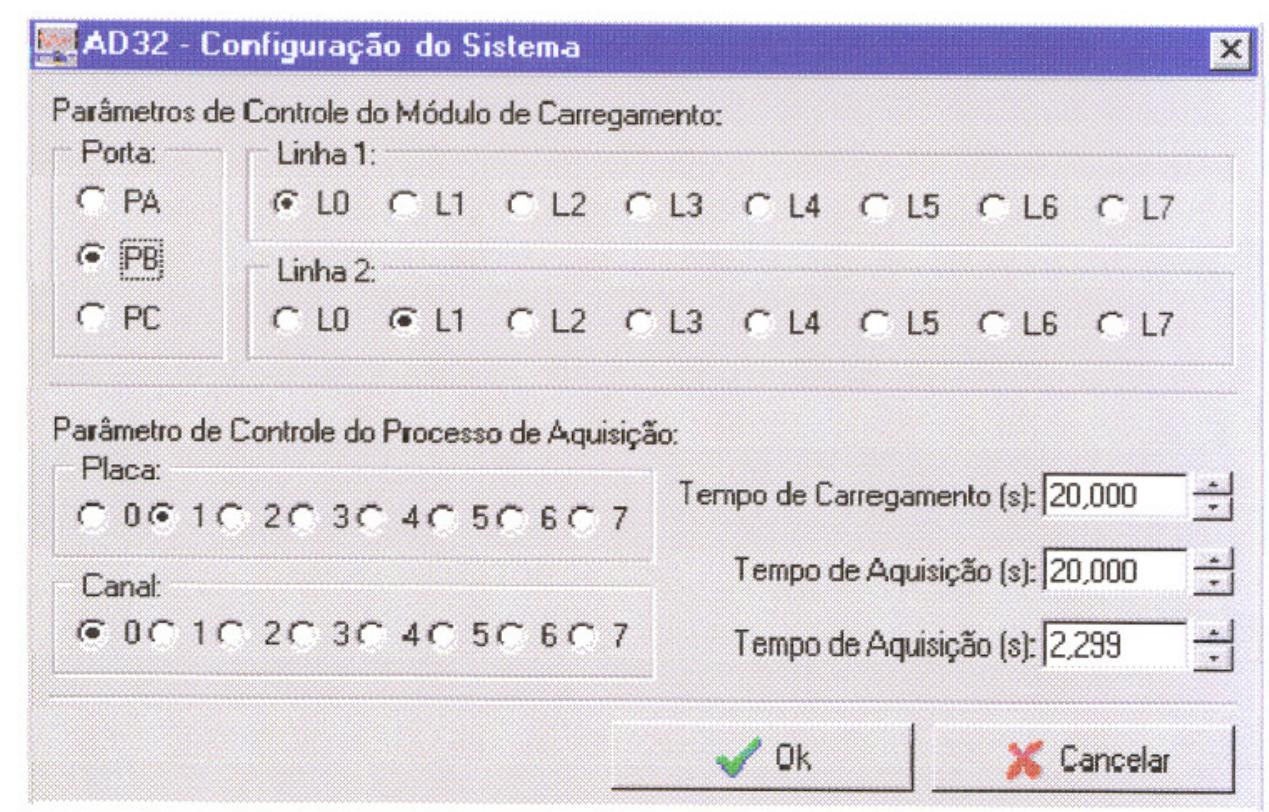

Figura I.22: Tela de configuração do sistema

\section{II.7. AJUDA}

Na figura I.23, clique na opção Ajuda e depois na opção Sobre o Programa para obter os tópicos de ajuda do programa AD32. 
Figura I.23: Tela da opção ajuda 
ANEXO II

\title{
CIRCUITOS CONTIDOS NO EQUIPAMENTO PARA MEDIÇÃO DO TEMPO DE DECAIMENTO DO POTENCIAL ELETROSTÁTICO DE AMOSTRAS TÊXTEIS
}

\author{
Neste anexo apresentamos todos os componentes \\ dos vários circuitos eletrônico do qual o \\ equipamento para medição do decaimento do potencial \\ eletrostático de tapetes e carpete é composto.
}

\section{II.1. OSCILADOR}

O oscilador é mostrado na figura II. 1 .

Como já foi dito no item 4.2, o oscilador construído tem na sua saída "V" uma forma de onda quadrada (ver figura II.1).

A atual montagem foi escolhida por causa da simplicidade dos componentes (utilizamos um CI 555, resistores e capacitores) e da facilidade de construção. 


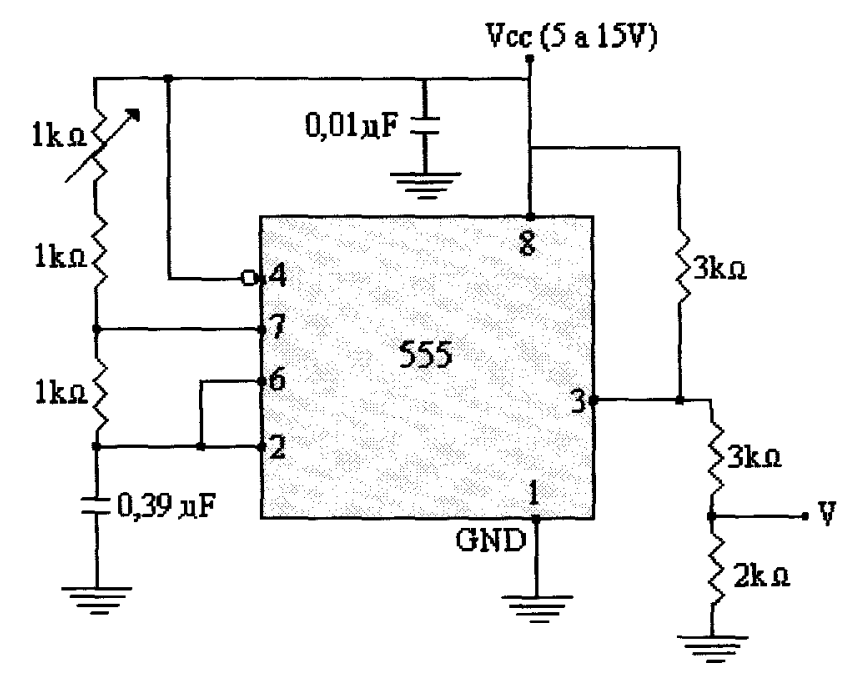

Figura II.1: Oscilador

\section{II.2. AMPLIFICADOR DO SINAL DO OSCILADOR}

A figura II.2 mostra o esquema do amplificador utilizado, como citado no item 4.3 .

O amplificador foi construído a partir do circuito integrado TDA 2002 (amplificador de áudio); a saída "OUT" é conectada diretamente nos terminais de entrada do alto-falante, e, pela entrada "IN" a freqüência a ser amplificada entra no amplificador. 


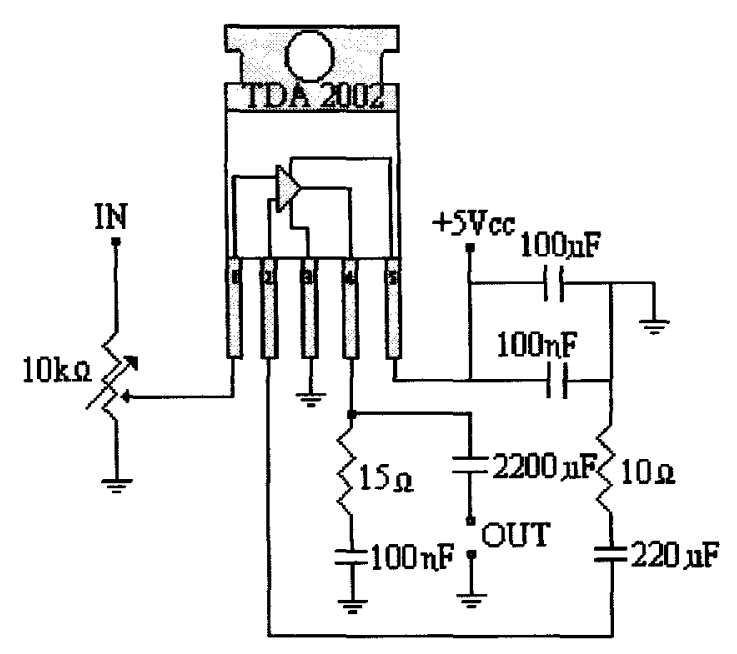

Figura II.2: Amplificador do sinal do oscilador

\section{II.3. FONTE DE ALIMENTAÇÃo PARA O OSCILAdOR E AMPLIFICADOR}

A fonte de alimentação para o oscilador e para o amplificador citada no item 4.4 é representada na figura II.3.

Ela é composta de três partes: o retificador, o estabilizador e o regulador da tensão de saída da fonte DC.

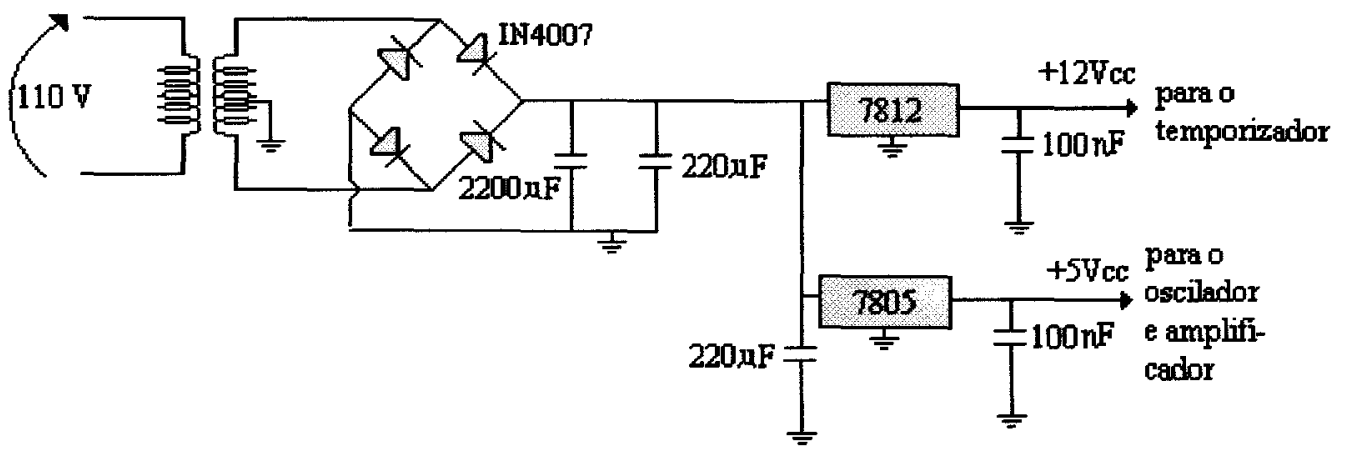

Figura II.3: Fonte DC para alimentação do oscilador e do amplificador 
O retificador é composto pelos diodos (IN4007) e tem a função de retificar a tensão $\mathrm{AC}$, fornecida pelo transformador em uma tensão com forma de onda completa (DC).

O estabilizador é composto pelos capacitores de $220 \mu \mathrm{F}$ e $2.200 \mu \mathrm{F}$ e tem a função de atenuar o "ripple" ${ }^{13}$ da fonte DC.

Já o regulador é formado pelos circuitos integrados 7812 e 7805 e pelos capacitores de $100 \eta \mathrm{F}$. Os circuitos integrados (7812 e 7805) são dimensionados para regular a tensão de saída da fonte DC.

Os capacitores $(100 \eta \mathrm{F})$ fazem o desacoplamento do circuito, isto é, eliminam qualquer vestígio de sinal $\mathrm{AC}$ que ainda esteja presente na fonte $\mathrm{DC}$.

Como pode ser observado na figura 4.10 , a fonte DC gera tanto $12 \mathrm{Vcc}$ como 5 Vcc, para alimentar o oscilador e o amplificador, respectivamente.

\section{I.4. FONTE REGULADA DE TENSÃO E REGULADOR DE TENSÃO}

Como foi dito no item 4.6, foi construída uma fonte regulada de baixa tensão e um regulador de tensão para produzir os $8,7 \mathrm{~V}$ destinados à alimentação da fonte chaveada de alta tensão. 
O circuito construído para a fonte regulada de baixa tensão e para o regulador de tensão é mostrado nas figuras II.4 e II.5, respectivamente.

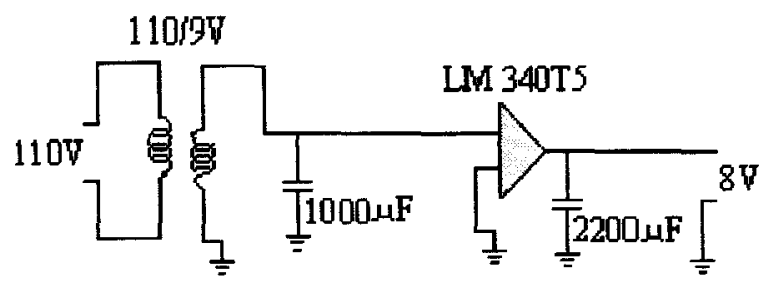

Figura II.4: Fonte regulada de baixa tensão DC

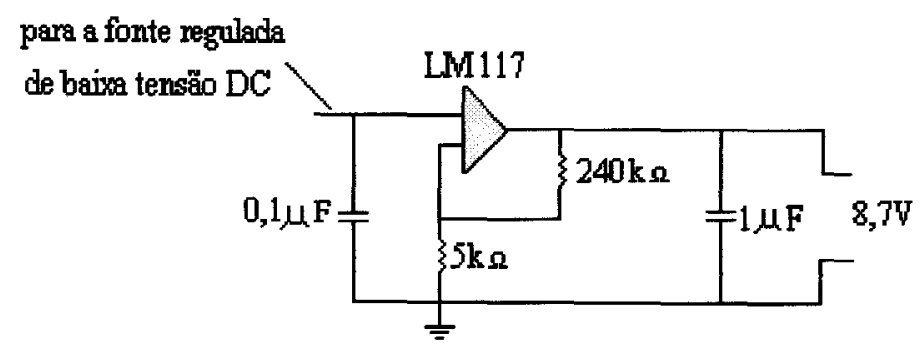

Figura II.5: Regulador de tensão

Na figura II.6, pode-se observar o circuito completo, ou seja, como fica a disposição da fonte regulada de baixa tensão DC e do regulador de tensão, conectado na saída dela. 


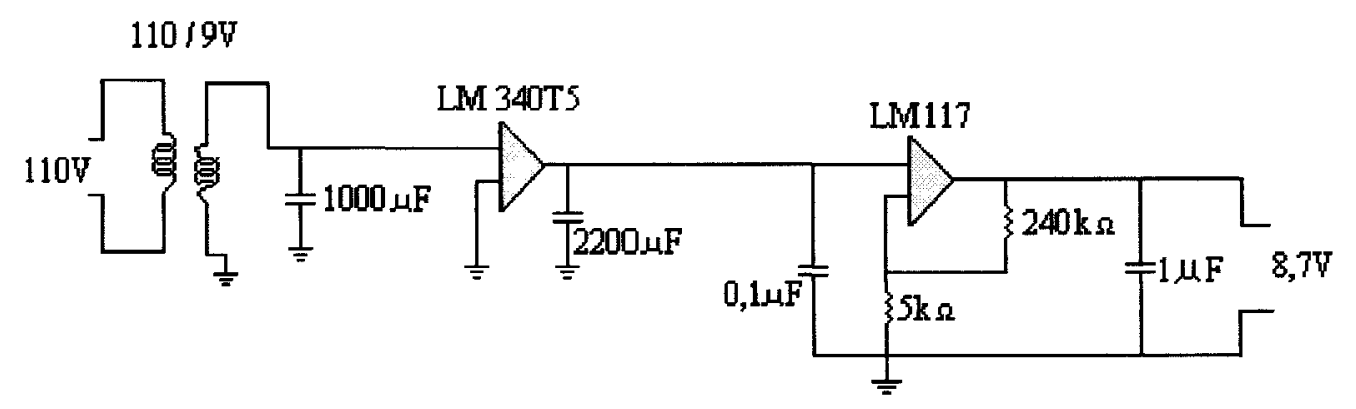

Figura Il.6: Circuito completo: fonte de baixa tensão DC e regulador de tensão

\section{II.5. AMPLIFICADOR DE SINAL}

O amplificador construído para amplificar o sinal do potencial eletrostático e levá-lo até a placa de aquisição de dados, citado no item 4.7, é mostrado na figura II.7.

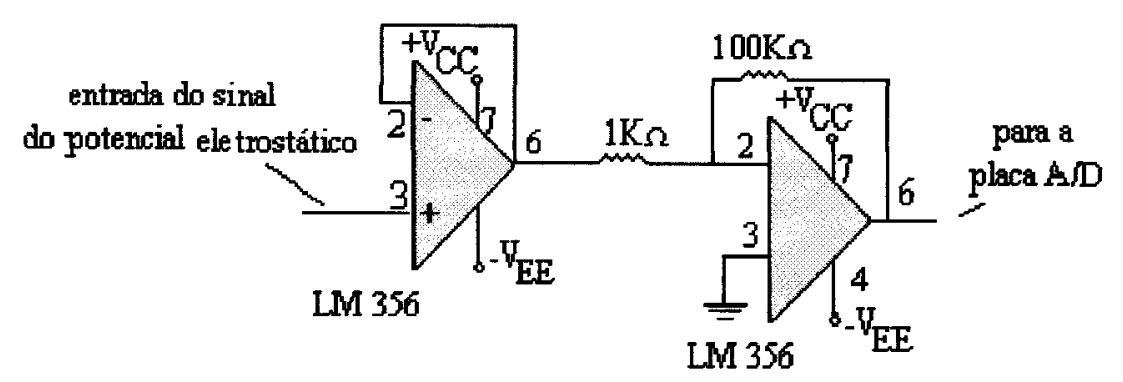

Figura II.7: Amplificador para o sinal do potencial eletrostático 


\section{II.6. AMPLIFICADOR DE POTÊNCIA}

O circuito do amplificador de potência, citado no item 4.10, está representado na figura II.8. Este circuito utiliza como elemento principal o amplificador operacional LF351, que é empregado porque trabalha sem drenar corrente do circuito anterior, no caso, a interface, sendo capaz de excitar a base do transistor, provocando a sua saturação $\mathrm{e}$, consequentemente, $\mathrm{o}$ acionamento do relé pelo chaveamento do transistor.

Quando existir uma tensão no pino 3 do LF351, emitida pelo microcomputador, o amplificador operacional provocará uma tensão ainda maior no pino 6 , fazendo com que o transistor seja chaveado.

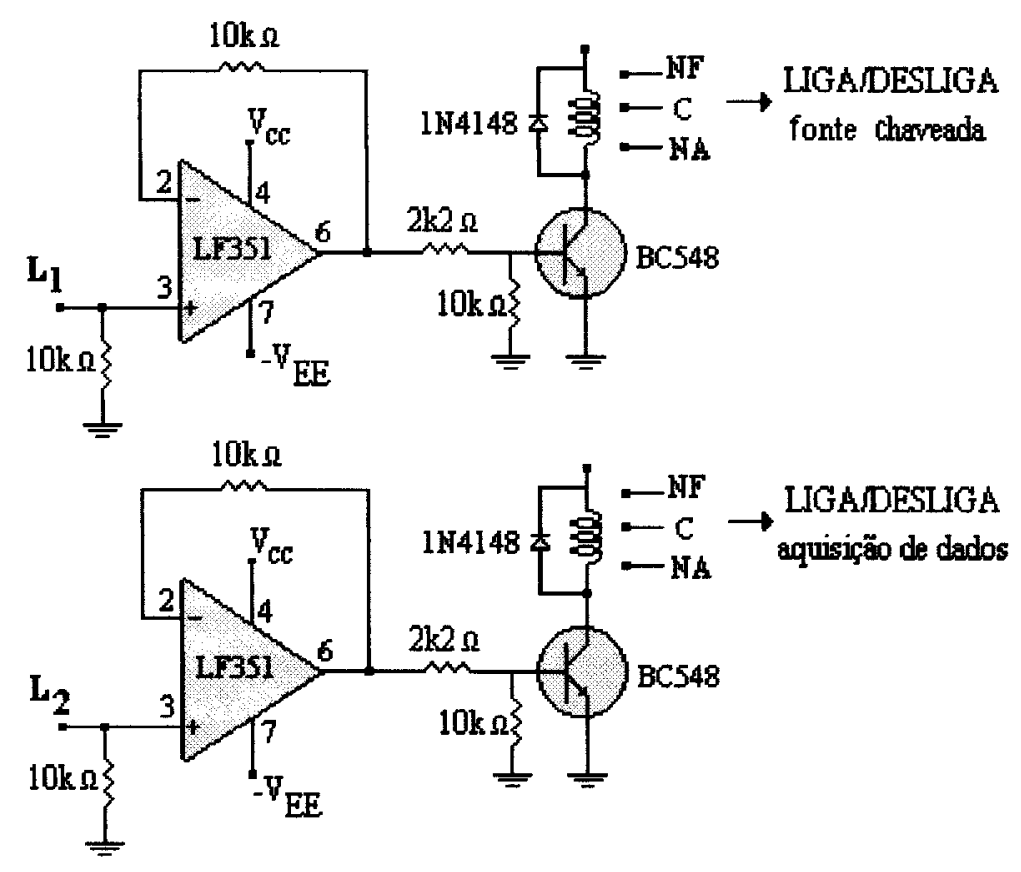

Figura II.8: Amplificador de potência

$\mathrm{O}$ diodo $1 \mathrm{~N} 4148$ tem a finalidade de evitar qualquer corrente reversa vinda do relé, evitando também a ocorrência de danos no transistor. 
O transistor BC548 foi escolhido para esse circuito pelo fato de ser um componente de uso geral e de baixo custo.

Na figura II.9 é apresentado o circuito completo que representa o equipamento para medição do decaimento do potencial eletrostático, com a indicação de todos os blocos e todos os compenentes eletrônicos de que ele se compõe. 


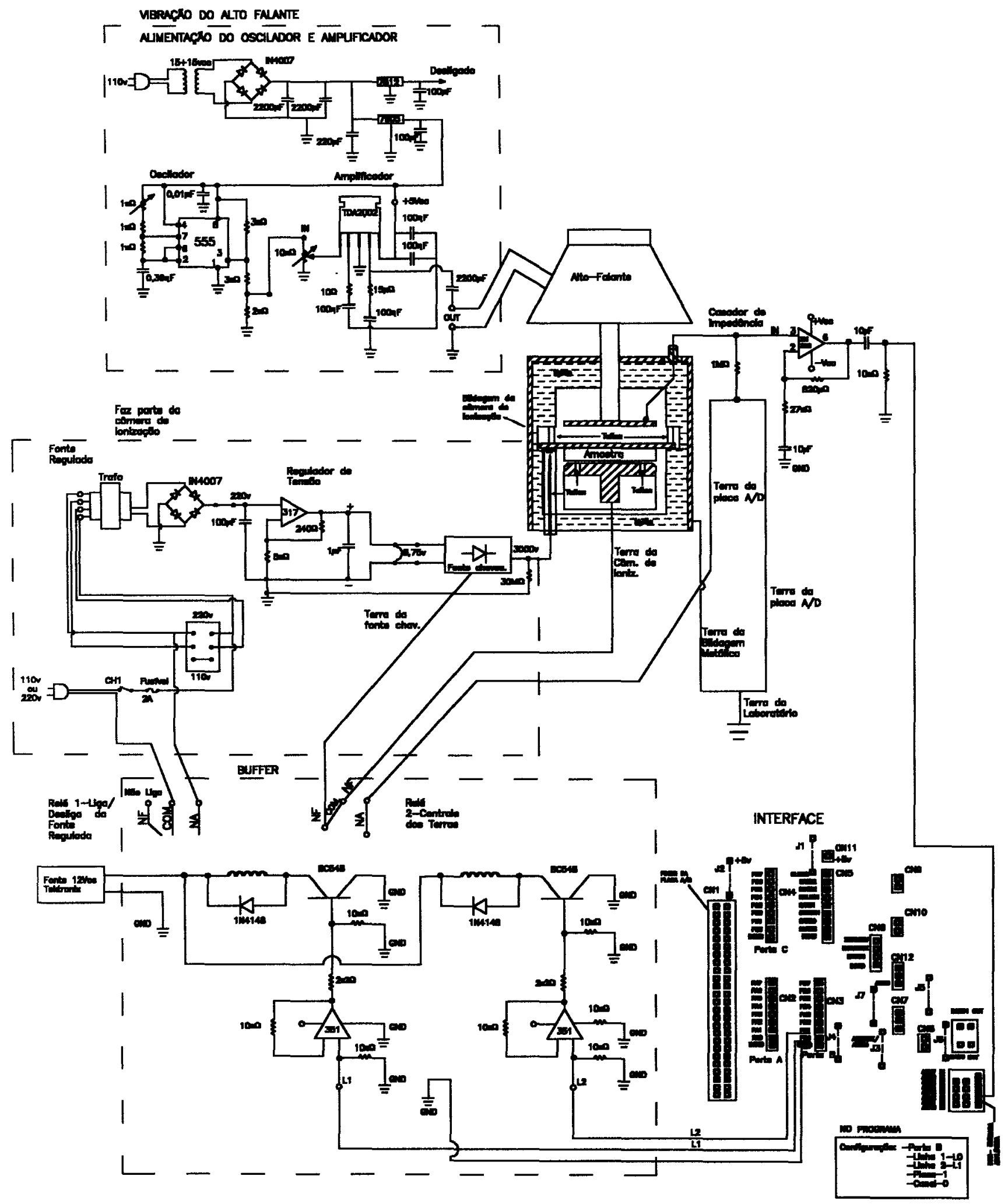

Figura II.9: Circuito completo do equipamento para medicä́o do decaimento do potencial eletrastdtico de revestimentos têrteis 
ANEXO III

\section{PÁGINAS DA “INTERNET" QUE FORAM CONSULTADAS NO TRABALHO}

Neste anexo apresentamos todas as páginas

dos vários endereços eletrônicos

consultados durante a confecção

da tese de doutorado aqui apresentada. 


\title{
III.1. Primeiros passos da Eletrostática
}

\author{
Www. fortunecitv.com/victorian/belvedere/112/nota l.htm
}

Desde que começaram os estudos de Eletrostática, os homens se preocuparam por saber qual seria a natureza da eletricidade. A primeira teoria a esse respeito foi formulada por Benjamin Franklin, e é conhecido como teoria do fluido único. Admitia que todo corpo possuísse certa quantidade de um fluido indestrutível, associado à matéria em maior ou menor quantidade. Um corpo em estado neutro teria uma quantidade desse fluido elétrico que era chamada a quantidade normal de fluido para esse corpo. Se o corpo tivesse excesso desse fluido estaria eletrizado positivamente. Se o corpo tivesse falta, estaria eletrizado negativamente. Para explicar as atrações e repulsões entre os corpos eletrizados admitia que as partículas que constituem a matéria se repeliam umas com as outras, e atraiam o fluido elétrico. A eletrização por atrito entre os dois corpos era explicada pela passagem de fluido de um corpo a outro.

Posteriormente se creou a teoria dos dois fluidos. Consistia em admitir que os corpos existissem, em quantidades praticamente ilimitada, dois fruídos elétricos: um positivo, outro negativo. Os fruídos de mesma espécie se repeliriam, e os de espécies diferentes se atrairiam. Um corpo estaria eletrizado positivamente ou negativamente de acordo com o excesso de um fluido sobre o outro.

As idéias atuais a respeito da eletricidade só puderam surgir depois que os físicos começaram a desconfiar da existência do elétron, em fins do século passado, e pouco tempo depois vieram a confirmar a sua existência.

Atualmente, tomando como ponto de partida que os elétrons e os prótons são partículas materiais dotadas de carga elétrica, nós conseguimos explicar quase a totalidade dos fenômenos elétricos conhecidos. Apesar disso existe uma verdadeira lenda entre os leigos de que "não sabemos nada a respeito da eletricidade". Essa idéia é falsa, e é tremendamente prejudicial para os principiantes, que passam a considerar a eletricidade como uma coisa um tanto misteriosa e um tanto perigosa. Não estamos querendo afirmar aqui que os físicos já sabem tudo a respeito da eletricidade. Não, porque há muitos e muitos fatos que ainda não foram explicados. Por exemplo, não sabemos até hoje porque os elétrons têm carga elétrica, porque os prótons têm carga elétrica, como a atração entre prótons e elétrons no átomo se combina com a atração gravitacional ( devida às mecânicas deles), não sabemos explicar bem porque certas substâncias são condutoras quando a eletricidade passa num sentido e são isolantes quando a eletricidade passa em sentido oposto, e muitos outros fatos. Mas não é porque ignoramos muita coisa que vamos passar a olhar a el etricidade assim meio de esguelha, e não acreditar em fatos que se passam diante de nós todos os dias . Em qualquer parte de qualquer ciência existem e sempre existirão muitos fatos que o homem não sabe explicar. E são exatamente esses fatos que puxam a ciência para frente. 


\title{
III.2. JCI 155 Charge Decay Test Unit
}

\author{
www.jchubb@ijci.co.uk \\ A compact instrument for direct measurement of the ability of materials to dissipate \\ static electricity \\ JCI 155 Charge Decay Test Unit mounted on JCI 176 Charge Measuring Sample \\ Support
}

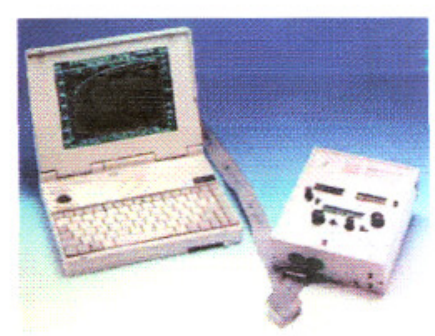

The JCI 155 Charge Decay Test Unit is compact and easy to use instrument for measuring the ability of materials to dissipate static electricity. If materials dissipate static quickly, and have a link to earth, then problems and risks with static will not arise. The simple and appropriate way to test materials is to put some charge on the material surface and see how quickly this charge disappears. In the JCI 155 a high voltage corona discharge is used to deposit a patch of charge on the surface of the material to be tested. A fast response electrostatic fleldmeter is used to observe the voltage generated by this charge and measure how quickly the voltage falls as this charge migrates away. Corona charge deposition is the simplest way to simulate practical static changing events. It allows control of initial surface voltage and charge polarity and is applicable for all types of surfaces - whether uniform or with localised conducting features. Studies have shown that the decay of corona charge matches well the practical situation of the decay of charge generated by rubbing surfaces together $[1,2,3]$.

\section{Why bother about static?}

Many materials, in particular plastics, become electrostatically charged when rubbed against other materials. Such 'triboelectric' charging causes problems in many areas of industry. It can cause ignition of flammable gases and give shocks to personnel. It can make thin films and light fabrics cling, attract airborne dust and debris, damage semiconductor devices and upset the operation of microelectronic equipment. The risks and problems arising from static electricity are best avoided by ensuring that static charge can dissipate over and through the surfaces of materials and away to earth more quickly than charge is generated. For normal manual handling and body actions this means the charge decay time need to be below $1 / 2$ second.

\section{INSTRUMENT FEATURES}

Test Area: The JCI 155 rests directly on the test surface with a $45 \times 54 \mathrm{~mm}$ test aperture in the instrument baseplate. Contact with the surface around the test area provides a return route for outwardly migrating charge and high local capacitance to trap such charge. 
Charging: The surface is charged by a high voltage corona discharge from points mounted as a small conical cluster on the underside of a light plate which is moved between the fieldmeter sensing aperture and the material surface under the instrument baseplate. A brief pulse (e.g. $20 \mathrm{~ms})$ of high voltage $(5-9 \mathrm{kV})$ causes corona discharges with charge deposited as a patch in the middle of the exposed test area of the material. Charge deposition time is short compared to the time for the light plate to move fully away (about $20 \mathrm{~ms}$ ) and the minium decay times which can be measured. This also ensures that observations are little influenced by the position of the outer boundary. Feedback stabilisation of the corona voltage and opportunity for dynamic analogue measurement of the corona voltage and current is provided in instruments supplied from the beginning of 1998 . The quantity of charge received by planar samples can be measured using the JCI 176 Charge Measuring Sample Support. The moving plate carrying the cluster of corona points shields the fieldmeter from high voltage connections and from the influence of corona ionisation so reliable measurements can be made down to low even surface voltages.

Fieldmeter: A proprietary fast response 'field mill' electrostatic fieldmeter is used to provide sensitive and stable measurement of surface potential. The response time to surface voltage changes is below $10 \mathrm{~ms}$ and charge decay times can be measured to below $50 \mathrm{~ms}$. The infinite input time constant means that reliable measurements can be made on materials with even very long decay time constants.

Sample support: Measurements are normally made both with the material freely supported and also resting against an earthed backing surface. These two arrangements represent the extremes of practical constraints. The longer of the two decay times is used for assessment of the suitability of the material. Both the JCI 166 Sample Support and the JCI 176 Charge Measuring Sample Support provide these test arrangements.

Measurements may also be made on liquids and powders with suitable care to avoid these materials entering the instrument. Samples of powder may conveniently be studied using the Powder Sample Support JCI 170 in conjunction with the Support Plate JCI 172.

Test acceptance criterion: The decay time, from the initial peak voltage to $1 / \mathrm{e}(37 \%)$ of this, should be less than half a second for nomal manual and body activities.

JCI 155 Operation: The JCI 155 may be operated from internal rechargeable batteries or directly from the mains supply. As from the beginning of 1998 the power supply automatically selects between $115 \mathrm{~V}$ and $230 \mathrm{~V}$ operation, there is automatic changeover between mains and battery operation and batteries are Smart charged as required without need for operator action.

Signal outputs and computer linkage: Analogue signal output connections enable observations to be displayed and recorded on an oscilloscope or a paper chart recorder. An integral serial communication interface enables decay curves to be transferred in real time to an IBM PC or compatible microcomputer opereating MSDOS. JCI software 0 provides automatic storage, display and analysis of charge decay curve information. Opportunity is also provided to operate the JCI 155 under software control to set the corona charging voltage and duration and to make repetitive measurements.

JCI-Graph: This software enables charge decay curve observations recorded from operation of a JCI 155 using DECAY18 operating in MSDOS to be processed and 
graphed within a Windows $95 / 98$ operating environment. This enables charge decay graphs to be displayed, manipulated and transferred into Windows based applications together with text details of test conditions and numerical result data. This new software will recognise and accept observations stored from early version JCI 155 instruments using earlier DECAY software as well as from the latest versions.

Calibration: Instrument performance can be formally calibrated using measurements whose accuracy is traceable to National Standards (BS 7506: Part 2: 1996 Annex 1) [1] Design and operational features of the JCI 155 are described in an IEEE paper "Instrumentation and standards for testing static control materials" Trans IEEE Ind Appl (6) Nov/Dec 1990 pl182.

[2] Measurement of charge decay for the assessment of materials is described in the British Standard BS 7506: Part 2: 1996 "Methods for measurements in electrostatics" and on the J(I Website.

[3] Studies on the use of the JCI 155 are reported in:

"Dependence of charge decay on charging parameters" Proc 'Electrostatics 1995' Inst Phy Confr Ser 143 p103,

"Corona charging of practical materials for charge decay measurement" $J$.

Electrostatics 371996 p53,

"Instrumentation to assess the static charge dissipation capabilities of materials" 13th Int Symp Contamination Control, The Hague 16-20 Sept, 1996

"Charging and charge decay measurements on a variety of materials" Paper presented at 'Electrostatics 1999' Conference in Cambridge, March 29-31, 1999

"Measurement of tribo and corona charging features of materials for assessment of risks from static electricity" IEEE-IAS Meeting, Phoenix, Arizona, Oct 1999 (To be published in Trans IEEE Ind Appl)

"New approaches for testing materials" Electrostatics Society of America 'ESA 2000' meeting, Niagara Falls, June 18-21, 2000

\section{SPECIFICATION}

Controls:

- 3 position slide switch (on rear of instrument) to switch instrument ON and OFF

- 3 position slide switch to 'Set for charging' and to 'Discharge'.

- 3 position high voltage on/off switch with middle position providing 20 msec pulse of corona charging at instant of 'Discharge'

- high voltage level control potentiometer

- high voltage polarity changeover rotary switch

- 3 position switch to select manual or computer control of instrument operation

- 3 position slide switch to select display of surface voltage at: 'start of timing'/'present'/'end of timing'

- screwdriver zero adjustment for fieldmeter via $2 \mathrm{~mm}$ hole in front end plate of instrument

Displays:

- 8 digit liquid crystal display showing elapsed time in $0.001 \mathrm{~s}$ units. 
- $31 \frac{1}{2}$ digit liquid crystal display of corona voltage with LO BATT indication.

- $4^{1 / 2}$ digit liquid crystal display of surface voltage

Test area:

- $45 \times 54 \mathrm{~mm}$ aperture in instrument baseplate

Sample:

- the unit may be placed directly on a surface or area of sample.

- the JCI 166 Sample Support Unit provides a simple support for open and earthed backing tests with open and earthed backing

- powders and liquids may be studied by placing in an earthed cup (for example the JCI 170).

- the JCI 176 sample support enables the charge received by planar samples to be measured.

Fieldmeter:

- fast response 'field mill' fieldmeter measures surface voltage with response time less than $10 \mathrm{~ms}$.

- sensitivity: 20,000 volts full scale. $4 \frac{1}{2}$ digit display with last digit equal to 1 volt of surface potential.

- zero stability: within $\pm 10 \mathrm{~V}$ long term. Noise on liquid crystal display within $\pm 1 \mathrm{~V}$, on analogue and serial data link outputs within $\pm 5 \mathrm{~V}$.

Operating times:

- about 2 seconds to 'set for charging', 20msec opening.

HV supply:

- internal high voltage supply with feedback stabilisation providing positive and negative potentials to about $9 \mathrm{kV}$. 10 Megohm personnel safety resistor is used in the link to the corona discharge points.

Connections for dynamic measurement of corona voltage and current via 8 w miniature DIN connector socket

Surface voltage:

- from about $50 \mathrm{~V}$ to about $3 \mathrm{kV}$, depending on rate of charge dissipation Measurement range:

- from about $50 \mathrm{~ms}$ to 100,000 seconds.

Operation:

- integral $100 \mathrm{mAh}$ nickel cadmium rechargeable batteries providing about 1 hour continuous operation

- integral mains power supply (automatic selection between 240V/6VA $50 \mathrm{~Hz} \& 115 \mathrm{~V} / 6 \mathrm{VA} 60 \mathrm{~Hz}$ operation)

Battery charging:

- the nickel cadmium batteries are 'Smart' charged in about an hour from the internal mains power supply while the instrument is not operating. LED indication of fast charging.

Connections:

- mains input via IEC connector

- signal outputs (analogue and serial data) via 8w miniature DIN connector 
Accessories:

- JCI 166 Sample Support

- JCI 176 Charge Measuring Sample Support

- JCI 170 Powder Sample Support and Support Plate JCI 172

- JCl-Graph

Software:

- DECAY18E (or later versions) to transfer charge decay curve data into an IBM PC or compatible micro operating MSDOS for analysis, display and storage of observations and for optional control of operation. Operation can conveniently be initiated from a 'jci' icon with Windows $95 / 98$

\section{Dimensions:} operating environments.

- $173 \times 216 \times 67 \mathrm{~mm}$

Packaging:

\section{HELPLINE:}

- in carrying case with mains input, signal output and serial data link cables

JCI is happy to discuss applications and experience with JCI 155 operation. JCI also offers consultancy to help customers understand problems and risks concerning static electricity and undertake charge decay performance studies of materials for customers.

| Home | News | Products | Specifications | Papers | Meetings | Contact JCI | Sitemap | For best results view these pages with a Netscape Navigator browser. John Chubb Instrumentation,

Unit 30, Lansdown Industrial Estate, Gloucester Road, Cheltenham, GL51 8PL, UK Tel: +44 (0) 1242573347 Fax: +44 (0) 1242251388

email: jchubbajci.co.uk

Page Update: 19/07/2000. (C) John Chubb Instrumentation. 


\title{
III.3. ZEOLITE MOLECULAR SIEVES
}

\author{
www.drjohn.demon.co.uk/zeolites.html
}

The Swedish Mineralogist Cronstedt discovered zeolites in 1756 and named them zeolites after his dog who dug up the rocks when out for a walk. Zeolite is a Swedish word meaning "dog". This is contrary to the popular belief that he named them after the Greek words meaning boiling stone. This is clearly nonsense as Greek was not part of the Swedish national curriculum at the time (and who has ever heard of boiling stones anyway). He christened this particular zeolite "stilbite", because his dog was still biting it when he got home. As a result of this discovery he has guaranteed himself a mention on the first page of every book, thesis and paper ever written on the subject.

Another term for Zeolites is "aluminosilicate molecular sieve". This is derived from two Greek words, *aluiminosilicate* and *sieve*, which mean ZEOLITE.

Contributed by Dr. Keith Franklin

\section{But Really !!!!!!!!!}

In 1756 Cronstedt discovered a selection of natural minerals which, when heated produced steam. Due to this strange phenomenon he called them Zeolites from the Greek for Boiling Stone (zeo - from zein - to boil, lithos - stone).

Not until the early 1900's and in particular the 1940's did zeolites become of interest to man. In 1949, Milton working at Union Carbide produced the world's first man-made zeolites, the most important being Linde $\mathrm{A}$ and $\mathrm{X}$. Linde $\mathrm{A}$ has gone on to become one the most widely used zeolites.

\section{Zeolite Linde A}

Zeolites are highly crystalline alumino-silicate frameworks comprising $\left[\mathrm{SiO}_{4}\right]^{+}$and $\left[\mathrm{AlO}_{4}\right]^{\mathrm{T}}$ tetrahedral units. $\mathrm{T}$ atoms ( $\mathrm{Si}, \mathrm{Al})$ are joined by an oxygen bridges. Introduction of an overall negative surface charge requires counter ions e.g. $\mathrm{Na}^{+}, \mathrm{K}^{+}$and $\mathrm{Ca}^{2+}$. 


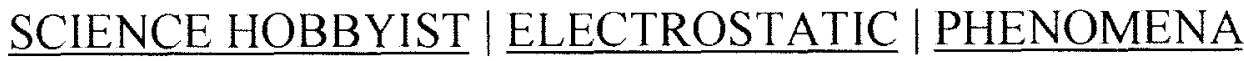

\section{III.4.HUMANS AND SPARKS}

\author{
The Cause, Stopping the Pain, "Electric People" \\ (c)1997 William J. Beaty
}

www charleswater com/introcsd.html

(jump down to "Car Sparks," "Electric People", and LINKS)

"Static" sparks can be irritating and their cause sometimes seems mysterious. Most people have encountered painful car-door sparks, as well as those wintertime sparks from doorknobs and large metal objects. What causes these, and what can be done to stop them?

Unexpected doorknob sparking only seems mysterious because of a misconception. As children, most of us learn the trick of scuffing our shoes across the carpet in order to charge our bodies. Then we go to search for victims to "zap" with our electric fingers. Sparks from rug-scuffing are familiar, but why do our bodies sometimes become charged from simply *walking* around? Why do we still experience those painful sparks if we don't cause any "friction" by scuffing on the carpet? Isn't friction required?

\section{ELECTRIFYING CAUSES}

Actually, no friction or rug-scuffing is required in order to electrically charge your body. The need for friction is a widespread misconception. It's true that the friction can increase the charge-separation process. However, opposite charges are separated whenever two different insulators touch together. Simply *walking* across certain rugs or plastic flooring will cause your shoe soles to touch the dissimilar material of the rug. This is enough to separate the negatives from the positives and create imbalanced electric charges on the bottoms of your shoes.

"Static" electricity ( more correctly called "net electric charge") appears whenever the quantities of positive and negative electricity in a substance are not perfectly equal. Everything is made of atoms, and atoms in turn are made of positive and negative electric charges. In other words, your body is just a collection of positive and negative charges. Normally the positives cancel out the negatives, and everything behaves electrically neutral. If you ever end up with more negative than positive, or with more positive than negative, then you have a charge-imbalance on your body. You will get zapped the next time you touch a large metal object.

Exactly how can this imbalance occur? When we walk, the soles of our shoes steal negative charge from the floor. We leave behind electrified positive footprints, and our bodies aquire an overall imbalance of negative. (Or sometimes vice versa with negative and positive, since polarity is determined by the type of shoe soles and the type of rug.) After many footsteps, our bodies attain a high level of electric charge and a high voltage. Your body-voltage can easily rise to several thousand volts, and the next time you touch 
someone... ZAP!, the imbalanced charge gets shared between you and the other person. The spark is painful because it's extremely hot. It drills into your skin like a white-hot needle, creating a microscopic burned area.

ARTICLE: Measuring the "Static Electric" Voltage on your Body

To prevent sparks, we must stop the charge separation process somehow. This can be done by:

- Changing your shoe soles to another type (try leather)

- Raising the humidity in the room

- Spraying carpets and floors with antistatic liquid

- Installing a balanced-polarity ionizer fan

- Wearing metal-coated shoe soles (try alum. foil, but it's slippery)

- Wearing a grounded wire connected to a wrist strap

The problem can also be prevented by discharging the excess charge in a way that doesn't cause pain. This can be done by:

- Wearing a conductive ankle-strap with a metal shoe-sole plate

- Knocking against doorknobs with knuckles (fewer nerve endings)

- Wearing a metal thimble, touch it to grounded objects.

- Hold keys or a metal pen, touch it to grounded objects.

High humidity prevents sparks. Raising the humidity in the environment causes shoes and rugs to become slightly conductive, so the separated charges can instantly flow back together. Usually all of the "static electricity" will vanish when the RH is above $60 \%$. Or, if we spray the floor with antistatic liquid, it can do the same thing. Antistatic liquids aren't magical, they simply make surfaces slightly conductive so the charge-separation cannot occur. Make your own antistatic spray by mixing a teaspoon of liquid fabricsoftener into a quart of water.

Electronics manufacturers use balanced polarity air ionizers to eliminate sparks. These make the air itself into a conductor, but they also are expensive ( $\$ 300$ is typical.) Manufacturers also sell conductive shoe-straps which connect your body electrically to the floor. These are meant to be used with special conductive carpets, and they won't work if the floor is wood, plastic, cloth, or other good insulators.

Shoe soles create the charge imbalance, so you can reduce the sparks by avoiding particular types of shoe soles. For example, rubber soles usually cause significant charge separation, while thin leather soles cause much less. Or wear no shoes at all, only wear thin socks or go barefoot. You might consider coating your shoe soles with heavy adhesive aluminum foil. The foil works because contact with metals can only generate a tiny amount of imbalanced charge. Unfortunately the foil makes your shoes dangerously slippery, and it leaves black scuff marks on floors.

Another solution: always knock your knuckles against doorknobs before grabbing the knob. This won't stop the spark, but the spark is less painful when it bores into your knuckle rather than into your delicate fingertips. If you whack your knuckles hard, you barely feel the spark at all. After all, you're EXPECTING the pain your knuckle's impact, and are controlling the impact, so the pain of the spark is no longer uncontrolled and unexpected. For some reason, unexpected sparks hurt far more. 
If you REALLY hate sparks, you might consider wearing a metal sewing thimble upon one finger at all times. Touch the thimble to the doorknob (or to other metal objects) and you'll feel no huge "zap." The spark will still occur, but the pain is gone. Instead of a thimble, you could carry a set of keys in your hand, then touch doorknobs with the keys to discharge yourself painlessly.

\section{CAR DOORS}

The cause of car-door sparking is well known: contact-electrification between insulating surfaces, followed by separation of those surfaces. But what does this mean? Well, *YOU* are one surface, and the car seat is the other. When you sit on a plastic car seat in dry weather, the contact between your clothes and the seat's surface causes electrical charges of the material to transfer between the surfaces. This is our old friend "frictional" or "contact" charging. One surface ends up with more negative charges than positive, and has a negative charge-imbalance. The other surface has fewer negatives than positives, so it has a positive imbalance. This is nearly same thing as rubbing a balloon upon your hair: both surfaces become electrically charged.

However, nothing happens as long as you remain seated. Keep your butt in one place. As long as the surfaces remain near each other, no overall "electricity" appears and no sparks are possible. The oppositely-charged surfaces cancel out because they are still close together. But when you open the car door and step outside, you take just one polarity of charge along with you, while the car seat has the opposite polarity. At the same time, the car seat causes the whole car to become charged (by a process called "Faraday's Icepail Effect.") As you step out of the car, the voltage between your body and the car becomes huge, up to 10,000 or even 20,000 volts. Your shoes are probably insulating, so the charge has no opportunity to leak into the earth. You reach out to close the car door and ZAP!, the opposite polarities rejoin by leaping through the air while giving you a tiny, deep burn in the flesh of your finger!

How to prevent this? One possibility: change the surface materials. Identify and avoid the specific clothing which makes the problem worse. These materials are usually wool sweaters and pants, certain manmade fabrics, plastic raincoats, etc. Or, replace your cheap plastic car seatcovers with cloth (stains easily!) or leather (expensive dead animals.) Another method: mix up some anti-static solution and spray your car seats. This solution remains slightly damp for weeks, which halts the contact-charging process. The formula: a teaspoon of fabric softener mixed in one quart of water. This tends to work well at first, but after many days it wears off and needs a re-coating. Another sillier method: always drive barefooted, so the charge will leak away when you step outside the car. Not good in winter! Cover your car seats with a conductor such as aluminum foil, which screws up the contact-charging effect. Have a tailor make some custom clothing out of black conductive carbon cloth? Or you could eliminate the problem by eliminating your clothes. Skin is fairly conductive, so it doesn't create charge-separation when held against plastic. Driving while nude might cure the sparking problem (unless you are a very hairy person!) A less frivilous method: develop the habit of holding your car keys as you leave the car, then grip the keys firmly and touch the door handle with the tip of the key. The spark will still jump, but it will not be painful, since it blasts a little hole in the tip of the key instead of in your finger.

A research paper: The Control of Body Voltage Getting Out of a Car, from JCI 
A safety issue: Sparks and gasoline

\section{MYSTERIES: Electric People}

The source of some human-body sparking is unexplained. There are reports of rare people, "Electric Humans," who develop high voltage on their bodies and suffer the continuous problem of "static" sparks. Their sparking occurs regardless of footwear, clothing, humidity, or even motion! Electric people are forever getting zapped when they touch others, or when they touch large metal objects. For the rest of us, "static electric" sparks can only occur after we walk across certain carpets, or when we wiggle around while sitting upon certain chairs. And for the rest of us, the problem vanishes when the humidity is high, or when we go barefoot or avoid wool or nylon sweaters/pants, avoid plastic seats, etc. But the bodies of "Electric Humans" instead seem to become electrified all the time, all by themselves, without involving the friction or the contact/separation of differing surfaces.

R.A. Ford mentions two cases in chapter 13 of his book HOMEMADE LIGHTNING (1991 Tab Books). In one case from 1837 a woman could repeatedly jump sparks 1-1/2" long to a metal object while she stood still on a thick carpet, or she could continuously create 1/16" sparks much faster (once per second.) Another case took place in 1920, when prison inmates in upstate New York suffering from Botulin food poisoning were found to be "electrified." They were able to attract paper, create sparks, etc., even when partially submerged in a bathtub. (Obviously the bathtub must not have been attached to grounded pipes, otherwise the excess charge would have vanished instantly.)

In modern times an Electric Human would have additional problems besides irritating sparks. Computers, stereo equipment, digital watches, etc., are easily damaged by high voltage and spark discharges. All sorts of electronic appliances would not survive very long under the electrostatic barrage. An electric human would be advized to buy mechanical watches, and to avoid buying any appliance which contains a microprocessor.

Unfortunately, scientific skepticism is currently at an all time high, so if a person with this sparking problem was to seek help, they would probably be ridiculed and their sanity questioned! Scientists don't believe in "electric people." Reputable scientists "know" that Electric Humans are mere superstition and cannot exist. Therefor anyone claiming to have this problem is irrational, perhaps deranged! At least the internet is there, giving opportunity for 'charged humans' to tell their stories (for example, at:

\section{Report Your Unusual Phenomena}

An organization in the UK:

Mr. Hilary Evans

Co-ordinator of Street Lamp Interferance Data Exchange (SLIDE)

59 Tranquil Vale, London SE3 OBS

England

What could cause the "Electric Human" problem? First, shoe sole material and clothing material needs to be eliminated as a possible cause. Maybe you aren't an "electric human", maybe you simply have electric shoes! If sparks are ALWAYS a problem, regardless of whether various conductive clothing (cotton) or shoe soles (leather, metal 
foil, etc.) are worn, then perhaps the problem isn't from "frictional" charging at all. In order to create a static electric imbalance on our bodies other than through "contact" or "frictional" methods, we would have to be sending out ELECTRICALLY CHARGED AIR (and so our bodies would take on an opposite charge.) Perhaps the skin does this somehow. Or maybe the membranes of our lungs can somehow emit air which is electrically non-neutral. If a person were to constantly be breathing out ions (charged air molecules), then, unless their body was electrically grounded to the earth, they would rapidly accumulate a charge imbalance on their body, an imbalance which is equal and opposite to the charged air being breathed out.

Are you an unexplainable human oddity? Here's a possible way to test it: see if you can create sparks without moving around and rubbing against things. First, put on some thick shoes, hold a metal object in your hand, then sit on an insulating chair that's within reach of grounded metal. Plumbing, radiators, and the screw on an electric outlet all are examples of grounded metal. The best "insulating chair" would be a plastic-resin lawn chair, or perhaps an upside-down plastic waste basket. If the chair has metal legs and metal bolts on the seat, it is *not* a good insulator. Next, sit down, take your metal object, and slowly touch it to grounded metal. Was there a spark? If so, then your body is no longer charged. As long as you don't rub against anything, YOUR BODY SHOULD NOT CHARGE BACK UP BY ITSELF. Sit there for a couple of minutes without moving. Don't lean back in the chair, since you don't want your back to touch/peel from the plastic chair back. Now, touch the metal object slowly to the grounded metal again. There should be no spark. If there WAS a spark, then something very weird is going on. Wait another minute or two and try again. If you can keep on creating sparks in this way, then you are an "electric people." (Hey, if this works, drop me an email note at billb@eskimo.com. Maybe we can write this up and force the mainstream research community to take this phenomenon seriously.

Another, more exotic possibility: maybe it's not static. Maybe it's something else, Torsion Fields for example. The Russians believe that Torsion Fields explain telepathy, psychokinesis, hands-on healing, and many other "paranormal" phenomena. If the human aura exists, then Torsion Physics might explain it, and the "electric human" effect might come about because of a super-strong torsion effect which surrounds a particular person.

Possible cures: buy some conductive ankle-straps that lead to adhesive conductor footpads attached to your shoe soles, then walk only on conductive mats which are electrically grounded via a wire. These products are used in the elctronics manufacturing industry and are available through "ESD" abatement companies (perhaps search for "ESD", "static", or "wrist strap" on the WWW.) ESD stands for "Electro-Static Discharge."

Simple but crude cure: wear a thimble on your finger, then constantly touch grounded metal objects during your travels. The painful "zap" will be eliminated, since it doesn't blow a pinhole in your flesh when the spark jumps. An un-tried high-tech cure: buy an "ionizing blower" from an ESD-abatement company. Expect to pay $\$ 200$ or $\$ 300$. (Don't mistake these for "negative ion generators", you instead want a "balanced polarity" blower intended for stopping ESD in electronics manufacturing.) These blowers send out large quantities of both + and - polarities of charged air. This adds neutralised yet 
movable charges to the air which make the air itself become conductive. The air then silently discharges any charged objects in the room (including any "Electric Humans".)

\section{LINKS}

- NPR Car Talk: your car is a VandeGraaff Generator

- Car seats and sparks

- Report Your Unusual Phenomena

- Measuring your body voltage

- Electric Girl [comic book series]

- Electrical Hypersensitivity Syndrome (EHS)

- Electrically Hypersensitive People: static sparks

- World of The Strange: Electric People

- World of The Strange: Human Glow-worms

- World of The Strange: Switched On and Shocking $</ a$

World of The Strange: Live Wires and Loose Connections

- World of The Strange: The Weight of Evidence

Created and maintained by Bill Beaty. Mail me at: billbaeskimo.com. If you are using Lynx, type "c" to email. 


\section{III.5. ESD Systems.com Introduction to ESD}

www charleswater.com/introcsd.html

\section{STATIC ELECTRICITY}

\section{BASIC THEORY}

The effects of static electricity may macroscopically be familiar experiences, such as an electric storm, but microscopically, static events do occur everyday. Typical experiences may include the clinging of clothes, the dust build-up on our TVs or computer monitors, the unexpected "static" shock as we touch an object such as a door knob, pet or other object, or the plastic wrap that does not want to be thrown away.

When contact and separation occurs between two materials, a transfer of electrons from the atoms on the surface will take place. This process is referred to as triboelectric generation. The resulting imbalance of electrons is what is called an electrostatic charge. This electrostatic surface charge is either positive or negative depending on whether there is a deficiency or abundance of free electrons respectively. We refer to this charge state as static electricity because it tends to remain at rest or static unless acted upon by an outside force.

The amount of charge generated through the process of friction and separation will be influenced by the extent of the contact, the 
materials involved, relative humidity, and the texture of the materials. Static charges of up to 30,000 Volts are not uncommon and can be generated by the simple act of walking across a floor; yet a discharge of only 10 Volts can destroy a class 1 ESD Sensitive device

Static electricity is in essence invisible, although we often see its effects and can feel and measure its presence or electrostatic field. Since it is created by putting the surface's electrons into a state of imbalance of it is not in a natural or stable state. Material with an imbalance of electrons will, when possible, return to a balanced state. When this is done rapidly a zap or spark associated with rapid electrostatic discharge (ESD) occurs. We may feel these zaps if the discharge that occurs is over 3,000 Volts. Electrostatic discharges below that level are below the threshold of human sensation but are still lethal to electronics and associated semiconductor devices. Rapid electrostatic discharges above 6,000 Volts can be seen.

One common misconception is that conductive materials do not generate charges. This is because the dissipation of static charges from grounded conductive material tends to be complete and rapid. Ungrounded conductors can generate and hold static charges. A material that inhibits the generation of static charges from triboelectric generation is classified as antistatic. An antistatic 
material can be conductive (\&lt10E5 ohms/square), dissipative (10E5

- 10E11 ohms/square) or even insulative (\&gt10E12 ohms/square). Only

conductive or dissipative antistatic materials should be used in ESD safe areas.

Insulative materials are more commonly understood to generate and hold a static charge. Since they are insulators they do not allow the charge to move or distribute throughout the object. Grounding is not an effective method of neutralizing insulators. Static fields on insulators are not necessarily permanent either; they will eventually be neutralized by gradual recombination with free ions. Free ions are charged particles that occur naturally in air. They may be in the form of atoms, molecules, or groups of molecules such as water droplets. As free ions pass near a charged object of the opposite polarity they are attracted by the field and will gradually return the material to a state of balance. A charged object is surrounded by an electrostatic field. This field can also affect nearby objects by charge induction. Charge induction lets an electrostatically charged object charge other nearby objects without actually touching them; typically as far away as several feet.

\section{STATIC ELECTRICITY \& PRODUCT QUALITY}

In the processing of film materials or plastics, static electricity can cause materials to cling to each other causing product quality problems or production slowdown. In clean rooms, charged materials 
can hold static-laden dust, preventing these dust particles from being circulated and picked up by the filtration system.

Microelectronics suffer a different type of quality problem due to static electricity. Electronic components are composed of micro-miniature traces and structures of alternating layers that may be insulative, conductive or semi-conductive. Rapid electrostatic discharge (ESD) can cause damage to these underlying structures via the traces of the component.

Unfortunately, ESD damage to electronic components is not as readily apparent as the effects of static electricity in other industries.

This is because ESD damage is not generally visible as it occurs and may be latent or not show up in functional testing of electronic devices. ESD damage may lead to premature or intermittent failure. Estimates of the cost of ESD damage to electronic based equipment run as high as $\$ 5$ billion annually.

The cost of ESD damage is not simply the cost of the components, but includes the cost of labor and may include all of the expenses associated with field repair. Another cost is that of lost business due to customer dissatisfaction.

Many companies have implemented ESD control programs that have reduced their quality defects, resulting in significant cost savings. ISO 9000 certification is also driving the need for proper ESD control programs.

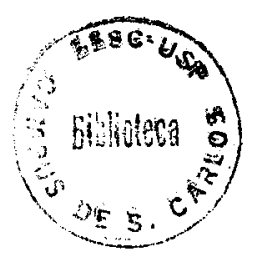




\section{ESD PRODUCTS}

Products that control ESD work by:

Charge Prevention

Grounding

Shielding

Neutralization

\section{Education}

\section{CHARGE PREVENTION}

Charge prevention is accomplished by reducing the exposure to charge generating materials. The prevention of charge generation is an important part of any ESD control program. We can prevent charge generation through the elimination of unnecessary activities that create static charges, the removal of unnecessary materials that are known charge generators and the use of antistatic materials. Antistatic materials are those materials that are shown to create minimal static charges - generally less than 200 Volts - when exposed to friction and separation. Antistatic material may be naturally low in charge generation properties or have been made or treated with an antistatic agent.

\section{GROUNDING}

Grounding works only on conductors. It simply means that we tie all conductors together (at a common point) so that electrostatic charges will flow from and through conductors to a common point and 
will therefore all end up at the same level. This is much like water seeking its own level. One of the conductors we must ground is the human body. The common point we normally use is the common facility ground.

\section{SHIELDING}

Shielding is used to prevent a sensitive device from being charged by exposure to an external electrostatic field or being touched by a charged object during transport or storage. This is done using the Faraday Cage concept. Metallized shielding bags are commonly used to protect static sensitive electronic components and assemblies by creating a Faraday Cage effect.

\section{NEUTRALIZATION}

Nonconductors must be neutralized in some other manner. As they do not conduct electricity, grounding won't work. The most common method of neutralizing insulators is through ionization. We flood an area with alternating positive and negative charged particles (ions). A charged material will then attract ions of the opposite polarity and quickly become neutralized.

\section{EDUCATION}

Education is absolutely necessary for a successful ESD protection program. As with all quality functions, ESD prevention depends upon the understanding and commitment of every person working with sensitive components. 
From the moment components arrive in the receiving department until the completed product is shipped, everyone must understand the danger of ESD and know the part each individual plays in preventing ESD failures.

HOME | STORE | PRODUCTS | KNOWLEDGE BASE | SUPPORT

Copyright (C) 2001 Desco Industries, Inc. All rights reserved. 


\section{REFERÊNCIA BIBLIOGRÁFICA}

[1] ALlEN, D. D., (1993), Controlling Static Generation In Carpets, Charleswater , www esdsystems.com/whtpaper/carpet.htmi, (22/12/98).

[2] WILSON, N, Antiestatic Fibers and Finishes, (Shirley Inst Manchester, Engl) Pap. Presented at the Shyrley Int. Semin on New Mater and Process in the Text Ind, $8^{\text {th }}$, Manchester, Engl, Apr 27-29 1976 Publ by Shirley Inst (Shirley Publ S 24), Manchester, Engl, 1976, 14p.

[3] COELHO, R. The Electrostatic Characterization of Insulating Mateials, (CNRS, Lab de Physique des Descharges, Fr) Journal of Electrostatics v17 n1 May 1985, Proc- $5^{\text {th }}$ Int Conf on Electrost, Poster Pap, Uppsala, Swed, Jun 3-5, 1985, p13-27.

[4] NORME FRANÇAISE NFG35-025 Essais des Revètements de Sol Textiles. Décembre, 1983.

[5] GIACOMETTI, J. A. CAMPOS, S. C. Constant Current Corona Triode With Grid Voltage Control, Application to Polymer Foil Charging. American Institute of Physics, 1990.

[6] ALTAFIM, R.A.C. FUJIWARA, J.K. GIACOMETTI, J.A. Electrostatic Characterization of carpets using a Corona Triode, In: Conference on Electrical Insulation and Dielectric Phenomena. Minneapolis, USA, oct 19-22, 1997, p591-592.

[7] TAYLOR, D.M., OWEN, D.R. e ELIAS, J. An Instrument for measuring static dissipation from materials. Journal of Electrostatics, 19, 1987, 53-64. 
[8] YASHIMA, M. KAWAMOTO, T., Principle of Surface Charge Measurement for Thick Insulating Specimens. IEEE Transactions on Dielectrics and Electrical Insulation. Vol.5, No 4, August 1998.

[9] REEDYK, C.W. and PERLMAN, M.M., The Measurement of Surface Charge, Electrets and Electrostatic charge Storage Phenomena, Edited by Lawrence $\mathbf{M}$. Baxt - Philips Morris Research Center - Richmond, Virginia and Martin $\mathbf{M}$. Perlman - College militaire royal de Saint-Jean - saint-Jean, Quebec, Dielectrics and Insulation Division - The Electrochemical Society, Inc, 1967.

[10] ARRIDGE, R.G.C., Contact electrification and polarization of nylon threads, M.A., B.Sc., A.Inst.P., Research Dept., British Nylon Spinners Limited, Pontypool, Mon., British Journal of Applied Physics, vol. 11, May 1960.

[11] ALFARO, R.A.M., Um Método para o Estudo de Cargas em Filmes Isolantes Carregados por Descarga Corona. Aplicação ao Polietileno. Tese apresentada ao Instituto de Física e Química de são Carlos, USP, para obtenção do título de Doutor em Ciências (Física), Departamento de Física e Ciência dos Materiais, 1977.

[12] BAUM, E.A., LEWIS, T.J. and TOOMER, R. Decay of electrical charge on polyethylene films. J. Phys. D: Appl. Phys., Vol. 10, 1977.

[13] SECKER, P.E. and CHUBB, J.N., Instrumentation for Electrostatic Measurements, Journal of Electrostatics, 16, 1984, 1-19.

[14] COElHO, R. LEVY, L., SARRAIL, D., MARQUE, J.P., Méthodes de caractérisation des matériaux isolants du point de vue de l'électrostatique, RGE - 7-8/85, Juillet-Août, 1985. 
[15] SESSLER, G.M., Spatial Depth and Density of Charge in Electrets, J. Appl. Phys., Vol. 43, No. 2, february 1972.

[16] WEINBERG, Z.A., MATTHIES, D.L., JOHNSON, W.C. and LAMPERT, M.A., Measurement of the steady-state potential difference across a thin insulating film in a corona discharge, Ver. Sci. Instrum., Vol. 46, No. 2, February 1975.

[17] SECKER, P.E., The design of simple instruments for measurement of charge on insulating surfaces, Journal of Electrostatics, Vol.1, 27-36, 1975.

[18] TAYLOR, D.M., and WILLIAMS, T.P.T., Decay of surface charge in the presence of a time-dependent bulk conductivity, J.Phys. C: Solid State Phys., Vol.11, 1978.

[19] HAENEN, H.T.M., The characteristic decay with time of surface charges on dielectrics, Journal of Electrostatics, Vol. 1, 173-185, 1975.

[20] BALLIK, E. A., Optical Technique for the Measurement of Surface Charges of Electrets, J. Appl. Phys., Vol.43, No.2, February, 1972.

[21] DAS-GUPTA, D.K., Charge decay on polymer surfaces, Journal of Electrostatics, Vol. 23, 341-350, 1989.

[22] EIA STANDARD, Packaging Material Standards for ESD Sensitive Items, EIA541, June 1988 
[23] ASTM, DESIGNATION: D 4470-91, Standard Test Method for Static Eletrification, p. $366-374$.

[24] GIACOMETTI, J. A., Radial current-density distributions and sample charge uniformity in a corona triode, J. Phys. D: Appl. Phys., 20, 1987, 675 - 682.

[25] WILSON, N. Antistatic Fibres and Finishes (Shirley Inst. Manchester, Engl.) Pap. Presented at the Shirley Int.semin on New Mater and Process in the Text Ind, $8^{\text {th }}$, Manchester, Engl, Apr 27-29 1976 Publ by Shirley Inst (Shirley Publ S 24), Manchester, Engl, 1976 14p.

[26] TECHNICAL REPORT ISO/TR 6356 - 1982 (E), published 1982 - 10-01, Textile floor coverings - Assesment of static electrical propensity - "Walking" test, International Orgasnization for Standardization.

[27] NF G 35-025, Essais des Revêtements de Sol Textiles-Propension à l'accumulation de Charges Életrostatiques, Méthode d'essai et spécification, Décembre 1983.

[28] FUJWWARA, J. K., Alguns Métodos para caracterização Eletrostática de Materiais Estático-Dissipativos, Dissertação apresentada ao Departamento de Engenharia Elétrica da Escola de Engenharia de São Carlos-USP-para obtenção do título Mestre em Engenharia Elétrica, 1997.

[29] CHUBB, J.N. JCI 155 Charge Decay Test Unit, John Chubb Instrumentation, Unit 30, LansdownInsdustrial Estate, Gloucester Road, cheltenham GL5i 8PL, jchubbàici.co.uk (10/99). 
[30] FÍSICA, (1999), Primeiros Passos da Eletrostática,

www fortunecitv.com/victorian/belvedere/112/notal.htm, (5/1/99).

[31] BEATY, W. J., Human and Sparks-The Cause-Stopping the Pain-"Electric People", www. eskimo.com/-billb/emotor/zappedhtml, (21/6/99).

[32] DESCO CHARLESWATER INDUSTRIEA INC-Manufaturer of ESD Control Products, (1997), Introduction to the Control of Electrostatic Discharge, www.charleswater.com/introesd.html, $(22 / 12 / 98)$.

[33] SENGBERG, Gerhard, Eletrostática, Tomo II, Escola Politécnica da USP, $8^{\text {a }}$ Edição.

[34] MELO, L. F. P., Projetos de Fontes Chaveadas, 1990. Editora Érica.

[35]CANOVA, J.S. Sistema AD - Controle e Aquisição de Dados, projeto de Iniciação Científica, Departamento de Engenharia Elétrica - EESC - USP, fevereiro de 1997.

[36]YASHIMA, M. AND KAWAMOTO, T., IEEE Transactions on Dielectrics and Electrical Insulation, Principle of Surface Charge Measurement for Thick Insulating Specimens, vol.5, nº 4, August 1998.

[37]ZYGMUNT, S. A.; CURTISS, L. A. and ITON, L. E. - Molecular Sieve Material, Argone National Laboratory.

[38]FRANKLIN,K., (1999), Zeolite Molecular Sieves, www.drjohn.demon.co.uk/zeolites.html, $(26 / 1 / 99)$.

[39] ANDERSON, J. R., ALEXANDER, A. E., Theory of the Vibrating Condenser Converter and Application to Contact Potencial Measurement, Australian Journal of Chemistry, 109-122, 1953 
[40] WENTE, E. C., (1917) - Phys. Ver. 10:39.

[41] ASTM, DESIGNATION: D 257 - 78, Standard test Methods for D-C Resistance or Conductance of Insulating Materials, November 1978.

[42] TAKAHASHI, H., SATO, K. SAKATA, S. and OKADA, T., Charge leakage characteristic of glass substrate for liquid crystal display, Journal of Electrostatics, 35, 1995, p. $309-322$.

[43] BRANDRUP, J., IMMERGUT, E.H., Polymer Handbook, 2a edição, John Wiley \& Sons, Inc, 1975.

[44] INTERNATIONAL ELECTROTECHNICAL COMISSION-IEC, Recomendation, high voltage test techiniques, Part 2: Test produces, first edition, 1973. 